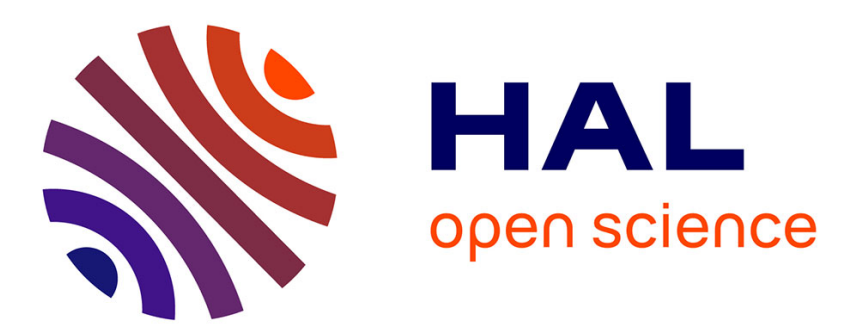

\title{
Weighted Kaplan-Meier estimators motivating to estimate HIV-1 RNA reduction censored by a limit of detection
}

Ismaïl Ahmed, Philippe Flandre

\section{- To cite this version:}

Ismail Ahmed, Philippe Flandre. Weighted Kaplan-Meier estimators motivating to estimate HIV-1 RNA reduction censored by a limit of detection. Statistics in Medicine, 2020, 39 (7), pp.968-983. 10.1002/sim.8455 . hal-02472470

\section{HAL Id: hal-02472470 https: / hal.sorbonne-universite.fr/hal-02472470}

Submitted on 10 Feb 2020

HAL is a multi-disciplinary open access archive for the deposit and dissemination of scientific research documents, whether they are published or not. The documents may come from teaching and research institutions in France or abroad, or from public or private research centers.
L'archive ouverte pluridisciplinaire HAL, est destinée au dépôt et à la diffusion de documents scientifiques de niveau recherche, publiés ou non, émanant des établissements d'enseignement et de recherche français ou étrangers, des laboratoires publics ou privés. 


\section{Weighted Kaplan-Meier estimators motivating to estimate HIV-1 RNA reduction censored by a limit of detection}

\begin{tabular}{|r|l|}
\hline Journal: & Statistics in Medicine \\
\hline Manuscript ID & SIM-19-0250.R2 \\
\hline Wiley - Manuscript type: & Research Article \\
\hline Date Submitted by the \\
Author: & n/a \\
\hline Complete List of Authors: & $\begin{array}{l}\text { Flandre, Philippe; INSERM, UMRS 1136 } \\
\text { Ahmed, Ismaïl; Inserm, U780; }\end{array}$ \\
\hline Keywords: & $\begin{array}{l}\text { dependent censoring, weighted kaplan-Meier, limit of detection, HIV-1 } \\
\text { RNA reduction }\end{array}$ \\
\hline
\end{tabular}

\section{SCHOLARONE ${ }^{m}$ Manuscripts}


ARTICLE TYPE

\section{Weighted Kaplan-Meier estimators motivating to estimate HIV-1 RNA reduction censored by a limit of detection}

\author{
Ahmed, $\mathrm{I}^{1}$ | Flandre, $\mathrm{P}^{* 2}$ \\ ${ }^{1}$ INSERM, UVSQ, Biostatistics, \\ Biomathematics, Pharmacoepidemiology \\ and Infectious Diseases (B2PHI), Villejuif, \\ France \\ ${ }^{2}$ INSERM, Sorbonne Université, Institut \\ Pierre Louis d'Epidémiologie et de Santé \\ Publique (IPLESP), Paris, France \\ Correspondence \\ INSERM UMR-S1136, 56 boulevard \\ Vincent Auriol, CS 81393, 75646 PARIS \\ Cedex 13, France E-mail: \\ philippe.flandre@iplesp.upmc.fr
}

\begin{abstract}
Summary
Measuring the magnitude of reduction in HIV-1 RNA levels accurately is difficult because many patients have a censored reduction due to the limit of detection (LOD) of the virologic assay being employed. The use of censored methods has improved the analysis of such reductions compared with crude methods but implies independent censoring. For HIV-1 RNA reduction data, the value at which a patient's HIV-1 RNA reduction becomes censored is mainly determined by the patient's baseline HIV-1 RNA level. We suggest two possibilities based on modification of the redistribution to the right algorithm to handle the situation of dependence either from a single continuous marker, i.e., the baseline HIV-1 RNA level, or from multiple markers. Two series of simulation, one in the HIV-1 RNA setting and one in the classical censoring setting, compared performance of the previous methods with our suggestions. Our proposed estimators show good performances when the dependent censoring is due to LOD. Overall, in the classical censoring setting, our suggestions perform as well as other methods including the Inverse Probability of Censoring Weighted (IPCW) and the Kaplan-Meier imputation with Bootstrap (KMIB). We applied those estimators to estimate the HIV-1 RNA reduction at week 8 of 502 patients who received a raltegravir-containing regimen and to data from the Mayo Clinic trial in primary biliary cirrhosis.
\end{abstract}

\section{KEYWORDS:}

dependent censoring; weighted Kaplan-Meier estimator; limit of detection, HIV-1 RNA reduction

\section{1 | INTRODUCTION}

Efficacy of antiretroviral treatments is currently assessed by measuring plasma HIV-1 RNA levels. In many clinical trials, efficacy is measured in comparing proportions of patients having 'undetectable' viral load, i.e. HIV-1 RNA below the limit of detection (LOD), in the $k$ randomized groups at a prespecified primary follow-up. Nevertheless, the average magnitude of reduction in HIV-1 RNA level from baseline to a prespecified time point remains an important secondary endpoint. ${ }^{1}$ Specifically this endpoint is still used in early development of antiretroviral drugs, ${ }^{[2}$ in comparing early decline of viral load, ${ }^{\sqrt[344]{4}}$ in building clinically relevant genotype interpretation of resistance,,$[16]$ and as complement to define the virologic response in studies investigating risk factors in treatment-experienced HIV-1 infected patients. $\frac{78}{78}$

Measuring the HIV-1 RNA reduction accurately, however, is difficult because some patients have a censored reduction of HIV-1 RNA due to the LOD of virologic assays being employed.1 ${ }^{1}$ The percentage of patients having a censored reduction has 
markedly increased with increasing potency of antiretroviral therapy despite decreasing values for LOD. For example, consider a patient having an HIV-1 RNA measurement of 5,000 copies $/ \mathrm{ml}$ at baseline, and a measurement below the LOD of 50 copies $/ \mathrm{ml}$ at the primary follow-up time. For this patient the actual reduction in HIV-1 RNA level is unknown, it is only know to be greater than $2 \log _{10}$ copies/ml. The crude method that consists to define all HIV-1 RNA levels below the LOD as equal to the LOD leads to serious bias. ${ }^{1}$ Classical survival methods, including Kaplan-Meier (KM) method and log-rank test, have been proposed to estimate the magnitude of viral load reduction. ${ }^{1}$ Censoring by the LOD, however, provides a loss of information and there is the potential for bias in HIV-1 RNA reduction estimates if the censoring is dependent to the magnitude of reduction. In our context, the value at which a patient's HIV-1 RNA reduction becomes censored is mainly determined by the patient's baseline HIV-1 RNA level, i.e., dependent censoring. .910

In classical survival analysis, several approaches have been proposed to recover some the lost of information due to censoring using prognostic covariates. A few of these methods use information from the prognostic covariates directly without modeling survival or censoring $\frac{1112 \mid 13}{13}$ or use working models to summarize prognostic covariates ${ }^{13 / 14}$ to define homogeneous risk groups to improve estimation of the marginal survival distribution. Another approach was to incorporate the probability of censoring to improve the estimation of the marginal survival distribution. ${ }^{[1516}$ The weighted Kaplan-Meier (WKM) approach from Malani, 11 using disease markers, suggested a modification of the redistribution to the right algorithm 17 as a new approach to recover information for censored individuals. A similar approach was also introduced by Murray and Tsiatis. ${ }^{[2]}$ The modification generalizes the Kaplan-Meier method in the presence of auxiliary information available from a disease marker. The method has been introduced when the disease marker is categorical or that continuous markers be categorized.

In this work, we suggest two other possibilities of handling a continuous marker to provide a weighted Kaplan-Meier estimator. All estimators are compared through two examples and a simulation study. Our motivating example concerns a cohort of 502 treatment-experienced HIV-1 infected patients receiving a raltegravir-based regimen. The study was originally designed to investigate factors associated with virological response and mutations selected at failure. ${ }^{8}$ In the present work, we want to estimate the HIV-1 RNA reduction from baseline to week 8. A first simulation study investigated the performance of the different estimators in such settings. Although, our suggestions were motivated by the above example, we also applied and investigated performance of our suggestions in the classical censoring settings. Data for the second example comes from the Mayo Clinic trial in primary biliary cirrhosis. A second series of simulation study investigated performance of all estimators in the classical survival setting suggested by Hsu and Taylor. ${ }^{14}$ This paper is organized as follows. In Section 2, we describe the different methods including our suggestions in the general setting of classical censoring. The two example and results with the different estimators are displayed in Section 3. Results of a series of two simulation studies are summarized in Section 4. Section 5 provides some elements for discussion.

\section{2 | METHODS}

Let $T$ denote time to the outcome of interest in the study, and $C$ the censoring time. The observed data consists of $Y_{i}=\min \left(T_{i}, C_{i}\right)$ and $\delta_{i}=I\left(T_{i} \leq C_{i}\right)$, where $I($.) is the indicator function and for $i$ in $1: \mathrm{N}$. To simplify the notations, it is supposed that there is no tie for the $T_{i}$ and $C_{i}$. Let $J$ be the number of distinct events and $T_{(j)}, j \in\{1, \ldots, J\}$, the ordered failure times. Let $L$, $L \in\{0, \ldots, N-J\}$ be the number of distinct censored times with $C_{(l)}, l \in\{1, \ldots, L\}$, the $L$ ordered censored times. The goal is to estimate $S(t)=P(T>t)$. In the HIV-1 RNA reduction setting, the goal is to estimate the probability of having a reduction greater than $x \log _{10}$ copies $/ \mathrm{ml}$.

\section{1 | Kaplan-Meier estimator and the redistribution algorithm}

Let $w_{i}(t)$ denote the weight associated with the $i$ th individual at time $t$. The redistribution algorithm starts by assigning a weight of $1 / N$ to all individuals, i.e., $w_{i}(0)=1 / N$ for all $i$. Without any censoring the weight remains unchanged until the end of the study and the survival function drops by $1 / N$ at each failure time. In the case of censoring, this process is continued by moving through the ordered failure times until the time of the first censored observation. At this time, the weight of the censored individual is re-allocated equally to the remaining individuals in the risk set as follows $w_{i}\left(C_{(l)}\right)=w_{i}\left(C_{(l-1)}\right)+\frac{w_{i}\left(C_{(l-1)}\right)}{n\left(C_{(l)}\right)}$, where $n\left(C_{(l)}\right)=\sum_{i} I\left(Y_{i}>C_{(l)}\right)$ and where $w\left(C_{(0)}\right)=1 / N$. The weights are modified similarly at each subsequent censoring 17 and the KM estimator is simply $\hat{S}_{K M}(t)=\sum_{i} I\left(Y_{i}>t\right) w_{i}(t)$. 


\subsection{Malani estimator for a discrete time-independent marker}

The basic idea is now to distinguish between censored individuals with different prognoses as measured by a marker. The estimator was originally proposed by Malani for both time-dependent and time-independent marker ${ }^{111}$ For ease of presentation and because our motivating example involves a time-independent marker, we introduce the Malani estimator only for the latter case. So let $Z_{i}$ denote the value of the marker for the $i$ th individual recorded at the start of the study and assume first that $Z_{i}$ is discrete and takes $\mathrm{G}$ different values denoted by $z_{g}(g=1, \ldots, \mathrm{G})$. The estimate of the survival function is

$$
\hat{S}_{M}(t)=\sum_{g=1}^{\mathrm{G}} \theta_{g} \hat{S}_{K M}\left(t \mid z_{g}\right)
$$

where $\hat{S}_{K M}\left(t \mid z_{g}\right)$ denotes the KM estimate of $\operatorname{pr}\left(T_{i}>T \mid Z_{i}=z_{g}\right), \theta_{g}=n_{g} / N$ is the proportion of patients in each group defined by the marker value, with $n_{g}$ the number of individuals with marker value $z_{g}$ at the start of the study. Then the redistribution to the right algorithm is modified to take account of the extra information: the weight of each censored observation is divided equally among only those individuals in the risk set who have the same value of the marker that the censored individual at the censoring time. ${ }^{11}$ In this simple case, the resulting estimator involves stratifying the data according to different prognosis groups based on the marker, estimating the survival function separately for each group, and then combining the results by taking a weighted average. The asymptotic variance was introduced by Malani ${ }^{111}$ and Murray and Tsiatis $\frac{\sqrt{12}}{12}$ and can be consistently estimated by

$$
\sum_{g=1}^{G} \theta_{g}^{2} \text { est. } \operatorname{var}\left(\hat{S}_{K M}\left(t \mid z_{g}\right)\right)+\frac{1}{N} \sum_{g=1}^{G} \theta_{g}\left(\hat{S}_{K M}\left(t \mid z_{g}\right)\right)^{2}-\frac{1}{N} \hat{S}_{M}(t)^{2}
$$

where est. $\operatorname{var}\left(\hat{S}_{K M}\left(t \mid z_{\mathrm{g}}\right)\right)$ is obtained using Greewood's formula. Different authors show that the estimator is consistent under an assumption that censoring is independent conditional on $Z . \underline{1112}$

\section{3 | The case of a continuous marker}

Now suppose that we have several continuous markers recorded at patient's entry. First we reduce these markers values into a single value in a similar way of Hsu and Taylor. ${ }^{14}$ The procedure can be summarized into the following steps. Step 1: fit a working model to the observed failure time and the observed censoring time (observed event times are treated as censored observations), respectively. Step 2: compute the risk score for both working models. Step 3: perform principal component analysis on the two standardized risk scores to generate two orthogonal components. Step 4: the first component is used to calculate the neighbours closest to the component value of the censored individual. Step 6: perform the weighted Kaplan-Meier using the approaches described below. The choice of the model for the two working models depends on the mechanism of censoring. For our motivating example we choose a parametric model using a normal distribution. ${ }^{1}$ In the case of a single or very strong prognostic factor, for example the patient's baseline HIV-1 RNA level of the censored individual, the value of that marker itself may replace the first component in the derivation of our estimators. We use the Cox PH model for classical survival data.

Two approaches can be envisaged for this, such as

(i) redistributing the weight among the $k$ neighbours closest to the first component value of the censored individual, or

(ii) redistributing the weight among all the individuals but according to a function giving more weight to individuals having a first component value close to the value of the censored individual.

Note that for the first possibility the redistribution among the $k$ neighbours can be balanced (equal weight is redistributed for the $k$ individuals) or unbalanced (as in (ii) given more weight to individuals having a first component close to the first component value of the censored individual).

Intuitively the neighbours approach seems promising and flexible. For the individual censored at time $C_{(l)}$, the first step consists of determining the genuine number of neighbours available. This number is equal to $k^{(l)}=\min \left(k, n\left(C_{(l)}\right)\right)$, where $k$ is the desired number of neighbours. It is clear that at the end of the follow-up for estimating the tail of $S(t)$ the number of available neighbours can be less than $k$. The criterion to select the $k^{(l)}$ neighbours of the individual censored at time $C_{(l)}$ according to the first component value $(p c a 1)$ can be summarized by $d_{i}^{(l)}=\left|p c a 1_{i}-p c a 1_{(l)}\right|, i \in \mathcal{R}\left(C_{(l)}\right)$ where $p c a 1_{(l)}$ denotes the first component value of the censored individual, and $\mathcal{R}\left(C_{(l)}\right)$ denotes the set of the individuals at risk at time $C_{(l)}$. 
Defining $\mathcal{K}^{(l)} \subset \mathcal{R}\left(C_{(l)}\right)$ the set of the $k^{(l)}$ individuals with a minimum criterion $d^{(l)}$, the weight $w_{(l)}\left(C_{(l)}\right)$ of the $l$ th censored individual is redistributed according to

$$
\begin{aligned}
\forall i \in \mathcal{K}^{(l)}, & w_{i}\left(C_{(l)}\right)=w_{i}\left(C_{(l-1)}\right)+w_{(l)}\left(C_{(l)}\right) \cdot f\left(\text { pca }_{i}, \text { pca }_{(l)}\right) \\
\forall i \notin \mathcal{K}^{(l)}, & w_{i}\left(C_{(l)}\right)=w_{i}\left(C_{(l-1)}\right)
\end{aligned}
$$

where $f\left(p c a 1_{i}, p c a 1_{(l)}\right)$ is a weighted function.

Malani suggests that $f\left(p c a 1_{i}, p c a 1_{(l)}\right)=1 / k^{(l)}, \forall i \in \mathcal{K}^{(l)}$ which means that the weight is equally distributed among these $k^{(l)}$ neighbours. ${ }^{11}$ Other functions, however, can be employed leading to an unbalanced redistribution of the weight. In particular we suggest

$$
f\left(p c a 1_{i}, p c a 1_{(l)}\right)=\frac{1 / d_{i}^{(l)}}{\sum_{i^{\prime} \in \mathcal{K}^{(l)}} 1 / d_{i^{\prime}}^{(l)}}, \text { and } f\left(p c a 1_{i}, p c a 1_{(l)}\right)=\frac{1 / r_{i}^{(l)}}{\sum_{i^{\prime} \in \mathcal{K}^{(l)}} 1 / r_{i^{\prime}}^{(l)}}
$$

where $r_{i}^{(l)}$ corresponds to the rank of individual $i$ among the $k^{(l)}$ neighbours defined according to the criterion $d^{(l)}$. In the first suggestion the weight received by an individual in the risk set, and belonging to the $k^{(l)}$ neighbours, is proportional to the inverse of the distance between its first component value and the first component value of the censored individual while in the second suggestion the weight is proportional to the inverse of the rank of that distance.

Our second suggestion is to consider that the weight of a censored individual be redistributed among all individuals at risk but not equally, individuals having a first component value close to the value of the censored individual receiving more weight than the others. The weight is then redistributed according to

$$
\forall i \in \mathcal{R}\left(C_{(l)}\right), \quad w_{i}\left(C_{(l)}\right)=w_{i}\left(C_{(l-1)}\right)+w_{(l)}\left(C_{(l)}\right) \cdot f\left(p c a 1_{i}, p c a 1_{(l)}, \sigma\right)
$$

where $f\left(p c a 1_{i}, p c a 1_{j}, \sigma\right)$ is based on a normal distribution centered on $p c a 1_{i}$

$$
f\left(p^{\prime} c a 1_{i}, p c a 1_{(l)}, \sigma\right)=\frac{\exp \left\{-\frac{\left(p c a 1_{i}-p c a 1_{(l)}\right)^{2}}{2 \sigma^{2}}\right\}}{\sum_{i^{\prime} \in \mathcal{R}\left(C_{(l)}\right)} \exp \left\{-\frac{\left(p c a 1_{i^{\prime}}-p c a 1_{(l)}\right)^{2}}{2 \sigma^{2}}\right\}}
$$

for the weight redistribution. All these estimators can be considered as weighted Kaplan-Meier estimates (WKM) and estimating the survival function at time $t$ is still done by summing the corresponding weights of the individuals still at risk at time $t$. Of note, although the standard Kaplan-Meier estimator can handle tied data, in the setting of our motivating example (HIV-1 RNA reduction) tied data are very rare. Redistribution of the weights among the $k$ neighbours, using a uniform distribution, according to the inverse of the distance, or to the inverse of the rank will be noted $\mathrm{WKM}_{U, x \%}, \mathrm{WKM}_{D, x}$ and $\mathrm{WKM}_{R, x \%}$, with $x=k / N$ where $k$ is the desired number of neighbours from the total sample size. The estimator based on the redistribution using a normal distribution is called $\operatorname{WKM}_{\mathcal{N}}(\sigma)$.

\section{4 | Existing methods}

The KMIB estimator used two working proportional hazards models to summarize the association between prognostic covariates and event and censoring times into two risk scores. $\frac{13}{13}$ One is for the association between the covariates and the event times; the other is for the association between the covariates and the censoring times. The two risk scores are weighted to define the distance between subjects, which is then used to select an imputing risk set for each censored observation. We choose a weight of 0.8 and 0.2 for failure and censoring risk scores, respectively, when defining the distance between subjects and the size of the imputing risk set for each censored observation is set at $5 \cdot \frac{13114}{16}$ The event times are imputed using a multiple imputation strategy including a Bootstrap stage. The authors showed that imputing event times for censored observation through the use of the two risk scores can induce a double robustness property in the estimation of the survival distribution. Specifically, if one of the two working models is correctly specified, the survival estimate derived from the imputed data sets is consistent under defined conditions. More details of the procedure can be found in Hsu et al ${ }^{[13} \mathrm{In}$ our setting the two working models involved only a single prognostic factor, that is the baseline HIV-1 RNA level.

The same idea was further used to propose a second estimator. ${ }^{[14}$ They proposed using principal component analysis on the two standardized risk scores (centered and scaled) to derive two orthogonal components (linear combinations of two risk scores) and then categorized these two components separately based on their percentiles into $I * J$ groups, where $I$ is the number of categories for the first component and $J$ is the number of categories for the second component. ${ }^{14}$ The WKM estimator can then 
5

6

7

8

9

TABLE 1 Data analysis of the motivating example $(\mathrm{N}=248)$ : estimation of the parameters used in the KM estimators using two working parametric regression models with a normal distribution (top) or using two working Cox PH models (bottom).

\begin{tabular}{|c|c|c|c|c|c|c|}
\hline \multirow[b]{3}{*}{ Covariates } & \multicolumn{6}{|c|}{ Regression models with a normal distribution } \\
\hline & \multicolumn{3}{|c|}{ Failure time model } & \multicolumn{3}{|c|}{ Censoring time model } \\
\hline & Estimate & SE & p-value & Estimate & SE & $\mathrm{p}$-value \\
\hline Baseline viral load & 0.605 & 0.131 & $<.01$ & 1.023 & 0.019 & $<.01$ \\
\hline Baseline CD $4 \times 10^{-2}$ & 0.092 & 0.054 & 0.09 & 0.014 & 0.008 & 0.07 \\
\hline Age & 0.017 & 0.100 & 0.09 & 0.002 & 0.001 & 0.11 \\
\hline NRTIs & -0.008 & 0.093 & 0.93 & 0.013 & 0.014 & 0.34 \\
\hline NNRTIs & 0.044 & 0.196 & 0.82 & 0.003 & 0.028 & 0.91 \\
\hline Previous ARVs used & -0.077 & 0.026 & $<.01$ & 0.004 & 0.003 & 0.20 \\
\hline
\end{tabular}

Cox propotional hazard models

\begin{tabular}{|c|c|c|c|c|c|c|}
\hline \multirow[b]{3}{*}{ Covariates } & \multicolumn{5}{|c|}{ Cox propotional hazard models } & \\
\hline & \multicolumn{3}{|c|}{ Failure time model } & \multicolumn{3}{|c|}{ Censoring time model } \\
\hline & Estimate & SE & p-value & Estimate & SE & p-value \\
\hline Baseline viral load & -0.783 & 0.161 & $<.01$ & -8.774 & 0.693 & $<.01$ \\
\hline Baseline CD $4 \times 10^{-2}$ & -0.099 & 0.060 & 0.10 & -0.141 & 0.065 & 0.03 \\
\hline Age & -0.020 & 0.010 & 0.04 & -0.023 & 0.012 & 0.06 \\
\hline NRTIs & 0.043 & 0.090 & 0.63 & -0.196 & 0.109 & 0.07 \\
\hline NNRTIs & -0.061 & 0.181 & 0.74 & -0.014 & 0.238 & 0.95 \\
\hline Previous ARVs used & 0.073 & 0.025 & $<.01$ & -0.003 & 0.027 & 0.91 \\
\hline
\end{tabular}

be derived based on the $I * J$ categorized groups. In the presence of a single prognostic factor, e.g., the baseline HIV-1 RNA level, then $J$ is fixed to 1 and the estimator is noted $\mathrm{WKM}_{I, 1}$. More details of the procedure can be found in Hsu and Taylor. $\frac{14}{14}$

The IPCW estimator is

$$
\hat{S}(t)=\prod_{j: T_{(j)}<t}\left\{1-\frac{1 /\left\{\hat{K}_{(j)}^{Z}\left(T_{(j)}\right)\right\}}{\sum_{i \in \mathcal{R}\left(T_{(j)}\right)} 1 /\left\{\hat{K}_{i}^{Z}\left(T_{(j)}\right)\right\}}\right\}
$$

where $\mathcal{R}\left(T_{(j)}\right)$ is the risk set at time $T_{(j)}$ and $\hat{K}_{i}^{Z}(t)$ is a the conditional probability of being uncensored by time $t$ given $Z_{i p}$ derived from a proportional hazards model for censoring time using $p$ prognostic variables as the covariates.

\section{3 | EXAMPLES}

\section{1 | Motivating example}

The data consist of 502 patients who received a raltegravir-containing regimen. .8 Overall, 254 (51\%) patients had a censored reduction due to an HIV-1 RNA level at week 8 below the LOD. Both 20 copies $/ \mathrm{ml}$ and 50 copies $/ \mathrm{ml}$ were used as LOD in the several departments of virology involved in the study. The crude method, in which all values below the LOD were replaced by the value of 20 or 50 copies $/ \mathrm{ml}$, leads to a mean reduction of $2.3 \log _{10}$ copies $/ \mathrm{mL}$ (variance of 0.88 ) and median reduction of 2.4 $\log _{10}$ copies/ml (interquartile range of 1.8 to 2.9 ). The HIV-1 RNA reduction distributions is given in the supplementary material (supplementary Figure 1). Six variables were analysed with the working models: baseline HIV-1 RNA, baseline CD4 cell count, age (years), the number of Nucleoside Reverse Transcriptase Inhibitors (NRTIs) and of Non Nucleoside Reverse Transcriptase Inhibitors (NNRTIs) used in the raltegravir-containing regimen and the total number of antiretroviral (ARVs) drugs used in the treatment's history. Results of working models are shown in the supplementary Table I and the presence of the same significant variables in both censoring and failure time models indicate the potential for dependent censoring for these data. 14 
TABLE 2 Data analysis of a random sample of PBC data: estimation of two working Cox PH models on a sample (N=250) of data from the Mayo Clinic trial in primary biliary cirrhosis (PBC data)

\begin{tabular}{lcccccccc} 
& \multicolumn{3}{c}{ Failure time model } & & \multicolumn{3}{c}{ Censoring time model } \\
\cline { 2 - 3 } Covariates & Estimate & SE & p-value & & Estimate & SE & p-value \\
\hline Age & 0.017 & 0.010 & 0.11 & & -0.025 & 0.009 & $<.01$ \\
Sex & 0.745 & 0.264 & 0.01 & & -0.821 & 0.396 & 0.04 \\
Albumin & -0.663 & 0.257 & 0.01 & & -0.686 & 0.260 & $<.01$ \\
Protime* & 0.586 & 0.108 & $<.01$ & & -0.714 & 0.150 & $<.01$ \\
Stage & 0.498 & 0.146 & $<.01$ & & 0.042 & 0.104 & 0.68
\end{tabular}

* Standardised blood cloting time

A conceptual departure of HIV-1 RNA reduction data from time-to-event data is that the reduction in HIV-1 RNA level can be negative, corresponding to an increase HIV-1 RNA level from baseline. This difficulty is circumvented by simply adding any single number to each HIV-1 RNA reduction such that all observations are positive and then substracting this number after the analysis. In our data, $+2 \log _{10}$ copies/ml was added to all viral load reduction. The Kaplan-Meier and other estimators previously introduced are applied to data of the 502 patients of the raltegravir study (supplementary Figure 2). It is difficult, however, to evaluate the performance of the different estimators without a gold standard represented by a fully observed analysis (analysis without censoring). Most of the estimators provide slightly higher or higher estimates of the HIV-1 RNA reduction compared with the partially observed analysis (KM PO) that is the analysis with censored and uncensored observations. It is well know, however, that censored reduction data by a LOD tend to underestimate the true HIV-1 RNA reduction, especially when around half of patients have a censored reduction. 1 .

We then selected the 248 observations having an uncensored reduction. From this subset we obtain the Fully Observed (FO) analysis in deriving the KM estimates which is treated as the gold standard. Of note, as the true survival function is unknown in our motivating example, the KM FO obtained from the selected sample does not reflect the true HIV-1 RNA reduction. We then applied two LOD of virologic assays (100 nd 200 copies/ml) that were employed few years ago to provide artificially censored observations. For each observation, the LOD of 100 or 200 copies/ml was generated at random. All HIV-1 RNA measurements at week 8 between 20 and the LOD are considered censored at LOD. That leads to 109 (44\%) censored reduction out of 248 observations. Results of the working models needed for the KM estimators are provided in Table I. Parameter estimates of the working Cox models are used by the IPCW, KMIB and $\mathrm{WKM}_{I, J}$ estimators whereas $\mathrm{WKM}_{f, x \%}$ and $\mathrm{WKM}_{\mathcal{N}}(\sigma)$ used parameter estimates from the regression with a normal distribution. From these results we conclude that baseline HIV-1 RNA is the main prognostic factor of both uncensored and censored viral load reduction.

Figure 1 display the estimated curves for the FO analysis and the other estimators introduced above. In the top of Figure 1 parameter estimates of the six variables are used to derive the corresponding estimators whereas in the bottom only the baseline HIV-1 RNA is used. WKM $_{I, J}$ methods provided poor estimates of the HIV-1 RNA reduction even poorer than the KM PO estimator. IPCW and KMIB estimators provide almost similar to estimates than KM PO. Our suggestions using $x=5$ and $10 \%$ for $\mathrm{WKM}_{u, x \%}$ and $\sigma=0.1$ and 0.25 for $\mathrm{WKM}_{\mathcal{N}}(\sigma)$ provide very promising alternatives to estimate the HIV-1 RNA reduction with estimates much closer to the gold standard (KM FO) than all other estimators. Using only the baseline value of HIV-1 RNA provided almost similar to estimates for most methods. 

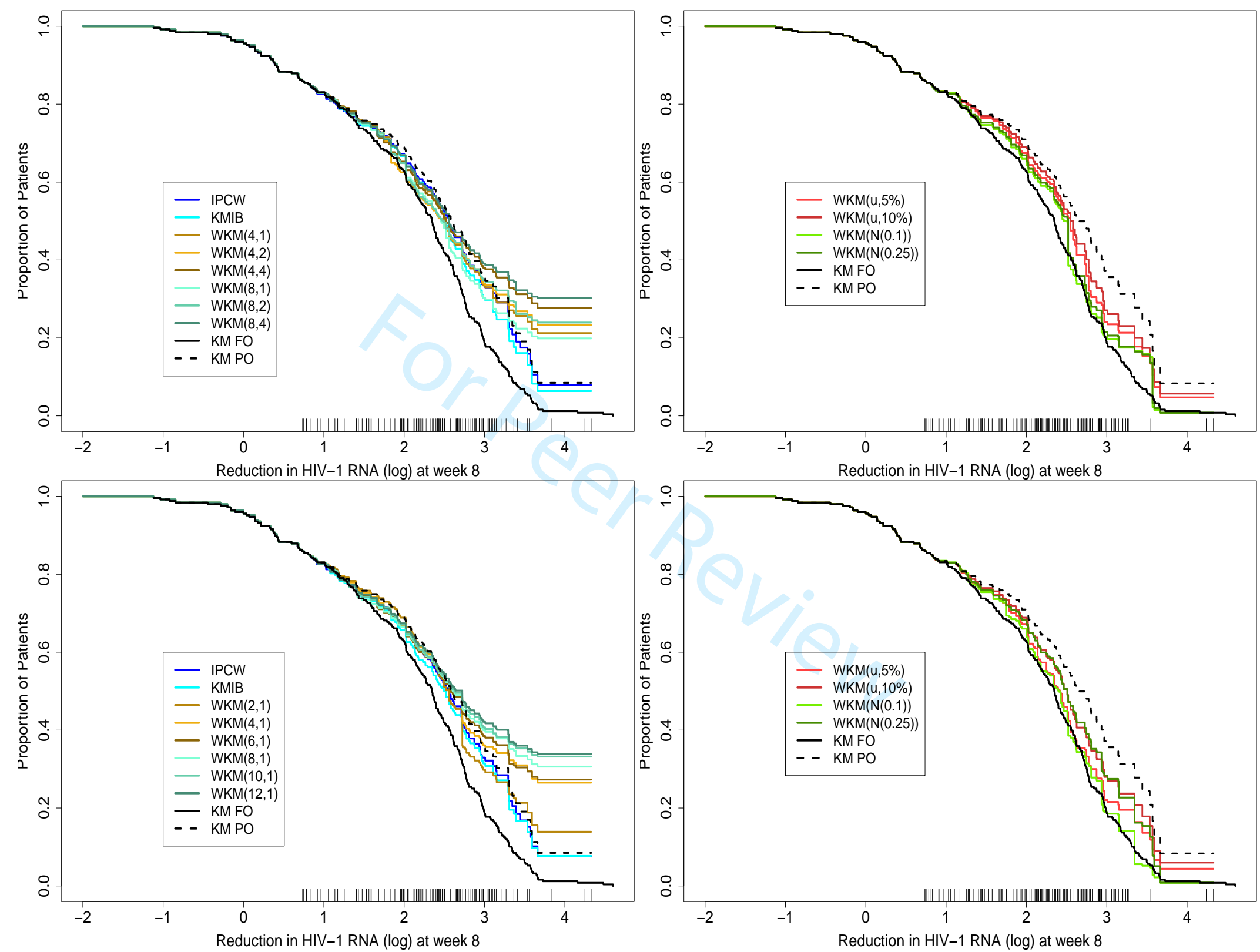

FIGURE 1 Estimates of the reduction in HIV-1 RNA (in $\log _{10}$ copies $/ \mathrm{ml}$ ) at week 8 in the 248 uncensored observations applying a LOD of 100 or 200 copies/ml. Top: using the six covariates in the working models; bottom: using only the baseline HIV-1 RNA in the working models. Marks on the $x$-axis indicated times of censored observations. 


\section{2 | Example from Primary Biliary Cirrhosis Data}

In this example data comes from the Mayo Clinic trial in primary biliary cirrhosis (PBC) of the liver conducted between 1974 and 1984 and including 424 patients. Those data are available in the Survival R package. A subset of 250 patients was randomly selected including 102 deaths (59\% censoring). A random subset is used because (i) we used the event death (removing the status transplant in the original dataset), (ii) we removed observations having missing data (variables stage and protime), and (iii) we selected a random sample to have variables strongly associated in both models (failure time model and censoring time model) indicating potential for dependent censoring according to Hsu and Taylor. $\frac{14}{14}$ The following five variables were used in the two working PH models: age, sex, serum albumin, protime (standardised blood clotting time) and histologic stage of disease. Parameter estimates of the two working models suggest a potential for dependent censoring for these data (Table II). Estimates of the survival curve are provided in Figure 2. In this example, as pointed out above, our estimators $\mathrm{WKM}_{f, x \%}$ and $_{\mathrm{WKM}}(\sigma)$

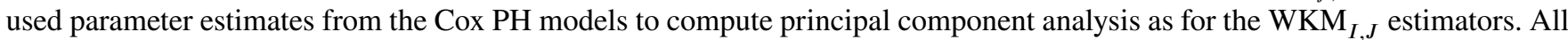
methods, except the KMIB estimator, provided slightly higher estimated survival compared with the PO analysis. KMIB method provided similar estimates than the KM PO analysis.
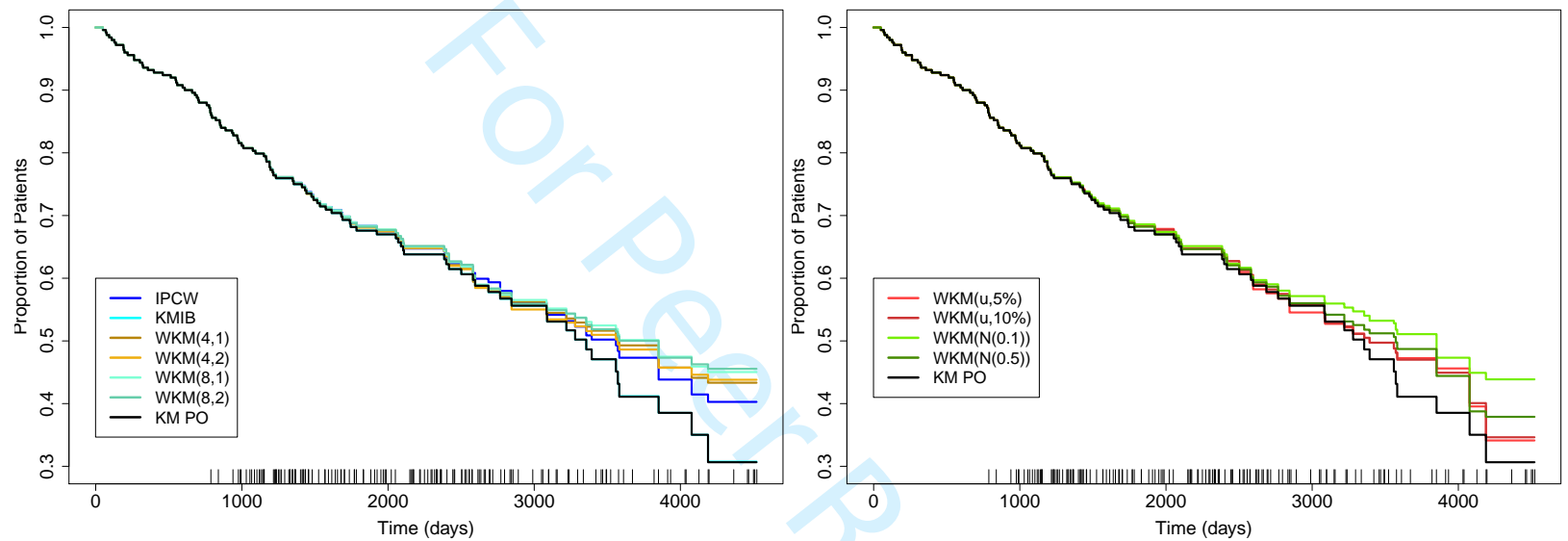

FIGURE 2 Estimates of the reduction in HIV-1 RNA (in $\log _{10}$ copies/ml) at week 8 derived KM Fully Observed, KM partially observed, IPCW, KMIB, $\mathrm{WKM}_{I, J}$ and $\mathrm{WKM}_{U, X \%}$ and $\mathrm{WKM}_{\mathcal{N}}(\sigma)$ estimators for the 257 patients with an uncensored reduction but applying a LOD of 200 copies/ml (2.3 $\log _{10}$ copies/ml). Marks on the $x$-axis indicated times of censored observations.

\section{4 | SIMULATION STUDY}

\section{1 | Simulation methods}

We performed two series of simulation study to investigate the performance of our proposed WKM estimators. The first series investigates performance of the methods in the settings of assessing HIV-1 RNA reduction whereas the second series is carried out in the classical survival settings of two competing risks (event time and censored time). For the latter series, we used exactly the same simulation settings and parameter values than Hsu and Taylor. ${ }^{144}$ Details of the simulation study may be found in ${ }^{144}$ and in the $\mathrm{R}$ code is available upon request.

In the first series, five hypothetical prognostic covariates $\left(Z_{1}, \ldots, Z_{5}\right)$ are independently generated. Three variables $\left(Z_{1}, Z_{2}\right.$ and $Z_{3}$ ) are generated from a $\mathcal{N}(0,1)$ distribution, $Z_{4}$ is generated from a $U(0,5)$ distribution and $Z_{5}$ takes value from 0 to 30 based on a normal distribution. $Z_{1}$ represents baseline HIV-1 RNA, $Z_{2}$ baseline $\sqrt{C D 4}$ count and $Z_{3}$ age. $Z_{4}$ and $Z_{5}$ represents the number of NRTIs used and the number of previous ARVs used, respectively. The uncensored viral load reduction at week 8 is generated from a normal $\left(3+0.347 Z_{1}+0.437 Z_{2}+0.099 Z_{3}+0.102 Z_{4}-0.041 Z_{5}, 1\right)$. Parameter values were derived from the analysis of our example after standardization of the baseline HIV-1 RNA from a $\mathcal{N}(5.39,0.80)$ distribution, baseline $\sqrt{C D 4}$ count from a $\mathcal{N}(13.8,6.7)$ distribution and age from a $\mathcal{N}(46.8,10)$ distribution. For each hypothetical observation the HIV-1 
TABLE 3 Monte Carlo results for estimating a hypothetical HIV-1 RNA reduction. Estimators are derived using the five covariates $Z_{1}-Z_{5}$ with $\mathrm{N}=200$.

\begin{tabular}{|c|c|c|c|c|c|c|c|c|c|c|c|c|}
\hline \multirow[b]{2}{*}{ Method } & \multicolumn{4}{|c|}{ True value: 0.5} & \multicolumn{4}{|c|}{ True value: 0.35} & \multicolumn{4}{|c|}{ True value: 0.2} \\
\hline & Est $^{1}$ & $\mathrm{R}$ bias $^{2}$ & $\mathrm{MSE}^{3}$ & $\mathrm{CR}^{4}$ & Est & $\mathrm{R}$ bias & MSE & CR & Est & $\mathrm{R}$ bias & MSE & $\mathrm{CR}$ \\
\hline
\end{tabular}

LOD is either 100 copies $/ \mathrm{ml}(\operatorname{Pr}=70 \%)$ or 200 copies $/ \mathrm{ml}(\operatorname{Pr}=30 \%)$ leading to an overall censoring rate $=45 \%$.

$$
\text { Censoring rate }=24 \%^{5}
$$

Censoring rate $=34 \%$

Censoring rate $=42 \%$

\section{Existing methods}

$\begin{array}{lrrrrrrrrrrrr}\text { KM FO } & 0.498 & -0.2 & 0.0013 & 95.4 & 0.349 & -0.1 & 0.0012 & 94.3 & 0.199 & -0.1 & 0.0009 & 93.6 \\ \text { KM PO } & 0.520 & 2.0 & 0.0019 & 92.4 & 0.379 & 2.9 & 0.0027 & 89.1 & 0.236 & 3.6 & 0.0037 & 87.9 \\ \text { IPCW } & 0.515 & 1.5 & 0.0019 & 92.1 & 0.374 & 2.4 & 0.0026 & 89.8 & 0.231 & 3.1 & 0.0038 & 86.8 \\ \text { KMIB } & 0.506 & 0.6 & 0.0018 & 93.9 & 0.363 & 1.3 & 0.0023 & 93.6 & 0.220 & 2.0 & 0.0031 & 91.5 \\ \text { WKM }_{4.1} & 0.486 & -1.4 & 0.0026 & 88.4 & 0.349 & -0.1 & 0.0033 & 86.6 & 0.242 & 4.2 & 0.0059 & 75.8 \\ \mathrm{WKM}_{4.2} & 0.517 & 1.7 & 0.0025 & 87.5 & 0.406 & 5.6 & 0.0058 & 69.7 & 0.329 & 12.9 & 0.0197 & 20.0 \\ \mathrm{WKM}_{8.1} & 0.491 & -0.9 & 0.0024 & 89.2 & 0.363 & 1.3 & 0.0030 & 87.9 & 0.266 & 6.6 & 0.0078 & 62.3 \\ \mathrm{WKM}_{8.2} & 0.529 & 2.9 & 0.0027 & 85.1 & 0.427 & 7.7 & 0.0081 & 50.1 & 0.360 & 16.0 & 0.0278 & 4.2 \\ \text { Proposed methods } & & & & & & & & & & & \\ \mathrm{WKM}_{U, 15 \%} & 0.493 & -0.7 & 0.0017 & 94.1 & 0.346 & -0.4 & 0.0020 & 92.6 & 0.208 & 0.8 & 0.0023 & 91.9 \\ \mathrm{WKM}_{U, 20 \%} & 0.496 & -0.4 & 0.0016 & 94.7 & 0.351 & 0.1 & 0.0019 & 93.5 & 0.213 & 1.3 & 0.0024 & 92.5 \\ \mathrm{WKM}_{\mathcal{N}(1)} & 0.501 & 0.1 & 0.0016 & 94.8 & 0.354 & 0.4 & 0.0019 & 93.8 & 0.211 & 1.1 & 0.0025 & 91.6\end{array}$

LOD is either 100 copies $/ \mathrm{ml}(\operatorname{Pr}=30 \%)$ or 200 copies $/ \mathrm{ml}(\operatorname{Pr}=70 \%)$ leading to an overall censoring rate $=50 \%$.

\section{Existing methods}

$$
\text { Censoring rate }=30 \%
$$

Censoring rate $=40 \%$

Censoring rate $=47 \%$

$\begin{array}{lrrrrrrrrrrrr}\text { KM FO } & 0.499 & -0.1 & 0.0013 & 94.1 & 0.349 & -0.1 & 0.0013 & 94.1 & 0.200 & 0.0 & 0.0009 & 93.9 \\ \text { KM PO } & 0.525 & 2.5 & 0.0024 & 89.9 & 0.385 & 3.5 & 0.0034 & 89.5 & 0.240 & 4.0 & 0.0053 & 84.8 \\ \text { IPCW } & 0.515 & 1.5 & 0.0042 & 82.8 & 0.374 & 2.4 & 0.0054 & 79.8 & 0.232 & 3.2 & 0.0083 & 76.7 \\ \text { KMIB } & 0.509 & 0.9 & 0.0022 & 92.4 & 0.367 & 1.7 & 0.0029 & 90.4 & 0.225 & 2.5 & 0.0046 & 88.3 \\ \mathrm{WKM}_{4,1} & 0.487 & -1.3 & 0.0033 & 85.7 & 0.354 & 0.4 & 0.0043 & 82.5 & 0.256 & 5.6 & 0.0084 & 70.6 \\ \mathrm{WKM}_{4,2} & 0.526 & 2.6 & 0.0036 & 82.7 & 0.424 & 7.4 & 0.0090 & 55.7 & 0.354 & 15.4 & 0.0275 & 14.0 \\ \mathrm{WKM}_{8,1} & 0.494 & -0.6 & 0.0029 & 88.0 & 0.371 & 2.1 & 0.0039 & 82.6 & 0.284 & 8.4 & 0.0111 & 51.8 \\ \mathrm{WKM}_{8,2} & 0.540 & 4.0 & 0.0039 & 76.2 & 0.446 & 9.6 & 0.0119 & 36.4 & 0.386 & 18.6 & 0.0373 & 2.8 \\ \text { Proposed methods } & & & & & & & & & & & \\ \mathrm{WKM}_{U, 15 \%} & 0.493 & -0.7 & 0.0021 & 92.9 & 0.347 & -0.3 & 0.0023 & 92.1 & 0.210 & 1.0 & 0.0033 & 90.7 \\ \mathrm{WKM}_{U, 20 \%} & 0.496 & -0.4 & 0.0020 & 93.2 & 0.353 & 0.3 & 0.0022 & 93.4 & 0.216 & 1.6 & 0.0035 & 90.9 \\ \mathrm{WKM}_{\mathcal{N}(1)} & 0.502 & 0.2 & 0.0019 & 93.3 & 0.357 & 0.7 & 0.0023 & 92.2 & 0.214 & 1.4 & 0.0037 & 89.2\end{array}$

LOD is either 200 copies $/ \mathrm{ml}(\operatorname{Pr}=70 \%)$ or 500 copies $/ \mathrm{ml}(\operatorname{Pr}=30 \%)$ leading to an overall censoring rate $=57 \%$.

\section{Existing methods}

$$
\text { Censoring rate }=39 \%
$$

Censoring rate $=49 \%$

Censoring rate $=56 \%$

45
46
47
48
49
50
51
52
53
54
55
56
57
58
59
60

KM $\quad 0.499$

KM PO $\quad 0.535$

IPCW $\quad 0.528$

$\begin{array}{llll}-0.1 & 0.0013 & 93.8 & 0.348 \\ 3.5 & 0.0032 & 85.3 & 0.394\end{array}$

KMIB $\quad 0.517$

$\begin{array}{lll}3.5 & 0.0032 & 85.3\end{array}$

0.348

$\begin{array}{rr}-0.2 & 0.0012 \\ 4.4 & 0.0047\end{array}$

94.1

0.199

$-0.1$

0.0009

93.3

$\mathrm{WKM}_{4.1} \quad 0.486$

\section{$\begin{array}{lll}2.8 & 0.0031 & 86.6\end{array}$}

0.387

3.4

0.0047

84.6

0.250

0.245

5.0

0.0083

$\mathrm{WKM}_{4.2} \quad 0.552$

$\begin{array}{ll}-1.4 & 0.0047\end{array}$

91.7

0.374

\section{$2.4 \quad 0.0038$}

90.7

0.233

$\mathrm{WKM}_{8.1} \quad 0.496$

$\begin{array}{ll}5.2 & 0.0059\end{array}$

80.3

0.359

$0.9 \quad 0.0058$

80.7

0.277

0.409

$\mathrm{WKM}_{8.2} \quad 0.569$

$\begin{array}{lll}-0.4 & 0.0039 & 84.4\end{array}$

0.381

$11.4 \quad 0.0167$

33.1

0.311

0.490

0.446

$\begin{array}{ll}4.5 & 0.0085\end{array}$

83.3

Pred methods

$\mathrm{WKM}_{U .15 \%} 0.492$

$\begin{array}{lll}-0.8 & 0.0025 & 92.1\end{array}$

0.347

$\begin{array}{ll}-0.3 & 0.0028\end{array}$

$93.1 \quad 0.216$

3.3

0.0071

85.5

0.355

$0.5 \quad 0.0027$

93.3

0.222

7.7

0.0129

62.7

$\begin{array}{llll}0.7 & 0.0022 & 91.7 & 0.361\end{array}$

$\begin{array}{lll}1.1 & 0.0029 & 92.2\end{array}$

0.220

20.9

0.0476

4.6

$\begin{array}{lll}11.1 & 0.0177 & 39.5\end{array}$

${ }^{2}$ Relative bias $\left(100 \times(\right.$ Bias $/ S(t)) \quad{ }^{3}$ Mean square error

${ }^{5}$ Censoring rate at the time of the true value of $S(t)$ 
TABLE 4 Monte Carlo results for estimating a hypothetical HIV-1 RNA reduction. Estimators are derived using only $Z_{1}$ representing the baseline HIV-1 RNA with $\mathrm{N}=200$.

\begin{tabular}{|c|c|c|c|c|c|c|c|c|c|c|c|c|}
\hline \multirow[b]{2}{*}{ Method } & \multicolumn{4}{|c|}{ True value: 0.5} & \multicolumn{4}{|c|}{ True value: 0.35} & \multicolumn{4}{|c|}{ True value: 0.2} \\
\hline & Est $^{1}$ & $\mathrm{R}$ bias $^{2}$ & $\mathrm{MSE}^{3}$ & $\mathrm{CR}^{4}$ & Est & $\mathrm{R}$ bias & MSE & $\mathrm{CR}$ & Est & $\mathrm{R}$ bias & MSE & $\mathrm{CR}$ \\
\hline
\end{tabular}

LOD is either 100 copies $/ \mathrm{ml}(\operatorname{Pr}=70 \%)$ or 200 copies $/ \mathrm{ml}(\operatorname{Pr}=30 \%)$ leading to an overall censoring rate $=45 \%$.

$$
\text { Censoring rate }=24 \%^{5}
$$

Censoring rate $=34 \%$

Censoring rate $=42 \%$

Existing methods

$\begin{array}{lrrrrrrrrrrrr}\text { KM FO } & 0.498 & -0.2 & 0.0013 & 95.4 & 0.349 & -0.1 & 0.0012 & 94.3 & 0.199 & -0.1 & 0.0009 & 93.6 \\ \text { KM PO } & 0.520 & 2.0 & 0.0019 & 92.4 & 0.379 & 2.9 & 0.0027 & 89.1 & 0.236 & 3.6 & 0.0037 & 87.9 \\ \text { IPCW } & 0.515 & 1.5 & 0.0019 & 91.5 & 0.373 & 2.3 & 0.0026 & 90.1 & 0.230 & 3.0 & 0.0037 & 87.8 \\ \text { KMIB } & 0.512 & 1.2 & 0.0019 & 92.8 & 0.371 & 2.1 & 0.0025 & 92.3 & 0.229 & 2.9 & 0.0037 & 88.9 \\ \mathrm{WKM}_{2.1} & 0.511 & 1.1 & 0.0020 & 93.2 & 0.386 & 3.6 & 0.0052 & 78.8 & 0.306 & 10.6 & 0.0153 & 40.8 \\ \mathrm{WKM}_{4.1} & 0.527 & 2.7 & 0.0029 & 85.4 & 0.425 & 7.5 & 0.0083 & 57.3 & 0.356 & 15.6 & 0.0274 & 12.6 \\ \mathrm{WKM}_{8.1} & 0.543 & 4.3 & 0.0037 & 78.0 & 0.450 & 10.0 & 0.0122 & 33.7 & 0.390 & 19.0 & 0.0383 & 1.4 \\ \mathrm{WKM}_{10.1} & 0.546 & 4.6 & 0.0040 & 73.8 & 0.455 & 10.5 & 0.0131 & 27.0 & 0.396 & 19.6 & 0.0406 & 0.6 \\ \text { Proposed methods } & & & & & & & & & & & \\ \mathrm{WKM}_{U, 15 \%} & 0.509 & 0.9 & 0.0018 & 93.5 & 0.366 & 1.6 & 0.0024 & 92.5 & 0.226 & 2.6 & 0.0032 & 90.4 \\ \mathrm{WKM}_{U, 20 \%} & 0.510 & 1.0 & 0.0017 & 93.6 & 0.368 & 1.8 & 0.0023 & 92.3 & 0.228 & 2.8 & 0.0032 & 89.7 \\ \mathrm{WKM}_{\mathcal{N}(1)} & 0.511 & 1.1 & 0.0017 & 93.3 & 0.369 & 1.9 & 0.0023 & 92.3 & 0.227 & 2.7 & 0.0033 & 88.5\end{array}$

LOD is either 100 copies $/ \mathrm{ml}(\operatorname{Pr}=30 \%)$ or 200 copies $/ \mathrm{ml}(\operatorname{Pr}=70 \%)$ leading to an overall censoring rate $=50 \%$.

Censoring rate $=30 \%$

Censoring rate $=40 \%$

Censoring rate $=47 \%$

Existing methods

$\begin{array}{lrrrrrrrrrrrr}\text { KM FO } & 0.499 & -0.1 & 0.0013 & 94.1 & 0.349 & -0.1 & 0.0013 & 94.1 & 0.200 & 0.0 & 0.0009 & 93.9 \\ \text { KM PO } & 0.525 & 2.5 & 0.0024 & 89.9 & 0.385 & 3.5 & 0.0034 & 89.5 & 0.240 & 4.0 & 0.0053 & 84.8 \\ \text { IPCW } & 0.514 & 1.4 & 0.0039 & 83.6 & 0.374 & 2.4 & 0.0052 & 79.3 & 0.233 & 3.3 & 0.0079 & 77.8 \\ \text { KMIB } & 0.516 & 1.6 & 0.0026 & 89.9 & 0.375 & 2.5 & 0.0037 & 87.7 & 0.232 & 3.2 & 0.0060 & 83.2 \\ \mathrm{WKM}_{2,1} & 0.513 & 1.3 & 0.0028 & 91.1 & 0.394 & 4.4 & 0.0082 & 65.5 & 0.314 & 11.4 & 0.0199 & 40.1 \\ \mathrm{WKM}_{4,1} & 0.533 & 3.3 & 0.0043 & 77.6 & 0.434 & 8.4 & 0.0116 & 51.3 & 0.369 & 16.9 & 0.0339 & 17.2 \\ \mathrm{WKM}_{8,1} & 0.550 & 5.0 & 0.0051 & 69.8 & 0.460 & 11.0 & 0.0153 & 32.7 & 0.404 & 20.4 & 0.0450 & 3.4 \\ \mathrm{WKM}_{10,1} & 0.555 & 5.5 & 0.0056 & 65.7 & 0.467 & 11.7 & 0.0167 & 27.6 & 0.412 & 21.2 & 0.0485 & 1.8 \\ \text { Proposed methods } & & & & & & & & & & & \\ \mathrm{WKM}_{U .15 \%} & 0.512 & 1.2 & 0.0022 & 92.6 & 0.371 & 2.1 & 0.0030 & 89.6 & 0.231 & 3.1 & 0.0047 & 87.9 \\ \mathrm{WKM}_{U .20 \%} & 0.513 & 1.3 & 0.0021 & 92.7 & 0.373 & 2.3 & 0.0029 & 89.6 & 0.232 & 3.2 & 0.0047 & 87.3 \\ \mathrm{WKM}_{\mathcal{N}(1)} & 0.515 & 1.5 & 0.0021 & 92.5 & 0.374 & 2.4 & 0.0030 & 89.2 & 0.232 & 3.2 & 0.0049 & 86.5\end{array}$

LOD is either 200 copies $/ \mathrm{ml}$ (70\%) or 500 copies $/ \mathrm{ml} \mathrm{(30 \% )} \mathrm{leading} \mathrm{to} \mathrm{an} \mathrm{overall} \mathrm{censoring} \mathrm{rate}=57 \%$.

\section{Existing methods}

$$
\text { Censoring rate }=39 \%
$$

Censoring rate $=49 \%$

Censoring rate $=56 \%$

$\begin{array}{ll}45 & \\ 46 \\ 47 \\ 48 \\ 49 \\ 50 \\ 51 \\ 52 \\ 53 \\ 54 \\ 55 \\ 56 \\ 57 \\ 58 \\ 59\end{array}$

$\begin{array}{ll}0.526 \\ \mathrm{WKM}_{4.1} & 0.558\end{array}$

$\mathrm{WKM}_{8.1} \quad 0.584$

0.592
Proposed methods

$\mathrm{WKM}_{U .15 \%} 0.519$

$\mathrm{NKM}_{U .20 \%} 0.521$

$-0.1 \quad 0.0013$

93.8

0.348

$-0.2 \quad 0.0012$

94.1

0.199

$-0.1$

0.0009

$\mathrm{KM}_{\mathcal{N}(1)} \quad 0.523$

verage of 1000 point estimates

3.5
2.7

0.0032

85.3
86.5

0.394

$4.4 \quad 0.0047$

84.6

0.250

5.0

0.0083

0.244

4.4

0.0084

$\begin{array}{ll}3.6 & 0.0045 \\ 3.4 & 0.0044\end{array}$

87.6

0.243

2.6

0.0030

88.8

0.384

3.4
9.0

0.0044

$\begin{array}{ll}5.8 & 0.0077\end{array}$

59.5

0.440

9.0

0.353

8.4

$0.0101 \quad 45.0$

0.475

12.5

0.0210

47.3

0.424

4.3
15.3

0.0082

0.512

16.20 .0298

11.9

0.472

22.4

0.0327

$27.2-0.0781$

0.0781

0.485

28.5

0.0846

0.239

3.9

0.0072

86.4

\section{$2.1 \quad 0.0027$}

89.7
89.8

0.381

3.1

0.0038

88.8

0.241

4.1

0.0073

86.4

2.3

$0.0028 \quad 89.2$

0.382

3.2

0.0040

87.9

0.241

4.1

0.0075

85.2 
RNA at week 8 is calculated using both the baseline HIV-1 RNA $\left(Z_{1}\right)$ and the uncensored reduction. For each subject a LOD of 100,200 or 500 copies $/ \mathrm{ml}$ is randomly assigned with different probabilities. We can then distinguish between censored (HIV-1 RNA at week $8<$ LOD) and uncensored (HIV-1 RNA at week $8>$ LOD) reduction. To select observations having plausible data in our settings, all observations with a baseline HIV-1 RNA $<3$ or $>7$, or with an uncensored reduction $<1.5$ or $>6.5$ were deleted. Due to that selection, to analyse approximately $N$ observations we generate $N \times 1.2$ observations. Weighted estimators are derived using the 5 covariates used to generate the data but also using only the main prognostic factor of censoring $Z_{1}$ (misspecification of the model) representing the baseline HIV-1 RNA level.

The second series used the same settings and parameter values than the simulation of Hsu and Taylor ( see ${ }^{\sqrt{14}}$ for more details). Briefly, five hypothetical covariates are generated from a $U(0,1)$ distribution. In particular, they investigated the effects of misspecification of the two link functions on survival estimates. In a situation that the link functions are correctly specified for the two working PH models, i.e. the true failure and censoring time models are from a PH family, the event time is generated from a hypothetical PH model conditional on prognostic covariates, where the hazard function is $\lambda(t)=4 t^{3} \exp \left(-2.0 Z_{1}+\right.$ $\left.0.5 Z_{2}-2.0 Z_{3}+2.0 Z_{4}+2.0 Z_{5}\right)$ and the censoring time is generated from a hazard function $\lambda_{c}(t)=3 t^{2} \exp \left(-3.0 Z_{1}+0.5 Z_{2}-\right.$ $2.0 Z_{3}+1.5 Z_{4}+2.0 Z_{5}$ ) under a dependent censoring scenario. In a situation where the link functions are incorrectly specified for the two working PH models, i.e. the true failure and censoring time models are not from a PH family, the event time is generated from lognormal $\left(0.1-2 Z_{1}+0.5 Z_{2}-2 Z_{3}+2 Z_{4}+2 Z_{5}, 1\right)$ and the censoring time is generated from lognormal $\left(0.08-2.5 Z_{1}+0.5 Z_{2}-2 Z_{3}+2.5 Z_{4}+2 Z_{5}, 1\right)$. Misspecification of the failure time model is investigated using only $Z_{1}, Z_{2}$ and $Z_{3}$ in the fitted model. We do not investigate misspecification of the censoring time model.

For each of 1000 independent such simulated data sets we derived the estimators introduced above. We studied different values of $x$ for $\mathrm{WKM}_{f, x}$ and of $\sigma$ for $\mathrm{WKM}_{\mathcal{N}}(\sigma)$. For the first series, values for the 'true' reduction, equivalent to $S(t)$ in the classical survival analysis, are derived on the basis of a simulated datasets of 100,000 observations analyzed without censoring. For the second series, the true survival curve is derived from the distribution used. For the FO analysis, treated as the gold standard, the KM estimates is derived before any censoring. The KM PO is derived after censoring. The Grenwwod's formula is used to estimate the standard error for both estimators. For the KMIB method, based on previous work, the number of imputation is set at 10 and the size of each imputing risk set is set at 5.13 The weights on risk scores derived from working failure time and censoring time models are set at 0.8 and 0.2 , respectively. Standard errors for the KMIB estimator were computed using the Rubin's rules. ${ }^{18}$ Standard errors for $\mathrm{WKM}_{I, J}$ were computed using the formula of Malani ${ }^{11}$ given in Section (2.2). Bootstrap resampling (150 samples) was used to compute standard errors for our proposed estimators ( $\mathrm{WKM}_{f, x \%}$ and $\mathrm{WKM}_{\mathcal{N}}(\sigma)$ ) and for the IPCW method. We also investigated the influence of the principal component analysis in our method. Then, we also derived our proposed estimators using directly the risk score for the failure time model without doing principal component analysis.

Performance of the different estimators are compared through relative bias $(100 \times[\mathrm{Bias} / S(t)])$ with Bias $=$ $(1 / 1000)\left(\sum_{i=1}^{1000}\left(\hat{S}_{i}(t)-S(t)\right)\right)$, where $S(t)$ is given by the KM FO and $S_{i}(t)$ denote the estimated survival function obtained from the $i$ th simulated dataset using a given method. We also determined the mean standard error $\left(\mathrm{MSE}=(1 / 1000)\left(\sum_{i=1}^{1000}\left(\hat{S}_{i}(t)-S(t)\right)^{2}\right)\right)$ of the estimators across the 1000 simulated datasets. Finally, we computed the coverage rates, i.e., the proportion of $95 \%$ confidence intervals that covered the KM FO for each method. Performance of all these methods are displayed at the middle and end of survival curve when $S(t)=0.5, S(t)=0.35$ and $S(t)=0.2$.

\section{2 | Simulation results}

Results for the first series of simulation, i.e. estimating an hypothetical HIV-1 RNA reduction, are displayed in Tables 3 and 4 for $\mathrm{N}=200$ (complete results are displayed in supplementary tables 2-9 for $\mathrm{N}=200$ and tables 16-23 for $\mathrm{N}=100$ ). Using three distinct LOD (100, 200 and 500 copies $/ \mathrm{ml}$ ) leads to overall censoring rate from 45 to $65 \%$. As expected the KM PO analysis provided lower performance compared with the FO analysis (gold standard) with biased estimates and a lower coverage rate than the nominal level. Bias (coverage rate) increases (decreases) with increasing censoring rate from $S(t)=0.5$ to $S(t)=0.2$ and for an increasing overall censoring rate from 45 to $65 \%$. $\mathrm{WKM}_{I J J}$ method shows poor performances with a large relative bias and very low coverage rates (below 70\%) especially for the tail of the curve. Performances decrease with increasing value of both $I$ and $J$ and, as for all estimators, with increasing censoring rate. Performances markedly decrease when only $Z_{1}$ is used in the two working Cox PH models (Table 4). For example, with an overall censoring rate of $50 \%$, the coverage rate moves from 70.6 to $17.2 \%$ and the relative bias from 5.6 to $16.9 \%$ for $\mathrm{WKM}_{4,1}$. Of note, $\mathrm{WKM}_{I, J}$ method provides poor performances in term of coverage probability even at the median of the curve $(S(t)=0.5)$ with $24 \%$ censoring at that time. 
In contrast, KMIB method provides much better performance with low coverage rates than the nominal value only for the tail of the curve and for a level of censoring greater than $50 \%$. In general, performances are almost similar in terms of bias and coverage rate when only $Z_{1}$ is used to derive the KMIB estimator. Surprisingly, in this setting, IPCW method provided similar or lower performances than the PO analysis. There is no clear trend of the performance when the censoring increase since performances decrease from an overall censoring rate of $45 \%$ to $50 \%$ but then increase from $50 \%$ to $57 \%$ and decrease again from $57 \%$ to $64 \%$ (supplementary Table 5). On the other hand, the use of $Z_{1}$ as single variable in the Cox model provides almost similar performances than the use of the 5 variables in the model.

In general, best performances are obtained for $\mathrm{WKM}_{U, x}(x=15$ and $20 \%)$ and $\mathrm{WKM}_{\mathcal{N}(1)} . \mathrm{WKM}_{D, x}$ and $\mathrm{WKM}_{R, x \%}$ estimators may provide reasonable estimates but with poorer or slightly poorer performance than $\mathrm{WKM}_{U, x}(\operatorname{supplementary}$ tables 2-9). For $\mathrm{WKM}_{f, x \%}(f=D$ and $R)$ the relative bias tends to decrease with increasing number of neighbours for $S(t)=$ 0.50 and 0.35 . For the tail of the curve, the relative bias is smallest around $x=10-20 \%$. For $\mathrm{WKM}_{U, x \%}$ the relative bias has an $\mathrm{U}$ shape with lowest bias around $10 \%$. For $\mathrm{WKM}_{\mathcal{N}(\sigma)}$, lowest relative bias are obtained with $\sigma=0.5$ and 1 but better coverage rates are obtained with $\sigma=1$. Performances of $\mathrm{WKM}_{U, x \%}(x=15$ and $20 \%)$ and $\mathrm{WKM}_{\mathcal{N}(1)}$ are similar or slightly better than KMIB method with an overall censoring of $45 \%$. These estimators, however, outperform the KMIB method when the overall censoring is greater than $50 \%$. Whatever the values of $x$ for $\mathrm{WKM}_{U, x \%}$ and of $\sigma$ for $\mathrm{WKM}_{\mathcal{N}(\sigma)}$, except $\sigma=0.1$, these estimators lead to better performances than $\mathrm{WKM}_{I, J}$. In contrast, KMIB method provided better performance than $\mathrm{WKM}_{R, x \%}$ and $\mathrm{WKM}_{D, x}$. Performances of our estimators in terms of coverage rate are decreased for $\mathrm{WKM}_{R, x \%}, \mathrm{WKM}_{D, x \%}$ and $\mathrm{WKM}_{\mathcal{N}(0.1)}$ when $Z_{1}$ alone is used instead of the five variables (supplementary Tables 6-9). WKM $\mathrm{W}_{U, x}$ with $x \geq 5 \%$ and WKM $\mathrm{W}_{\mathcal{N}(\sigma)}$ with $\sigma \geq 0.5$, provide almost similar performances with the use of $Z_{1}$ alone.

It is difficult to summarize all the results obtained with a smaller sample size $(\mathrm{N}=100)$ except that for all methods MSE was higher than with $\mathrm{N}=200$ (supplementary Tables 16-23). In general, for $\mathrm{WKM}_{D, x \%}$ relative bias were similar or slightly lower and coverage probabilities were similar or slightly higher with $\mathrm{N}=100$ compared with $\mathrm{N}=200$. For $\mathrm{WKM}_{R, x}, \mathrm{WKM}_{U, x} \%$ and $\mathrm{WKM}_{\mathcal{N}(\sigma)}$ performances were roughtly similar except in few occasions. Similar conclusions were found when only $Z_{1}$, representing the baseline HIV-1 RNA, was used in both failure and censoring models (mis-specified models).

In general, we also obtained good performances when the risk score for the failure time model is used without a principal component analysis (supplementary tables 30-33). For example, the relative bias is low and coverage probabilities not far from the nominal level for $\mathrm{WKM}_{U, 10-15 \%}$ and $\mathrm{WKM}_{\mathcal{N}(0.5-1)}$. Of note, when most of the weights of censored observations are redistributed among less observations $\left(\mathrm{WKM}_{U, x \%}\right.$ with $x \leq 5 \%$ and $\mathrm{WKM}_{\mathcal{N}(\sigma)}$ with $\left.\sigma \leq 0.5\right)$ performances are better or slightly better compared with the use of a principal component analysis. In contrast, with $x>5 \%$ and $\sigma>0.5$ performances are similar or slightly lower than with the use of principal component analysis. With a high level of censoring (overall censoring rate of $64 \%$ ), however, the use of PCA tends to provide slightly better performances for the tail of the curve.

As expected, results of the second series (Table 5) provide similar results for $\mathrm{WKM}_{I, J}$, IPCW and KMIB methods than those found in Hsu and Taylor. ${ }^{14}$ Complete results for this second series of simulation are displayed in supplementary Tables $10-15$ for $\mathrm{N}=200$ and supplementary Tables 24-29 for $\mathrm{N}=100$. When the link functions are correctly specified WKM ${ }_{4,1}$, IPCW and KMIB methods show good performances although for $\mathrm{WKM}_{I J J}$ with $I>4$ or $J>1$ performances decrease for the tail of the curve $(S(t)=0.20)$. Our estimators $\mathrm{WKM}_{U, x}$, with $x=5$ and $10 \%$, and $\mathrm{WKM}_{\mathcal{N}(0.5)}$ provide similar performances than $\mathrm{WKM}_{4,1}$, IPCW and KMIB estimators. When the link functions are uncorrectly specified, WKM ${ }_{I, J}$ method has increasing bias and decreasing coverage rates with increasing censoring rate from $S(t)=0.5$ to $S(t)=0.2$. IPCW method show also lower coverage rates than the nominal value. $\mathrm{WKM}_{U, x \%}(x=5$ and $10 \%)$ and $\mathrm{WKM}_{\mathcal{N}(0.5)}$ provide similar results than the $\mathrm{KMIB}$ method with lower coverage rate than the nominal value for the tail of the survival curve.

As for the other methods, the use of $Z_{1}-Z_{3}$ in the failure time model (supplementary Tables 13-15), performances of our proposed methods are poorer than with a correct specification of the failure time model uing $Z_{1}-Z_{5}$ (supplementary Tables 10 12). In general, however, their performances are still better or slightly better than those provided by the $\mathrm{WKM}_{I, J}$ method mainly for th e tail of the survival curve. As above, MSE increased for all methods with a smaller ample size (N=100, supplementary tables 24-29). For our estimators, performances when $\mathrm{N}=100$ are roughly similar or slightly lower than whith $\mathrm{N}=200$ and still comparable to $\mathrm{WKM}_{I, J}$ for $\mathrm{WKM}_{U, 5-10 \%}$ and $\mathrm{WKM}_{\mathcal{N}(0.5)}$. The direct use of the risk score of the failure time model without a principal component analysis provides, overall, similar results than using the first component of a principal component analysis analysis (supplementary tables 34-36).

In summary, when censoring is due to a LOD for the reduction of variable approximately normally distributed $\mathrm{WKM}_{U, x \%}$ and $\mathrm{WKM}_{\mathcal{N}}(\sigma)$ can provide reasonable estimates of such a reduction. In contrast, $\mathrm{WKM}_{D, x}$ and $\mathrm{WKM}_{R, x \%}$ do not produce always reasonable estimates mainly for the tail of the curve. In general, our estimators are robust to misspecification of both working 
models and the direct use of the risk score of the failure time model provides also roughly similar results than the use of the first component of a principal component analysis. KMIB method can also produce reasonable estimate up to an overall censoring rate lower than $50 \%$. The $\mathrm{WKM}_{I J}$ method provide large bias and poor coverage rates especially for the tail of the curve. IPCW method does not provide good performance although better than $\mathrm{WKM}_{I, J}$. In the classical survival settings, the WKM $\mathrm{W}_{I, J}$ method can provide reasonable survival estimates mainly when the link functions are correctly specified. When the link functions are uncorrectly specified there an increasing bias and decreasing coverage rates for the tail of the curve. IPCW and KMIB methods can produce reasonable survival estimates, the latter method being more robust to misspecification of the link functions. Our estimators $\mathrm{WKM}_{U, x \%}$ and $\mathrm{WKM}_{\mathcal{N}}(\sigma)$ can produce reasonable survival estimates mostly similar to IPCW and KMIB methods. In the case of mis-specification of the failure time model, our estimators provide similar performances than other methods. Again the direct use of the risk score of the failure time model provides reasonable estimates of the survival function in most cases.

\section{5 | DISCUSSION}

We investigate in this work a procedure based on the WKM estimator proposed by Malani ${ }^{111}$ to estimate survival curve in the presence of dependent censoring. The procedure is based on principal components of standardized risks scores estimated from working models. Our simulations results, however, show good performances using directly the risk score without any principal component analysis. A similar procedure has been used to categorize observations in a certain number of groups. ${ }^{14}$ Such groups are defined at time 0 and are time independent. Our procedure is more flexible redistributing weights among observations still at risk when censored observations occurred. When the objective is to estimate an HIV-1 RNA reduction censored by a LOD, a parametric regression model with a normal distribution is chosen for both working models on event and censored times. When the goal is to estimate a classical survival curve, two working Cox PH models are used. Our proposition was motivated to estimate HIV-1 RNA reduction censored by a LOD in HIV-1 infected patients. Our estimators $\mathrm{WKM}_{U, x \%}$ and $\mathrm{WKM}_{\mathcal{N}(\sigma)}$ can provide reasonable estimates of such a reduction. In particular, with appropriate parameters our suggestions have lower relative bias and better coverage rates than existing methods. In the classical survival settings, our method can also provide reasonable estimates showing bias and coverage rates mostly similar to IPCW and KMIB methods.

Most of the existing methods used the Cox proportional hazards model to derive their estimators. A previous work has shown that all these estimators have some bias when event and censoring models are not from a PH family (link functions incorrectly specified). We show that the bias is more pronounced and the coverage rates lower for the tail of the survival curve. In our motivating example, given the level of the baseline HIV-1 RNA and the LOD of the assay used by the department of virology, the maximum uncensored reduction is known as the baseline value minus the LOD. Beyond this value the HIV-1 RNA reduction is censored. In a simulation study, similar censoring would be obtained using a uniform distribution for censoring times. Then, the censoring model is not from a PH family. Thus, our motivating example, as well as the first series of the simulation study, correspond to a situation where the link functions are incorrectly specified. Consequently, the double robustness properties of some estimators does not hold since the true model is not from a PH family. That explains the bias found in our study simulation for most estimators although, for few situations, the relative bias is important only for the tail of the curve. The bias is more pronounced for both $\mathrm{WKM}_{I, J}$ estimators than for KMIB and IPCW estimators. In the classical survival settings, we found the same results as Hsu and Taylor (2010), i.e. $\mathrm{WKM}_{I, J}$, KMIB and IPCW methods provide good performance mainly in the situation where the link functions are correctly specified. Our suggestions provide also reasonable estimates of the survival curve.

For all methods, one has to choose the variables included in models used to derive the estimators. IPCW method has the main advantage of not choosing any other parameters. For the KMIB method we have to choose weights for failure and censoring risks as well as the size of the imputing risk set. The number of groups should be determined for the $\mathrm{WKM}_{I, J}$ method, and, in general, the bias increases with increasing number of groups. The choice of the number of neighbours and the value of $\sigma$ is a limitation of our method. Our results have shown that the risk score can be used directly without a principal component analysis. As for $\mathrm{WKM}_{I, J}$, one have to choose both failure and censoring time models. Further studies are required to investigate other situations involving other variables having non-normal distributions. For $\mathrm{WKM}_{U, x \%}$, it is clear that especially at the end of the follow-up, the number of available neighbours can be less than the desired number which may explained the large variability for the tail of the curve.

As shown in our motivating example the main prognostic factor of censoring is the baseline HIV-1 RNA level though other variables may be involved. Then, one can use only this variable to derive all estimators. In this case, our motivating example, as well as simulation results, show that, in general, $\mathrm{WKM}_{U, x \%}, \mathrm{WKM}_{\mathcal{N}}(\sigma)$ and $\mathrm{KMIB}$ estimators have relatively good performance. 
Of course, our method can be used in many other situations. Variables following a normal distributions are common and the difficulty of measuring a variable below a LOD is a common problem in medical and biological studies. It occurs for other variables than the viral load in the management of HIV-1 infected patients. ${ }^{19}$ For example, assays to quantify most plasma cytokines and chemokines (IL-1 $\beta$, IL-2, IL6-M, ...) used a LOD. The difficulty of quantifying a variable below a LOD occurs also in environmental studies. 2021

\section{ACKNOWLEDGMENTS}

We would like to thank Jonathan Bartlett who maintain the InformativeCensoring package and help us for programming the KMIB method. We also would like to thank Pr Simon Day who give us the possibility to resubmit our manuscript, the associate editor and two anonymous referees for their constructive comments that significantly improved this article

\section{Bibliography}

1. Marschner IC, Betensky RA, DeGruttola V, Hammer SM, Kuritzkes DR. Clinical trials using HIV-1 RNA-based primary endpoints: statistical analysis and potential biases. J Acquir Immune Defic Syndr Hum Retrovirol 1999; 20(3): 220-7.

2. Pozniak AL, Morales-Ramirez J, Katabira E, et al. Efficacy and safety of TMC278 in antiretroviral-naive HIV-1 patients: week 96 results of a phase IIb randomized trial. AIDS 2010; 24(1): 55-65.

3. Flandre P, Marcelin AG, Calvez V, Group AARS. Addition of Etravirine Does Not Enhance the Initial Decline of HIV-1 RNA in Treatment-Experienced Patients Receiving Raltegravir. J Acquir Immune Defic Syndr 2017; 75(4): 448-454.

4. Bansi L, Sabin C, Gilson R, et al. Virological response to initial antiretroviral regimens containing abacavir or tenofovir. $J$ Infect Dis 2009; 200(5): 710-4.

5. Marcelin AG, Dalban C, Peytavin G, et al. Clinically relevant interpretation of genotype and relationship to plasma drug concentrations for resistance to saquinavir-ritonavir in human immunodeficiency virus type 1 protease inhibitor-experienced patients. Antimicrob Agents Chemother 2004; 48(12): 4687-92.

6. Marcelin AG, Flandre P, Pavie J, et al. Clinically relevant genotype interpretation of resistance to didanosine. Antimicrob Agents Chemother 2005; 49(5): 1739-44.

7. Marcelin AG, Flandre P, Descamps D, et al. Factors associated with virological response to etravirine in nonnucleoside reverse transcriptase inhibitor-experienced HIV-1-infected patients. Antimicrob Agents Chemother 2010; 54(1): 72-7.

8. Marcelin AG, Delaugerre C, Beaudoux C, et al. A cohort study of treatment-experienced HIV-1-infected patients treated with raltegravir: factors associated with virological response and mutations selected at failure. Int J Antimicrob Agents 2013; 42(1): 42-7.

9. Kalbfleisch J, Prentice R. The Statistical analysis of Failure Time Data. Wiley; New York . 2002.

10. O’Quigley J. Proportional Hazards Regression. Springer; New York . 2008.

11. Malani H. A modification of the redistribution to the right algorithm using diseases markers. Biometrika 1995; 90 : $577-584$.

12. Murray S, Tsiatis AA. Nonparametric survival estimation using prognostic longitudinal covariates. Biometrics 1996; 52(1): 137-51.

13. Hsu CH, Taylor JM, Murray S, Commenges D. Survival analysis using auxiliary variables via non-parametric multiple imputation. Statistics in Medicine 2006; 25(20): 3503-17.

14. Hsu CH, Taylor JM. A robust weighted Kaplan-Meier approach for data with dependent censoring using linear combinations of prognostic covariates. Statistics in Medicine 2010; 29(21): 2215-23. 
5

6

7

8

9

10

15. Robins JM, Finkelstein DM. Correcting for noncompliance and dependent censoring in an AIDS Clinical Trial with inverse probability of censoring weighted (IPCW) log-rank tests. Biometrics 2000; 56(3): 779-88.

16. Robins JM, Rotnitzky A. Recovery of Information and Adjustment for Dependent Censoring Using Surrogate Markers: 24-33; Boston: Birkhauser. . 1992.

17. Efron B. The two sample problem with censored data.. In: Proceedings of the Fifth Berkeley Symposium on Mathematical Statistics and Probability, volume 5 of Berkeley, pages 831-853. ; 1967.

18. Rubin D. Multiple imptation for Nonresponse in Surveys. Wiley: New York . 1987.

19. Cozzi-Lepri A, French MA, Baxter J, et al. Resumption of HIV replication is associated with monocyte/macrophage derived cytokine and chemokine changes: results from a large international clinical trial. AIDS 2011; 25(9): $1207-17$.

20. Shumway RH, Azari RS, Kayhanian M. Statistical approaches to estimating mean water quality concentrations with detection limits. Environ Sci Technol 2002; 36(15): 3345-53.

21. Dinse GE, Jusko TA, Ho LA, et al. Accommodating measurements below a limit of detection: a novel application of Cox regression. Am J Epidemiol 2014; 179(8): 1018-24. 
TABLE 5 Monte Carlo results for estimating classical survival curves with five time independent covariates and dependent censoring.

The link functions correctly specified. Overall censoring rate $=35 \%$ and $\mathrm{N}=200$.

\begin{tabular}{|c|c|c|c|c|c|c|c|c|c|c|c|c|}
\hline \multirow[b]{2}{*}{ Method } & \multicolumn{4}{|c|}{ True value: 0.5} & \multicolumn{4}{|c|}{ True value: 0.35} & \multicolumn{4}{|c|}{ True value: 0.2} \\
\hline & Est $^{1}$ & $\mathrm{R}$ bias $^{2}$ & $\mathrm{MSE}^{3}$ & $\mathrm{CR}^{4}$ & Est & $\mathrm{R}$ bias & MSE & $\mathrm{CR}$ & Est & $\mathrm{R}$ bias & MSE & $\mathrm{CR}$ \\
\hline & \multicolumn{4}{|c|}{ Censoring rate $=26 \%{ }^{5}$} & \multicolumn{4}{|c|}{ Censoring rate $=29 \%$} & \multicolumn{4}{|c|}{ Censoring rate $=32 \%$} \\
\hline \multicolumn{13}{|c|}{ Existing methods } \\
\hline KM FO & 0.499 & -0.1 & 0.0012 & 94.5 & 0.350 & 0.0 & 0.0012 & 93.9 & 0.198 & -0.2 & 0.0008 & 93.4 \\
\hline KM PO & 0.565 & 6.5 & 0.0059 & 60.6 & 0.425 & 7.5 & 0.0074 & 55.3 & 0.268 & 6.8 & 0.0062 & 60.0 \\
\hline IPCW & 0.500 & 0.0 & 0.0018 & 93.0 & 0.352 & 0.2 & 0.0018 & 94.4 & 0.201 & 0.1 & 0.0013 & 94.2 \\
\hline KMIB & 0.510 & 1.0 & 0.0018 & 94.0 & 0.364 & 1.4 & 0.0018 & 93.4 & 0.212 & 1.2 & 0.0013 & 94.3 \\
\hline $\mathrm{WKM}_{4,1}$ & 0.505 & 0.5 & 0.0018 & 94.3 & 0.357 & 0.7 & 0.0017 & 93.4 & 0.211 & 1.1 & 0.0014 & 92.9 \\
\hline $\mathrm{WKM}_{4,2}$ & 0.509 & 0.9 & 0.0019 & 93.2 & 0.365 & 1.5 & 0.0020 & 91.7 & 0.221 & 2.1 & 0.0019 & 88.6 \\
\hline $\mathrm{WKM}_{4,4}$ & 0.516 & 1.6 & 0.0020 & 92.2 & 0.376 & 2.6 & 0.0025 & 87.9 & 0.237 & 3.7 & 0.0029 & 80.2 \\
\hline $\mathrm{WKM}_{8,1}$ & 0.504 & 0.4 & 0.0018 & 94.0 & 0.360 & 1.0 & 0.0019 & 91.9 & 0.217 & 1.7 & 0.0017 & 90.6 \\
\hline $\mathrm{WKM}_{8,2}$ & 0.513 & 1.3 & 0.0019 & 92.2 & 0.374 & 2.4 & 0.0024 & 87.9 & 0.236 & 3.6 & 0.0028 & 80.6 \\
\hline $\mathrm{WKM}_{16,1}$ & 0.510 & 1.0 & 0.0019 & 92.4 & 0.371 & 2.1 & 0.0023 & 89.1 & 0.233 & 3.3 & 0.0026 & 82.7 \\
\hline \multicolumn{13}{|c|}{ Proposed methods } \\
\hline $\mathrm{WKM}_{U, 5 \%}$ & 0.504 & 0.4 & 0.0017 & 93.7 & 0.355 & 0.5 & 0.0016 & 92.7 & 0.203 & 0.3 & 0.0011 & 93.5 \\
\hline $\mathrm{WKM}_{U, 10 \%}$ & 0.510 & 1.0 & 0.0018 & 93.7 & 0.361 & 1.1 & 0.0017 & 93.3 & 0.209 & 0.9 & 0.0012 & 93.5 \\
\hline $\mathrm{WKM}_{\mathcal{N}(0.5)}$ & 0.509 & 0.9 & 0.0017 & 93.9 & 0.360 & 1.0 & 0.0017 & 93.5 & 0.206 & 0.6 & 0.0012 & 94.0 \\
\hline
\end{tabular}

The link functions uncorrectly specified. Overall censoring rate $=51 \%$ and $\mathrm{N}=200$

True value: 0.5

Method

\begin{tabular}{llll}
\hline Est $^{1}$ & $\mathrm{R}_{\text {bias }}^{2}$ & $\mathrm{MSE}^{3}$ & $\mathrm{CR}^{4}$
\end{tabular}

Censoring rate $=34 \%$

\section{Existing methods}

\begin{tabular}{|c|c|c|c|c|c|c|c|c|c|c|c|c|}
\hline KM FO & 0.498 & -0.2 & 0.0012 & 94.8 & 0.349 & -0.1 & 0.0011 & 94.9 & 0.199 & -0.1 & 0.0008 & 94.3 \\
\hline KM PO & 0.603 & 10.3 & 0.0121 & 29.6 & 0.470 & 12.0 & 0.0163 & 24.3 & 0.318 & 11.8 & 0.0163 & 29.6 \\
\hline IPCW & 0.489 & -1.1 & 0.0066 & 81.7 & 0.334 & -1.6 & 0.0073 & 77.1 & 0.186 & -1.4 & 0.0053 & 81.3 \\
\hline KMIB & 0.521 & 2.1 & 0.0024 & 91.5 & 0.377 & 2.7 & 0.0029 & 90.3 & 0.23 & 3.0 & 0.0029 & 89.0 \\
\hline $\mathrm{WKM}_{4,1}$ & 0.515 & 1.5 & 0.0026 & 90.4 & 0.374 & 2.4 & 0.0034 & 88.1 & 0.243 & 4.3 & 0.0046 & 81.2 \\
\hline $\mathrm{WKM}_{4,2}$ & 0.522 & 2.2 & 0.0029 & 88.5 & 0.389 & 3.9 & 0.0043 & 81.9 & 0.266 & 6.6 & 0.0071 & 65.7 \\
\hline $\mathrm{WKM}_{4,4}$ & 0.535 & 3.5 & 0.0035 & 82.8 & 0.409 & 5.9 & 0.0061 & 66.5 & 0.294 & 9.4 & 0.0116 & 38.3 \\
\hline $\mathrm{WKM}_{8,1}$ & 0.518 & 1.8 & 0.0027 & 89.2 & 0.382 & 3.2 & 0.0038 & 85.1 & 0.257 & 5.7 & 0.0060 & 69.2 \\
\hline $\mathrm{WKM}_{8,2}$ & 0.532 & 3.2 & 0.0033 & 83.8 & 0.406 & 5.6 & 0.0058 & 68.8 & 0.291 & 9.1 & 0.0109 & 40.5 \\
\hline $\mathrm{WKM}_{16,1}$ & 0.529 & 2.9 & 0.0031 & 84.4 & 0.402 & 5.2 & 0.0053 & 70.7 & 0.286 & 8.6 & 0.0099 & 43.9 \\
\hline \multicolumn{13}{|c|}{ Proposed methods } \\
\hline $\mathrm{WKM}_{U, 5 \%}$ & 0.511 & 1.1 & 0.0021 & 92.1 & 0.363 & 1.3 & 0.0023 & 90.6 & 0.216 & 1.6 & 0.0021 & 89.6 \\
\hline $\mathrm{WKM}_{U, 10 \%}$ & 0.519 & 1.9 & 0.0023 & 91.8 & 0.373 & 2.3 & 0.0026 & 90.4 & 0.227 & 2.7 & 0.0024 & 89.2 \\
\hline $\mathrm{WKM}_{\mathcal{N}(0.5)}$ & 0.520 & 2.0 & 0.0023 & 90.4 & 0.372 & 2.2 & 0.0026 & 90.1 & 0.220 & 2.0 & 0.0024 & 88.5 \\
\hline
\end{tabular}

Est R bias MSE CR
True value: 0.2
True value: 0.35

Est R bias MSE CR

Censoring rate $=40 \%$

Censoring rate $=46 \%$ 


\section{Statistics in Medicine}

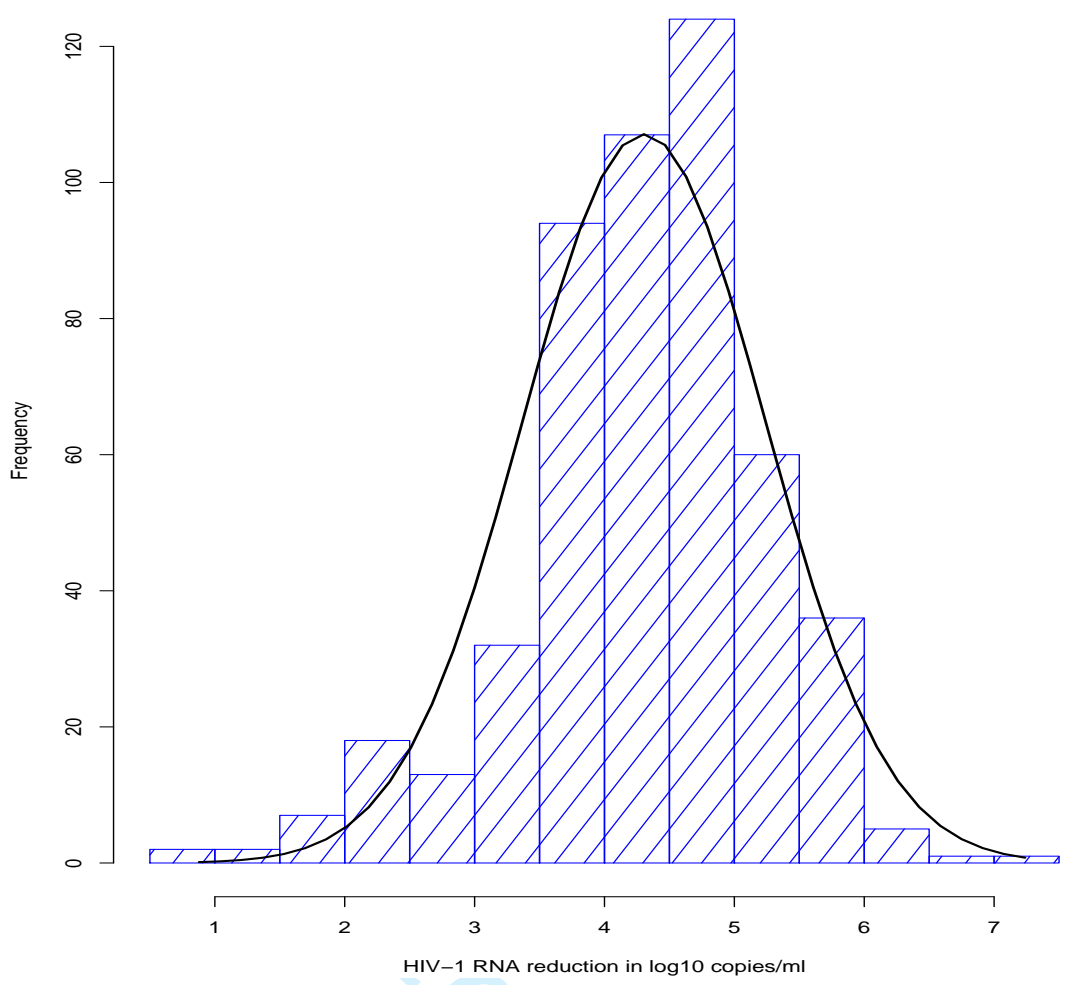

Figure 1. Distribution of the HIV-1 RNA reduction at week 8 in the 502 patients receiving a raltegravir-based regimen using the crude method 


\section{Statistics \\ in Medicine}

Table 1. Data analysis. top: estimation of two working regression models with a normal distribution on the HIV-1 RNA reduction in the 502 observations; bottom: estimation of two working Cox $\mathrm{PH}$ models

Regression models with a normal distribution

Failure time model

Censoring time model

\begin{tabular}{lccccccc}
\cline { 2 - 3 } Covariates & Estimate & SE & p-value & & Estimate & SE & p-value \\
\hline Baseline viral load & 0.324 & 0.091 & $<.01$ & & 0.980 & 0.010 & $<.01$ \\
Baseline CD4 $\times 10^{-2}$ & 0.159 & 0.038 & $<.01$ & & 0.003 & 0.004 & 0.41 \\
Age & 0.013 & 0.007 & 0.05 & & 0.001 & 0.001 & 0.17 \\
NRTIs & 0.109 & 0.066 & 0.10 & & -0.014 & 0.007 & 0.04 \\
NNRTIs & 0.219 & 0.137 & 0.11 & & 0.001 & 0.014 & 0.95 \\
Previous ARVs used & -0.057 & 0.017 & $<.01$ & & -0.007 & 0.002 & $<.01$
\end{tabular}

Cox proportional hazard models

Failure time model Censoring time model

\begin{tabular}{lcccccccc}
\cline { 2 - 3 } Covariates & Estimate & SE & p-value & & Estimate & SE & p-value \\
\hline Baseline viral load & -0.599 & 0.121 & $<.01$ & & -7.686 & 0.361 & $<.01$ \\
Baseline CD4 $\times 10^{-2}$ & -0.197 & 0.048 & $<.01$ & & -0.020 & 0.038 & 0.59 \\
Age & -0.008 & 0.006 & 0.17 & & -0.011 & 0.007 & 0.12 \\
NRTIs & -0.095 & 0.067 & 0.15 & & 0.203 & 0.069 & $<.01$ \\
NNRTIs & -0.254 & 0.134 & 0.06 & & 0.067 & 0.138 & 0.63 \\
Previous ARVs used & 0.056 & 0.017 & $<.01$ & & 0.078 & 0.019 & $<.01$
\end{tabular}




\section{Statistics in Medicine}

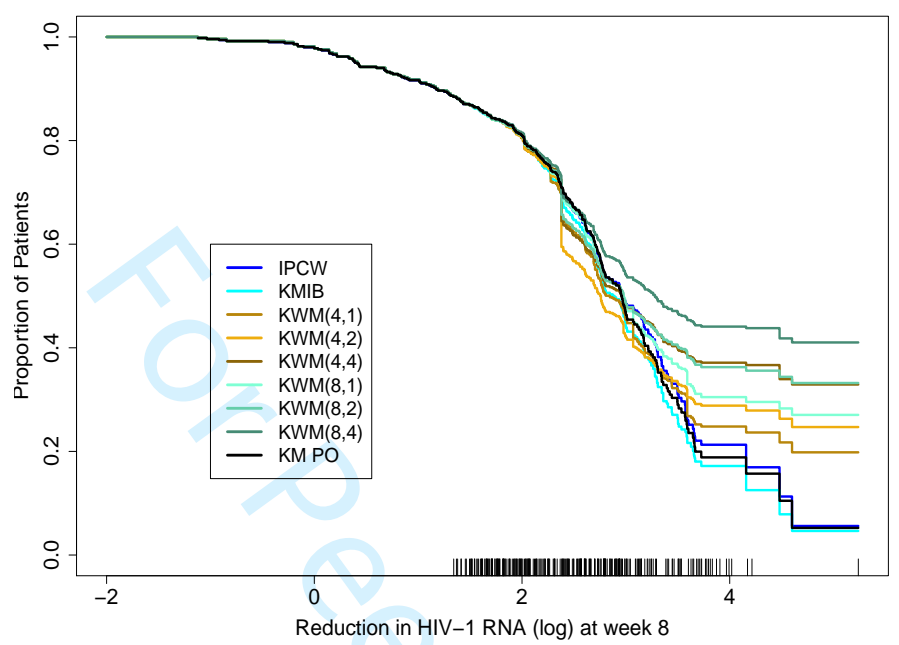

(a)

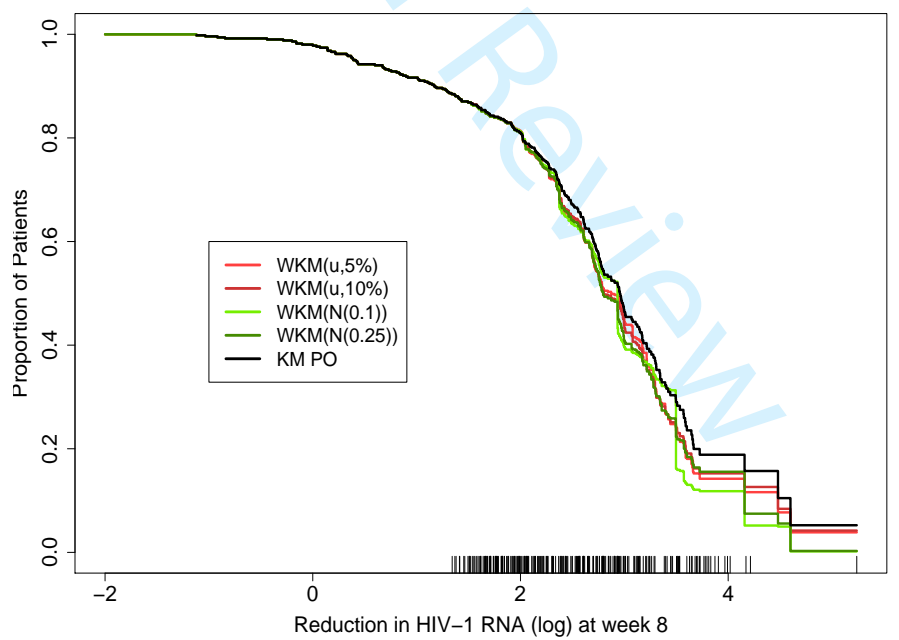

(b)

Figure 2. Estimates of the reduction in HIV-1 RNA (in $\log _{10}$ copies/ml) at week 8 in the 502 patients of whom 254 (51\%) have a censored HIV-1 RNA reduction. 


\section{Statistics}

\section{in Medicine}

Table 2. Monte Carlo results for estimating an hypothetical HIV-1 RNA reduction $(\mathbf{N}=\mathbf{2 0 0})$. $70 \%$ LOD=100 copies/ml and $30 \% \mathrm{LOD}=\mathbf{2 0 0}$ copies/ml leading to an overall censoring rate of $\mathbf{4 5 \%}$.

Estimators are derived using the 5 covariates.

True value: 0.5

Censoring rate $=24 \%$ व

Method Est * $\mathrm{R}^{\text {bias }^{\dagger}} \mathrm{MSE}^{\ddagger} \mathrm{CR}^{\S} \quad$ Est $\mathrm{R}$ bias $\mathrm{MSE} \quad \mathrm{CR}$

\begin{tabular}{|c|c|c|c|c|c|c|c|c|c|c|c|c|}
\hline KM FO & 0.498 & -0.2 & 0.0013 & 95.4 & 0.349 & -0.1 & 0.0012 & 94.3 & 0.199 & -0.1 & 0.0009 & 93.6 \\
\hline KM PO & 0.520 & 2.0 & 0.0019 & 92.4 & 0.379 & 2.9 & 0.0027 & 89.1 & 0.236 & 3.6 & 0.0037 & 87.9 \\
\hline IPCW & 0.515 & 1.5 & 0.0019 & 92.1 & 0.374 & 2.4 & 0.0026 & 89.8 & 0.231 & 3.1 & 0.0038 & 86.8 \\
\hline KMIB & 0.506 & 0.6 & 0.0018 & 93.9 & 0.363 & 1.3 & 0.0023 & 93.6 & 0.220 & 2.0 & 0.0031 & 91.5 \\
\hline $\mathrm{WKM}_{4,1}$ & 0.486 & -1.4 & 0.0026 & 88.4 & 0.349 & -0.1 & 0.0033 & 86.6 & 0.242 & 4.2 & 0.0059 & 75.8 \\
\hline $\mathrm{WKM}_{4,2}$ & 0.517 & 1.7 & 0.0025 & 87.5 & 0.406 & 5.6 & 0.0058 & 69.7 & 0.329 & 12.9 & 0.0197 & 20.0 \\
\hline $\mathrm{WKM}_{4,4}$ & 0.536 & 3.6 & 0.0031 & 82.2 & 0.439 & 8.9 & 0.0100 & 41.1 & 0.374 & 17.4 & 0.0324 & 2.3 \\
\hline $\mathrm{WKM}_{8,1}$ & 0.491 & -0.9 & 0.0024 & 89.2 & 0.363 & 1.3 & 0.0030 & 87.9 & 0.266 & 6.6 & 0.0078 & 62.3 \\
\hline $\mathrm{WKM}_{8,2}$ & 0.529 & 2.9 & 0.0027 & 85.1 & 0.427 & 7.7 & 0.0081 & 50.1 & 0.360 & 16.0 & 0.0278 & 4.2 \\
\hline $\mathrm{WKM}_{16,1}$ & 0.502 & 0.2 & 0.0020 & 90.5 & 0.383 & 3.3 & 0.0034 & 83.0 & 0.298 & 9.8 & 0.0123 & 32.2 \\
\hline $\mathrm{WKM}_{D, 2.5 \%}$ & 0.481 & -1.9 & 0.0026 & 84.5 & 0.327 & -2.3 & 0.0037 & 71.3 & 0.184 & -1.6 & 0.0041 & 55.5 \\
\hline $\mathrm{WKM}_{D, 5 \%}$ & 0.483 & -1.7 & 0.0024 & 86.8 & 0.330 & -2.0 & 0.0032 & 75.1 & 0.187 & -1.3 & 0.0034 & 60.9 \\
\hline $\mathrm{WKM}_{D, 10 \%}$ & 0.486 & -1.4 & 0.0021 & 88.4 & 0.334 & -1.6 & 0.0027 & 78.9 & 0.192 & -0.8 & 0.0028 & 65.7 \\
\hline $\mathrm{WKM}_{D, 15 \%}$ & 0.488 & -1.2 & 0.0020 & 89.7 & 0.337 & -1.3 & 0.0025 & 80.9 & 0.196 & -0.4 & 0.0027 & 68.5 \\
\hline $\mathrm{WKM}_{D, 20 \%}$ & 0.490 & -1.0 & 0.0019 & 90.8 & 0.340 & -1.0 & 0.0023 & 82.7 & 0.199 & -0.1 & 0.0026 & 71.0 \\
\hline $\mathrm{WKM}_{D, 30 \%}$ & 0.493 & -0.7 & 0.0018 & 92.2 & 0.345 & -0.5 & 0.0021 & 84.4 & 0.203 & 0.3 & 0.0026 & 71.7 \\
\hline $\mathrm{WKM}_{D, 40 \%}$ & 0.496 & -0.4 & 0.0017 & 92.7 & 0.348 & -0.2 & 0.0021 & 85.9 & 0.205 & 0.5 & 0.0026 & 71.9 \\
\hline $\mathrm{WKM}_{D, 50 \%}$ & 0.498 & -0.2 & 0.0017 & 93.2 & 0.350 & 0.0 & 0.0021 & 86.6 & 0.207 & 0.7 & 0.0026 & 71.5 \\
\hline $\mathrm{WKM}_{R, 2.5 \%}$ & 0.481 & -1.9 & 0.0026 & 85.8 & 0.327 & -2.3 & 0.0037 & 75.0 & 0.184 & -1.6 & 0.0040 & 66.3 \\
\hline $\mathrm{WKM}_{R, 5 \%}$ & 0.483 & -1.7 & 0.0024 & 87.2 & 0.330 & -2.0 & 0.0032 & 78.1 & 0.187 & -1.3 & 0.0033 & 73.5 \\
\hline $\mathrm{WKM}_{R, 10 \%}$ & 0.485 & -1.5 & 0.0021 & 88.6 & 0.334 & -1.6 & 0.0028 & 81.5 & 0.192 & -0.8 & 0.0028 & 79.5 \\
\hline $\mathrm{WKM}_{R, 15 \%}$ & 0.487 & -1.3 & 0.0020 & 89.9 & 0.337 & -1.3 & 0.0025 & 84.8 & 0.196 & -0.4 & 0.0026 & 82.9 \\
\hline $\mathrm{WKM}_{R, 20 \%}$ & 0.489 & -1.1 & 0.0019 & 90.2 & 0.339 & -1.1 & 0.0024 & 86.4 & 0.198 & -0.2 & 0.0026 & 84.6 \\
\hline $\mathrm{WKM}_{R, 30 \%}$ & 0.492 & -0.8 & 0.0018 & 91.1 & 0.343 & -0.7 & 0.0022 & 87.6 & 0.202 & 0.2 & 0.0025 & 85.6 \\
\hline $\mathrm{WKM}_{R, 40 \%}$ & 0.494 & -0.6 & 0.0017 & 91.6 & 0.346 & -0.4 & 0.0021 & 88.1 & 0.204 & 0.4 & 0.0025 & 86.1 \\
\hline $\mathrm{WKM}_{R, 50 \%}$ & 0.496 & -0.4 & 0.0017 & 92.4 & 0.348 & -0.2 & 0.0021 & 88.9 & 0.205 & 0.5 & 0.0025 & 86.3 \\
\hline $\mathrm{WKM}_{U, 2.5 \%}$ & 0.482 & -1.8 & 0.0024 & 88.8 & 0.329 & -2.1 & 0.0034 & 81.3 & 0.185 & -1.5 & 0.0035 & 78.6 \\
\hline $\mathrm{WKM}_{U, 5 \%}$ & 0.485 & -1.5 & 0.0021 & 90.5 & 0.334 & -1.6 & 0.0028 & 86.9 & 0.191 & -0.9 & 0.0027 & 86.7 \\
\hline $\mathrm{WKM}_{U, 10 \%}$ & 0.490 & -1.0 & 0.0019 & 93.4 & 0.340 & -1.0 & 0.0023 & 90.2 & 0.201 & 0.1 & 0.0023 & 91.5 \\
\hline $\mathrm{WKM}_{U, 15 \%}$ & 0.493 & -0.7 & 0.0017 & 94.1 & 0.346 & -0.4 & 0.0020 & 92.6 & 0.208 & 0.8 & 0.0023 & 91.9 \\
\hline $\mathrm{WKM}_{U, 20 \%}$ & 0.496 & -0.4 & 0.0016 & 94.7 & 0.351 & 0.1 & 0.0019 & 93.5 & 0.213 & 1.3 & 0.0024 & 92.5 \\
\hline $\mathrm{WKM}_{U, 30 \%}$ & 0.502 & 0.2 & 0.0016 & 94.6 & 0.359 & 0.9 & 0.0019 & 93.9 & 0.221 & 2.1 & 0.0027 & 91.0 \\
\hline $\mathrm{WKM}_{U, 40 \%}$ & 0.507 & 0.7 & 0.0016 & 94.2 & 0.366 & 1.6 & 0.0020 & 93.7 & 0.226 & 2.6 & 0.0029 & 90.6 \\
\hline $\mathrm{WKM}_{U, 50 \%}$ & 0.511 & 1.1 & 0.0016 & 93.8 & 0.370 & 2.0 & 0.0022 & 92.7 & 0.229 & 2.9 & 0.0032 & 89.7 \\
\hline $\mathrm{WKM}_{\mathcal{N}(0.1)}$ & 0.478 & -2.2 & 0.0033 & 82.5 & 0.323 & -2.7 & 0.0051 & 70.8 & 0.175 & -2.5 & 0.0072 & 51.7 \\
\hline $\mathrm{WKM}_{\mathcal{N}(0.5)}$ & 0.488 & -1.2 & 0.0019 & 91.1 & 0.337 & -1.3 & 0.0024 & 89. & 0.191 & -0.9 & 0.0030 & 84.9 \\
\hline $\mathrm{WKM}_{\mathcal{N}(1)}$ & 0.501 & 0.1 & 0.0016 & 94.8 & 0.354 & 0.4 & 0.0019 & 93.8 & 0.211 & 1.1 & 0.0025 & 91.6 \\
\hline $\mathrm{WKM}_{\mathcal{N}(2)}$ & 0.512 & 1.2 & 0.0017 & 93.6 & 0.369 & 1.9 & 0.0022 & 92.9 & 0.226 & 2.6 & 0.0030 & 90.4 \\
\hline $\mathrm{WKM}_{\mathcal{N}(5)}$ & 0.519 & 1.9 & 0.0018 & 92.5 & 0.377 & 2.7 & 0.0026 & 90.5 & 0.234 & 3.4 & 0.0036 & 88.2 \\
\hline
\end{tabular}

True value: 0.2

Censoring rate $=42 \%$

Est R bias MSE CR

ब Censoring rate at the time of the true value of $S(t)$

* Average of 1000 point estimates

$\dagger$ Relative bias $(100 \times($ Bias $/ S(t))$

$\ddagger$ Mean square error

$\S$ Coverage rate of 100095 per cent confidence intervals 
Table 3. Monte Carlo results for estimating an hypothetical HIV-1 RNA reduction (N=200). 30\% LOD=100 copies/ml and $\mathbf{7 0 \%} \mathrm{LOD}=\mathbf{2 0 0}$ copies $/ \mathrm{ml}$ leading to an overall censoring rate of $\mathbf{5 0 \%}$

Estimators are derived using the 5 covariates.

True value: 0.5

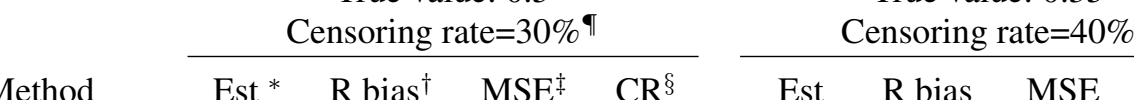

\begin{tabular}{|c|c|c|c|c|c|c|c|c|c|c|c|c|}
\hline KM FO & 0.499 & -0.1 & 0.0013 & 94.1 & 0.349 & -0.1 & 0.0013 & 94.1 & 0.200 & 0.0 & 0.0009 & 93.9 \\
\hline KM PO & 0.525 & 2.5 & 0.0024 & 89.9 & 0.385 & 3.5 & 0.0034 & 89.5 & 0.240 & 4.0 & 0.0053 & 84.8 \\
\hline IPCW & 0.515 & 1.5 & 0.0042 & 82.8 & 0.374 & 2.4 & 0.0054 & 79.8 & 0.232 & 3.2 & 0.0083 & 76.7 \\
\hline KMIB & 0.509 & 0.9 & 0.0022 & 92.4 & 0.367 & 1.7 & 0.0029 & 90.4 & 0.225 & 2.5 & 0.0046 & 88.3 \\
\hline $\mathrm{WKM}_{4,1}$ & 0.487 & -1.3 & 0.0033 & 85.7 & 0.354 & 0.4 & 0.0043 & 82.5 & 0.256 & 5.6 & 0.0084 & 70.6 \\
\hline $\mathrm{WKM}_{4,2}$ & 0.526 & 2.6 & 0.0036 & 82.7 & 0.424 & 7.4 & 0.0090 & 55.7 & 0.354 & 15.4 & 0.0275 & 14.0 \\
\hline $\mathrm{WKM}_{4,4}$ & 0.550 & 5.0 & 0.0046 & 70.8 & 0.462 & 11.2 & 0.0151 & 24.4 & 0.404 & 20.4 & 0.0443 & 1.0 \\
\hline $\mathrm{WKM}_{8,1}$ & 0.494 & -0.6 & 0.0029 & 88.0 & 0.371 & 2.1 & 0.0039 & 82.6 & 0.284 & 8.4 & 0.0111 & 51.8 \\
\hline $\mathrm{WKM}_{8,2}$ & 0.540 & 4.0 & 0.0039 & 76.2 & 0.446 & 9.6 & 0.0119 & 36.4 & 0.386 & 18.6 & 0.0373 & 2.8 \\
\hline $\mathrm{WKM}_{16,1}$ & 0.507 & 0.7 & 0.0025 & 88.7 & 0.395 & 4.5 & 0.0049 & 73.8 & 0.320 & 12.0 & 0.0176 & 22.7 \\
\hline $\mathrm{WKM}_{D, 2.5 \%}$ & 0.477 & -2.3 & 0.0035 & 80.9 & 0.325 & -2.5 & 0.0047 & 66.7 & 0.184 & -1.6 & 0.0051 & 52.9 \\
\hline $\mathrm{WKM}_{D, 5 \%}$ & 0.479 & -2.1 & 0.0031 & 82.9 & 0.328 & -2.2 & 0.0040 & 70.5 & 0.188 & -1.2 & 0.0043 & 57.6 \\
\hline $\mathrm{WKM}_{D, 10 \%}$ & 0.483 & -1.7 & 0.0027 & 85.3 & 0.332 & -1.8 & 0.0033 & 73.9 & 0.194 & -0.6 & 0.0038 & 62.3 \\
\hline $\mathrm{WKM}_{D, 15 \%}$ & 0.486 & -1.4 & 0.0025 & 87.1 & 0.336 & -1.4 & 0.0029 & 78.1 & 0.198 & -0.2 & 0.0036 & 63.0 \\
\hline $\mathrm{WKM}_{D, 20 \%}$ & 0.488 & -1.2 & 0.0023 & 87.8 & 0.340 & -1.0 & 0.0027 & 80.1 & 0.201 & 0.1 & 0.0036 & 63.8 \\
\hline $\mathrm{WKM}_{D, 30 \%}$ & 0.492 & -0.8 & 0.0022 & 89.4 & 0.345 & -0.5 & 0.0025 & 82.0 & 0.205 & 0.5 & 0.0036 & 63.8 \\
\hline $\mathrm{WKM}_{D, 40 \%}$ & 0.495 & -0.5 & 0.0021 & 90.2 & 0.348 & -0.2 & 0.0025 & 83.3 & 0.207 & 0.7 & 0.0036 & 64.2 \\
\hline $\mathrm{WKM}_{D, 50 \%}$ & 0.498 & -0.2 & 0.0020 & 90.8 & 0.351 & 0.1 & 0.0024 & 84.0 & 0.209 & 0.9 & 0.0037 & 64.8 \\
\hline $\mathrm{WKM}_{R, 2.5 \%}$ & 0.477 & -2.3 & 0.0034 & 82.5 & 0.325 & -2.5 & 0.0046 & 70.9 & 0.184 & -1.6 & 0.0050 & 63.8 \\
\hline $\mathrm{WKM}_{R, 5 \%}$ & 0.479 & -2.1 & 0.0031 & 84.9 & 0.328 & -2.2 & 0.0039 & 76.1 & 0.188 & -1.2 & 0.0042 & 69.4 \\
\hline $\mathrm{WKM}_{R, 10 \%}$ & 0.483 & -1.7 & 0.0027 & 86.8 & 0.332 & -1.8 & 0.0033 & 80.3 & 0.193 & -0.7 & 0.0037 & 76.2 \\
\hline $\mathrm{WKM}_{R, 15 \%}$ & 0.485 & -1.5 & 0.0025 & 88.0 & 0.336 & -1.4 & 0.0030 & 83.5 & 0.197 & -0.3 & 0.0036 & 78.6 \\
\hline $\mathrm{WKM}_{R, 20 \%}$ & 0.487 & -1.3 & 0.0024 & 88.6 & 0.339 & -1.1 & 0.0028 & 85.6 & 0.200 & 0.0 & 0.0035 & 80.0 \\
\hline $\mathrm{WKM}_{R, 30 \%}$ & 0.49 & -1.0 & 0.0022 & 89.4 & 0.343 & -0.7 & 0.0025 & 87.1 & 0.204 & 0.4 & 0.0035 & 82.0 \\
\hline $\mathrm{WKM}_{R, 40 \%}$ & 0.493 & -0.7 & 0.0021 & 90.7 & 0.347 & -0.3 & 0.0024 & 87.9 & 0.206 & 0.6 & 0.0035 & 83.1 \\
\hline $\mathrm{WKM}_{R, 50 \%}$ & 0.496 & -0.4 & 0.0020 & 91.1 & 0.349 & -0.1 & 0.0024 & 87.9 & 0.208 & 0.8 & 0.0036 & 83.7 \\
\hline $\mathrm{WKM}_{U, 2.5 \%}$ & 0.479 & -2.1 & 0.0031 & 86.7 & 0.327 & -2.3 & 0.0041 & 79.9 & 0.186 & -1.4 & 0.0045 & 75.6 \\
\hline $\mathrm{WKM}_{U, 5 \%}$ & 0.482 & -1.8 & 0.0027 & 89.4 & 0.332 & -1.8 & 0.0033 & 86.3 & 0.192 & -0.8 & 0.0037 & 84.1 \\
\hline $\mathrm{WKM}_{U, 10 \%}$ & 0.488 & -1.2 & 0.0023 & 91.7 & 0.340 & -1.0 & 0.0026 & 90.7 & 0.203 & 0.3 & 0.0033 & 89.8 \\
\hline $\mathrm{WKM}_{U, 15 \%}$ & 0.493 & -0.7 & 0.0021 & 92.9 & 0.347 & -0.3 & 0.0023 & 92.1 & 0.210 & 1.0 & 0.0033 & 90.7 \\
\hline $\mathrm{WKM}_{U, 20 \%}$ & 0.496 & -0.4 & 0.0020 & 93.2 & 0.353 & 0.3 & 0.0022 & 93.4 & 0.216 & 1.6 & 0.0035 & 90.9 \\
\hline $\mathrm{WKM}_{U, 30 \%}$ & 0.503 & 0.3 & 0.0019 & 93.5 & 0.363 & 1.3 & 0.0022 & 92.4 & 0.224 & 2.4 & 0.0039 & 90.6 \\
\hline $\mathrm{WKM}_{U, 40 \%}$ & 0.51 & 1.0 & 0.0019 & 93.2 & 0.370 & 2.0 & 0.0025 & 91.0 & 0.229 & 2.9 & 0.0043 & 88.8 \\
\hline $\mathrm{WKM}_{U, 50 \%}$ & 0.515 & 1.5 & 0.0020 & 92.8 & 0.375 & 2.5 & 0.0027 & 90.5 & 0.233 & 3.3 & 0.0046 & 87.1 \\
\hline $\mathrm{WKM}_{\mathcal{N}(0.1)}$ & 0.473 & -2.7 & 0.0045 & 77.8 & 0.319 & -3.1 & 0.0069 & 64.1 & 0.175 & -2.5 & 0.0093 & 48.6 \\
\hline $\mathrm{WKM}_{\mathcal{N}(0.5)}$ & 0.487 & -1.3 & 0.0024 & 90.6 & 0.336 & -1.4 & 0.0029 & 88.6 & 0.193 & -0.7 & 0.0042 & 81.0 \\
\hline $\mathrm{WKM}_{\mathcal{N}(1)}$ & 0.502 & 0.2 & 0.0019 & 93.3 & 0.357 & 0.7 & 0.0023 & 92.2 & 0.214 & 1.4 & 0.0037 & 89.2 \\
\hline $\mathrm{WKM}_{\mathcal{N}(2)}$ & 0.516 & 1.6 & 0.0021 & 92.5 & 0.374 & 2.4 & 0.0027 & 90.4 & 0.230 & 3.0 & 0.0045 & 88.0 \\
\hline $\mathrm{WKM}_{\mathcal{N}(5)}$ & 0.523 & 2.3 & 0.0023 & 90.6 & 0.383 & 3.3 & 0.0032 & 88.6 & 0.238 & 3.8 & 0.0051 & 85.5 \\
\hline
\end{tabular}

True value: 0.35

Censoring rate $=40 \%$

True value: 0.2

Censoring rate $=47 \%$

Est bias MSE CR

ब Censoring rate at the time of the true value of $S(t)$

* Average of 1000 point estimates

$\dagger$ Relative bias $(100 \times(\operatorname{Bias} / S(t))$

$\ddagger$ Mean square error

$\S$ Coverage rate of 100095 per cent confidence intervals 


\section{Statistics}

\section{in Medicine}

Table 4. Monte Carlo results for estimating an hypothetical HIV-1 RNA reduction (N=200). $70 \%$ LOD=200 copies/ml and $\mathbf{3 0} \% \mathrm{LOD}=\mathbf{5 0 0}$ copies/ml leading to an overall censoring rate of $\mathbf{5 7 \%}$

Estimators are derived using the 5 covariates.

True value: 0.5

Censoring rate $=39 \%$

Method Est* $\mathrm{R}^{\text {bias }}{ }^{\dagger} \mathrm{MSE}^{\ddagger} \mathrm{CR}^{\S} \quad$ Est $\mathrm{R}$ bias MSE $\mathrm{CR}$

\begin{tabular}{|c|c|c|c|c|c|c|c|c|c|c|c|c|}
\hline KM FO & 0.499 & -0.1 & 0.0013 & 93.8 & 0.348 & -0.2 & 0.0012 & 94.1 & 0.199 & -0.1 & 0.0009 & 93.3 \\
\hline KM PO & 0.535 & 3.5 & 0.0032 & 85.3 & 0.394 & 4.4 & 0.0047 & 84.6 & 0.250 & 5.0 & 0.0083 & 83.3 \\
\hline IPCW & 0.528 & 2.8 & 0.0031 & 86.6 & 0.387 & 3.7 & 0.0045 & 85.8 & 0.245 & 4.5 & 0.0085 & 83.3 \\
\hline KMIB & 0.517 & 1.7 & 0.0027 & 91.7 & 0.374 & 2.4 & 0.0038 & 90.7 & 0.233 & 3.3 & 0.0071 & 85.5 \\
\hline $\mathrm{WKM}_{4,1}$ & 0.486 & -1.4 & 0.0047 & 80.3 & 0.359 & 0.9 & 0.0058 & 80.7 & 0.277 & 7.7 & 0.0129 & 62.7 \\
\hline $\mathrm{WKM}_{4,2}$ & 0.552 & 5.2 & 0.0059 & 69.3 & 0.464 & 11.4 & 0.0167 & 33.1 & 0.409 & 20.9 & 0.0476 & 4.6 \\
\hline $\mathrm{WKM}_{4,4}$ & 0.580 & 8.0 & 0.0087 & 49.2 & 0.507 & 15.7 & 0.0272 & 7.2 & 0.463 & 26.3 & 0.0720 & 0.2 \\
\hline $\mathrm{WKM}_{8,1}$ & 0.496 & -0.4 & 0.0039 & 84.4 & 0.381 & 3.1 & 0.0058 & 78.0 & 0.311 & 11.1 & 0.0177 & 39.5 \\
\hline $\mathrm{WKM}_{8,2}$ & 0.569 & 6.9 & 0.0073 & 55.3 & 0.490 & 14.0 & 0.0224 & 13.8 & 0.446 & 24.6 & 0.0634 & 0.4 \\
\hline $\mathrm{WKM}_{16,1}$ & 0.514 & 1.4 & 0.0033 & 84.6 & 0.411 & 6.1 & 0.0075 & 64.7 & 0.354 & 15.4 & 0.0275 & 11.1 \\
\hline $\mathrm{WKM}_{D, 2.5 \%}$ & 0.472 & -2.8 & 0.0049 & 72.6 & 0.316 & -3.4 & 0.0066 & 57.2 & 0.186 & -1.4 & 0.0066 & 50.0 \\
\hline $\mathrm{WKM}_{D, 5 \%}$ & 0.474 & -2.6 & 0.0042 & 77.4 & 0.320 & -3.0 & 0.0054 & 61.8 & 0.190 & -1.0 & 0.0057 & 56.0 \\
\hline $\mathrm{WKM}_{D, 10 \%}$ & 0.479 & -2.1 & 0.0036 & 81.1 & 0.327 & -2.3 & 0.0043 & 66.5 & 0.196 & -0.4 & 0.0051 & 58.7 \\
\hline $\mathrm{WKM}_{D, 15 \%}$ & 0.482 & -1.8 & 0.0032 & 84.2 & 0.332 & -1.8 & 0.0038 & 70.2 & 0.201 & 0.1 & 0.0050 & 59.8 \\
\hline $\mathrm{WKM}_{D, 20 \%}$ & 0.486 & -1.4 & 0.0029 & 85.4 & 0.337 & -1.3 & 0.0035 & 73.5 & 0.204 & 0.4 & 0.0050 & 60.9 \\
\hline $\mathrm{WKM}_{D, 30 \%}$ & 0.491 & -0.9 & 0.0026 & 87.7 & 0.343 & -0.7 & 0.0033 & 75.3 & 0.209 & 0.9 & 0.0052 & 61.4 \\
\hline $\mathrm{WKM}_{D, 40 \%}$ & 0.495 & -0.5 & 0.0025 & 88.5 & 0.347 & -0.3 & 0.0032 & 77.5 & 0.211 & 1.1 & 0.0053 & 62.0 \\
\hline $\mathrm{WKM}_{D, 50 \%}$ & 0.499 & -0.1 & 0.0024 & 88.5 & 0.350 & 0.0 & 0.0031 & 78.4 & 0.213 & 1.3 & 0.0054 & 62.3 \\
\hline $\mathrm{WKM}_{R, 2.5 \%}$ & 0.472 & -2.8 & 0.0048 & 75.5 & 0.318 & -3.2 & 0.0065 & 62.8 & 0.187 & -1.3 & 0.0065 & 64.1 \\
\hline $\mathrm{WKM}_{R, 5 \%}$ & 0.475 & -2.5 & 0.0041 & 79.4 & 0.322 & -2.8 & 0.0053 & 69.8 & 0.191 & -0.9 & 0.0056 & 72.2 \\
\hline $\mathrm{WKM}_{R, 10 \%}$ & 0.479 & -2.1 & 0.0036 & 83.2 & 0.328 & -2.2 & 0.0043 & 74.8 & 0.197 & -0.3 & 0.0051 & 78.5 \\
\hline $\mathrm{WKM}_{R, 15 \%}$ & 0.482 & -1.8 & 0.0032 & 85.1 & 0.332 & -1.8 & 0.0038 & 79.3 & 0.201 & 0.1 & 0.0050 & 81.5 \\
\hline $\mathrm{WKM}_{R, 20 \%}$ & 0.485 & -1.5 & 0.0030 & 86.1 & 0.336 & -1.4 & 0.0035 & 82.4 & 0.204 & 0.4 & 0.0050 & 82.9 \\
\hline $\mathrm{WKM}_{R, 30 \%}$ & 0.489 & -1.1 & 0.0027 & 88.0 & 0.342 & -0.8 & 0.0032 & 84.7 & 0.209 & 0.9 & 0.0051 & 83.3 \\
\hline $\mathrm{WKM}_{R, 40 \%}$ & 0.493 & -0.7 & 0.0025 & 89.1 & 0.346 & -0.4 & 0.0031 & 86.0 & 0.211 & 1.1 & 0.0052 & 84.0 \\
\hline $\mathrm{WKM}_{R, 50 \%}$ & 0.496 & -0.4 & 0.0024 & 88.9 & 0.349 & -0.1 & 0.0031 & 86.5 & 0.213 & 1.3 & 0.0053 & 84.2 \\
\hline $\mathrm{WKM}_{U, 2.5 \%}$ & 0.474 & -2.6 & 0.0043 & 83.8 & 0.320 & -3.0 & 0.0057 & 75.5 & 0.190 & -1.0 & 0.0058 & 78.7 \\
\hline $\mathrm{WKM}_{U, 5 \%}$ & 0.478 & -2.2 & 0.0036 & 87.3 & 0.327 & -2.3 & 0.0043 & 84.2 & 0.197 & -0.3 & 0.0049 & 87.6 \\
\hline $\mathrm{WKM}_{U, 10 \%}$ & 0.486 & -1.4 & 0.0029 & 91.3 & 0.338 & -1.2 & 0.0032 & 90.6 & 0.208 & 0.8 & 0.0047 & 91.3 \\
\hline $\mathrm{WKM}_{U, 15 \%}$ & 0.492 & -0.8 & 0.0025 & 92.1 & 0.347 & -0.3 & 0.0028 & 93.1 & 0.216 & 1.6 & 0.0050 & 90.6 \\
\hline $\mathrm{WKM}_{U, 20 \%}$ & 0.497 & -0.3 & 0.0023 & 92.8 & 0.355 & 0.5 & 0.0027 & 93.3 & 0.222 & 2.2 & 0.0053 & 89.6 \\
\hline $\mathrm{WKM}_{U, 30 \%}$ & 0.507 & 0.7 & 0.0021 & 91.9 & 0.367 & 1.7 & 0.0029 & 92.3 & 0.231 & 3.1 & 0.0060 & 88.5 \\
\hline $\mathrm{WKM}_{U, 40 \%}$ & 0.515 & 1.5 & 0.0022 & 91.1 & 0.376 & 2.6 & 0.0032 & 90.2 & 0.237 & 3.7 & 0.0067 & 87.4 \\
\hline $\mathrm{WKM}_{U, 50 \%}$ & 0.522 & 2.2 & 0.0025 & 90.5 & 0.382 & 3.2 & 0.0036 & 88.6 & 0.241 & 4.1 & 0.0071 & 86.5 \\
\hline $\mathrm{WKM}_{\mathcal{N}(0.1)}$ & 0.468 & -3.2 & 0.0064 & 72.2 & 0.310 & -4.0 & 0.0103 & 56.2 & 0.172 & -2.8 & 0.0133 & 45.7 \\
\hline $\mathrm{WKM}_{\mathcal{N}(0.5)}$ & 0.485 & -1.5 & 0.0029 & 90.0 & 0.334 & -1.6 & 0.0038 & 86.5 & 0.194 & -0.6 & 0.0060 & 83.6 \\
\hline $\mathrm{WKM}_{\mathcal{N}(1)}$ & 0.507 & 0.7 & 0.0022 & 91.7 & 0.361 & 1.1 & 0.0029 & 92.2 & 0.220 & 2.0 & 0.0057 & 88.0 \\
\hline $\mathrm{WKM}_{\mathcal{N}(2)}$ & 0.524 & 2.4 & 0.0026 & 89.3 & 0.382 & 3.2 & 0.0037 & 88.4 & 0.239 & 3.9 & 0.0070 & 86.9 \\
\hline $\mathrm{WKM}_{\mathcal{N}(5)}$ & 0.533 & 3.3 & 0.0031 & 86.1 & 0.392 & 4.2 & 0.0045 & 85.5 & 0.248 & 4.8 & 0.0080 & 84.6 \\
\hline
\end{tabular}

ฯ Censoring rate at the time of the true value of $S(t)$

* Average of 1000 point estimates

$\dagger$ Relative bias $(100 \times($ Bias $/ S(t))$

$\ddagger$ Mean square error

$\S$ Coverage rate of 100095 per cent confidence intervals 
Table 5. Monte Carlo results for estimating an hypothetical HIV-1 RNA reduction ( $\mathbf{N = 2 0 0}$ ). 30\% LOD=200 copies/ml and $70 \% \mathrm{LOD}=\mathbf{5 0 0}$ copies/ $\mathrm{ml}$ leading to an overall censoring rate of $\mathbf{6 4 \%}$.

Estimators are derived using the 5 covariates.

True value: 0.5

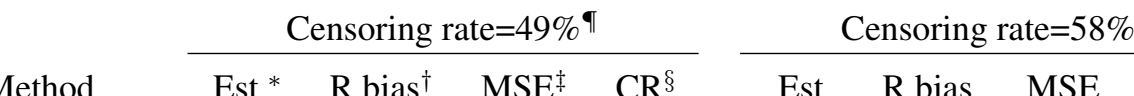

\begin{tabular}{lrrrr}
\hline KM FO & 0.499 & -0.1 & 0.0013 & 93.6 \\
KM PO & 0.545 & 4.5 & 0.0040 & 84.7
\end{tabular}

IPCW

KMIB

$\mathrm{WKM}_{4,1}$

$\mathrm{WKM}_{4,2}$

$\mathrm{WKM}_{4,4}$

$\mathrm{WKM}_{8,1}$

$\mathrm{WKM}_{8,2} \quad 0.584$

$\mathrm{WKM}_{16,1} \quad 0.524$

$\mathrm{WKM}_{D, 2.5 \%} \quad 0.467$

$\mathrm{WKM}_{D, 5 \%} \quad 0.470$

$\mathrm{WKM}_{D, 10 \%} \quad 0.476$

$\mathrm{WKM}_{D, 15 \%} \quad 0.481$

$\mathrm{WKM}_{D, 20 \%} \quad 0.485$

$\mathrm{WKM}_{D, 30 \%} \quad 0.491$

$\mathrm{WKM}_{D, 40 \%} 0.496$

$\mathrm{WKM}_{D, 50 \%} 0.500$

$\mathrm{WKM}_{R, 2.5 \%} 0.467$

$\mathrm{WKM}_{R, 5 \%} \quad 0.470$

$\mathrm{WKM}_{R, 10 \%}$

$\mathrm{WKM}_{R, 15 \%}$

$\mathrm{WKM}_{R, 20 \%}$

$\mathrm{WKM}_{R, 30 \%}$

$\mathrm{WKM}_{R, 40 \%}$

$\mathrm{WKM}_{R, 50 \%}$

$\mathrm{WKM}_{U, 2.5 \%}$

$\mathrm{WKM}_{U, 5 \%}$

$\mathrm{WKM}_{U, 10 \%}$

$\mathrm{WKM}_{U, 15 \%}$

$\mathrm{WKM}_{U, 20 \%}$

$\mathrm{WKM}_{U, 30 \%}$

$\mathrm{WKM}_{U, 40 \%}$

$\mathrm{WKM}_{U, 50 \%}$

$\mathrm{WKM}_{\mathcal{N}(0.1)}$

$\mathrm{WKM}_{\mathcal{N}(0.5)}$

$\mathrm{WKM}_{\mathcal{N}(1)}$

$\mathrm{WKM}_{\mathcal{N}(2)}$

$\mathrm{WKM}_{\mathcal{N}(5)}$

\subsection{6}

0.480

0.483

0.489

0.494

0.497

2.4

0.0065

$\begin{array}{lll}2.2 & 0.0031 & 91.6\end{array}$

$\begin{array}{lll}-1.4 & 0.0056 & 80.1\end{array}$

$\begin{array}{lll}6.2 & 0.0078 & 65.6\end{array}$

$\begin{array}{lll}9.9 & 0.0126 & 36.5\end{array}$

$\begin{array}{lll}0.1 & 0.0046 & 82.3\end{array}$

$\begin{array}{llll}8.4 & 0.0099 & 46.2\end{array}$

$\begin{array}{lll}2.4 & 0.0040 \quad 82.6\end{array}$

$\begin{array}{lll}-3.3 & 0.0058 & 66.9\end{array}$

$\begin{array}{lll}-3.0 & 0.0049 & 70.5\end{array}$

$-1.9$

$0.0035 \quad 81.9$

$-1.5$

$0.0031 \quad 83.9$

$\begin{array}{lll}-0.9 & 0.0028 & 86.7\end{array}$

$\begin{array}{lll}-0.4 & 0.0026 & 88.7\end{array}$

$\begin{array}{lll}0.0 & 0.0025 & 89.5\end{array}$

$\begin{array}{lll}-3.3 & 0.0057 & 71.3\end{array}$

$\begin{array}{lll}-3.0 & 0.0048 & 76.3\end{array}$

$\begin{array}{lll}-2.4 & 0.0040 & 82.0\end{array}$

$\begin{array}{lll}-2.0 & 0.0035 & 85.0\end{array}$

$\begin{array}{lll}-1.7 & 0.0032 & 86.8\end{array}$

$\begin{array}{lll}-1.1 & 0.0028 & 88.9\end{array}$

$\begin{array}{lll}-0.6 & 0.0026 & 89.7\end{array}$

$-0.3$

$0.0025 \quad 90.7$

$\begin{array}{lll}-3.1 & 0.0051 & 80.1\end{array}$

0.469

$-2.5$

$\begin{array}{ll}0.0040 \quad 87.8 \\ 0.0031 & 91.7\end{array}$

0.484

$-1.6$

$0.0031 \quad 91.7$

0.492

-0.8
-0.1

0.499

$0.0026 \quad 92.9$

$0.0023 \quad 93.9$

$0.0022 \quad 94.9$

$\begin{array}{lll}2.1 & 0.0025 & 93.5\end{array}$

0.521

2.9

$0.0028 \quad 91.4$

$\begin{array}{lll}-4.0 & 0.0084 & 67.8\end{array}$

$\begin{array}{lll}-1.7 & 0.0032 & 90.4\end{array}$

$\begin{array}{lll}1.1 & 0.0023 & 94.2\end{array}$

$\begin{array}{lll}3.2 & 0.0030 & 89.9\end{array}$

$\begin{array}{lll}4.2 & 0.0037 \quad 85.0\end{array}$

0.532

0.542 $\begin{array}{lll}-2.4 & 0.0040 & 77.8\end{array}$
True value: 0.35

Est R bias MSE CR
True value: 0.2

Censoring rate $=63 \%$

$\begin{array}{rrrrrrrr}0.350 & 0.0 & 0.0011 & 93.9 & 0.200 & 0.0 & 0.0008 & 94.4 \\ 0.406 & 5.6 & 0.0065 & 82.0 & 0.263 & 6.3 & 0.0161 & 68.2 \\ 0.385 & 3.5 & 0.0097 & 76.8 & 0.248 & 4.8 & 0.0190 & 74.7 \\ 0.383 & 3.3 & 0.0052 & 88.9 & 0.246 & 4.6 & 0.0138 & 78.9 \\ 0.371 & 2.1 & 0.0081 & 77.3 & 0.302 & 10.2 & 0.0196 & 55.2 \\ 0.484 & 13.4 & 0.0227 & 28.6 & 0.437 & 23.7 & 0.0616 & 4.5 \\ 0.536 & 18.6 & 0.0376 & 3.8 & 0.501 & 30.1 & 0.0941 & 0.1 \\ 0.398 & 4.8 & 0.0082 & 75.4 & 0.342 & 14.2 & 0.0269 & 29.9 \\ 0.514 & 16.4 & 0.0304 & 8.4 & 0.479 & 27.9 & 0.0816 & 0.1 \\ 0.436 & 8.6 & 0.0115 & 55.0 & 0.393 & 19.3 & 0.0418 & 4.5 \\ 0.318 & -3.2 & 0.0079 & 52.6 & 0.194 & -0.6 & 0.0106 & 47.0\end{array}$

0.199

0.206

0.211

0.214

0.219

0.222

0.225

0.356

$-0.2$

417

$0.0040 \quad 74.5$

0.195

$\begin{array}{llll}0.319 & -3.1 & 0.0077 & 61.9\end{array}$

$\begin{array}{llll}0.323 & -2.7 & 0.0064 & 68.6\end{array}$

0.199

0.206

0.210

$\begin{array}{lllll}0.336 & -1.4 & 0.0047 & 79.2\end{array}$

$\begin{array}{llll}0.340 & -1.0 & 0.0044 & 81.6\end{array}$

$\begin{array}{llll}0.347 & -0.3 & 0.0041 & 83.6\end{array}$

0.214

0.218

0.221

0.354

$\begin{array}{lll}0.1 & 0.0040 \quad 84.6\end{array}$

$\begin{array}{lll}0.4 & 0.0040 \quad 85.2\end{array}$

0.224

0.321

$-2.9$

$0.0067 \quad 75.6$

$\begin{array}{llll}0.329 & -2.1 & 0.0053 & 85.6\end{array}$

0.198

0.206

0.217

0.226

0.233

0.242

0.249

0.253

-0 .

0.6

1.1

1.4

1.9

2.2

2.5

$-0.5$

$-0$.

0.6

1.0
1.4

1.4
1.8

2.

2.4

$-0.2$

0.6
1.7

2.6

3.3

0.0099

0.0097

0.0098

0.0100

0.0103

0.0106

0.0109

0.0106

0.0100

0.0097

0.0098

0.0099

0.0102

0.0105

0.0107

0.0100

0.0096

0.0098

0.0104

3.3
4.9

$0.0111-80.9$

$\begin{array}{llll}0.376 & 2.6 & 0.0040 & 91.7\end{array}$

$\begin{array}{llll}0.385 & 3.5 & 0.0045 & 89.5\end{array}$

$\begin{array}{llll}0.392 & 4.2 & 0.0051 & 87.7\end{array}$

0.179

$\begin{array}{llll}0.307 & -4.3 & 0.0139 & 52.9\end{array}$

$\begin{array}{llll}0.335 & -1.5 & 0.0050 & 86.6\end{array}$

0.203

0.232

0.368

$\begin{array}{lll}1.8 & 0.0040 \quad 91.8\end{array}$

0.252

0.403

0.261

4.9

$0.0123 \quad 79.1$

ब Censoring rate at the time of the true value of $S(t)$

* Average of 1000 point estimates

$\dagger$ Relative bias $(100 \times(\operatorname{Bias} / S(t))$

$\ddagger$ Mean square error

$\S$ Coverage rate of 100095 per cent confidence intervals 


\section{Statistics}

\section{in Medicine}

Table 6. Monte Carlo results for estimating an hypothetical HIV-1 RNA reduction ( $\mathbf{N = 2 0 0 ) . 7 0 \% ~ L O D = 1 0 0 ~ c o p i e s / m l ~}$ and $\mathbf{3 0} \% \mathrm{LOD}=\mathbf{2 0 0}$ copies/ml leading to an overall censoring rate of $\mathbf{4 5 \%}$

Estimators are derived using only $Z_{1}$ representing the baseline HIV-1 RNA

True value: 0.5

Censoring rate $=24 \%$ व

Method $\quad$ Est * $\mathrm{R}^{*}$ bias $^{\dagger} \mathrm{MSE}^{\ddagger} \mathrm{CR}^{\S}$
True value: 0.35

Censoring rate $=34 \%$ Est R bias MSE CR
True value: 0.2

Censoring rate $=42 \%$

\begin{tabular}{|c|c|c|c|c|c|c|c|c|c|c|c|c|}
\hline KM I & .498 & -0.2 & 0.0013 & 95.4 & 0.349 & -0.1 & 0.0012 & 94.3 & 0.199 & -0.1 & 0.0009 & 93.6 \\
\hline KM PO & 520 & 2.0 & 0.0019 & 92.4 & 0.379 & 2.9 & 0.0027 & 89.1 & 0.236 & 36 & 0.0037 & 87.9 \\
\hline IPCW & 0.515 & 1.5 & 0.0019 & 91.5 & 0.373 & 2.3 & 0.0026 & 90.1 & 0.230 & 3.0 & 0.0037 & 87.8 \\
\hline KMIB & 512 & .2 & 0019 & 92.8 & .371 & 2.1 & 0.0025 & 92.3 & 0.229 & 2.9 & 0.0037 & 88.9 \\
\hline $\mathrm{WKM}_{2,1}$ & 511 & 1.1 & .0020 & 93.2 & 386 & 3.6 & 0.0052 & 78.8 & & 10.6 & 0.0153 & 40.8 \\
\hline $\mathrm{WKM}_{4,1}$ & 0.527 & 2.7 & 0.0029 & 85.4 & 0.425 & 7.5 & 0.0083 & 57.3 & 0.356 & 15.6 & 0.0274 & 12.6 \\
\hline $\mathrm{WKM}_{6,1}$ & .535 & 3.5 & 0.0034 & 81.2 & 0.440 & 9.0 & 0.0105 & 43.7 & 0.375 & 17.5 & 0.0334 & 5.5 \\
\hline $\mathrm{WKM}_{8,1}$ & 0.543 & 4.3 & 0.0037 & 78.0 & 0.450 & 10.0 & 0.0122 & 33.7 & 0.390 & 19.0 & 0.0383 & 1.4 \\
\hline $\mathrm{WKM}_{10,1}$ & 546 & 4.6 & 0.0040 & 73.8 & 0.455 & 10.5 & 0.0131 & 27.0 & 96 & 19.6 & 0.0406 & 0.6 \\
\hline $\mathrm{WKM}_{12,1}$ & 550 & 5.0 & 0.0043 & 71.8 & 0.460 & 11.0 & 0.0140 & 22.0 & .403 & 20.3 & .0431 & 0.3 \\
\hline $\mathrm{WKM}_{D, 2.5 \%}$ & 503 & 0.3 & 0028 & 82.4 & 0.358 & 0.8 & 0.0045 & 62.5 & 0.220 & 2.0 & 0.0060 & 42.3 \\
\hline $\mathrm{WKM}_{D .5 \%}$ & 0.505 & 0.5 & 0023 & 86.4 & 0.361 & 1.1 & 0.0035 & 69.2 & 21 & 2.1 & 0044 & 51. \\
\hline $\mathrm{WKM}_{D, 10 \%}$ & 0.506 & 0.6 & 0.0020 & 90.0 & 0.363 & 1.3 & 0.0028 & 76.3 & 0.222 & 2.2 & 0.0036 & 57.0 \\
\hline $\mathrm{WKM}_{D, 15 \%}$ & 0.507 & 0.7 & 0.0019 & 91.5 & 0.364 & 1.4 & 0.0026 & 79.8 & 0.224 & 2.4 & .0034 & 60.5 \\
\hline $\mathrm{WKM}_{D, 20 \%}$ & 0.508 & 0.8 & 0.0018 & 91.9 & 0.366 & 1.6 & 0.0025 & 81.3 & 0.225 & 2.5 & 0.0034 & 61.4 \\
\hline $\mathrm{WKM}_{D, 30 \%}$ & 0.510 & 1.0 & 017 & 92.6 & 0.368 & 1.8 & 24 & 82.8 & 226 & 2.6 & 0.0034 & 62.8 \\
\hline WKI & 0.511 & 1.1 & 0.0017 & 93.4 & 0.369 & 1.9 & 0.0024 & 84.0 & 0.227 & 2.7 & 0.0034 & 62. \\
\hline $\mathrm{WKM}_{D, 50 \%}$ & 0.512 & 1.2 & 0.0017 & 93.8 & 0.370 & 2.0 & 0.0024 & 84.4 & 0.228 & 2.8 & 0.0034 & 62. \\
\hline $\mathrm{WKM}_{R, 2.5 \%}$ & 0.503 & 0.3 & 029 & 84.9 & 358 & 0.8 & 48 & 64.7 & 220 & 2.0 & 062 & 49. \\
\hline & 0 & 0.5 & 023 & 87 & 360 & 1.0 & & 74.4 & & 2.0 & 45 & 61. \\
\hline $\mathrm{WKM}_{R, 10 \%}$ & 0.506 & 0.6 & 0020 & 89 & 0.362 & 1.2 & 0.0029 & 80.4 & 0.222 & 2.2 & 0.0037 & 73.2 \\
\hline $\mathrm{WKM}_{R, 15 \%}$ & 0.507 & 0.7 & 019 & 90.4 & 0.364 & 1.4 & 26 & 83.6 & 0.223 & 2.3 & .0034 & 76. \\
\hline $\mathrm{WKM}_{R, 20 \%}$ & 0.508 & 0.8 & 18 & 90.4 & 0.365 & 1.5 & 0. & 84.7 & 0. & 2.5 & 0.0034 & 78.2 \\
\hline WKI & 0.509 & 0.9 & 0.0018 & 91. & 0.367 & 1.7 & 0.0024 & 87.0 & 0.226 & 2.6 & 0.0034 & 80. \\
\hline WKN & 0.510 & 1.0 & 0.0017 & 91.2 & 0.368 & 1.8 & 0.0024 & 88.0 & 0.227 & 2.7 & 0.0034 & 81. \\
\hline $\mathrm{WKM}_{R, 50 \%}$ & 0.511 & 1.1 & 0.0017 & 91.3 & 0.369 & 1.9 & 0.0024 & 88.0 & 0.228 & 2.8 & 0.0034 & 81. \\
\hline WKI & & 0 & & & & 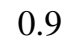 & & 79 & & 2.0 & & 68.2 \\
\hline $\mathrm{WKM}_{U, 5}$ & 0.506 & 0.6 & 0021 & 90.9 & 0.362 & 1.2 & & 87.1 & 0.221 & 2.1 & 039 & 83.5 \\
\hline $\mathrm{WKM}_{U, 10 \%}$ & 0.507 & 0.7 & 0.0019 & 92.1 & 0.364 & 1.4 & 0.0026 & 91.4 & 0.224 & 2.4 & 0.0032 & 89.7 \\
\hline $\mathrm{WKM}_{U, 15 \%}$ & 0.509 & 0.9 & 0.0018 & 93.5 & 0.366 & 1.6 & 24 & 92.5 & 0.226 & 2.6 & 0.0032 & 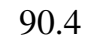 \\
\hline $\mathrm{WKM}_{U, 20 \%}$ & 0.5 & 1. & 0 & 93 & 0. & 1.8 & 0.0 & 92.3 & 0.228 & 2.8 & 0.0032 & 89. \\
\hline WKN & 0.512 & 1.2 & 0.0017 & 93 & 0.371 & 2.1 & 0.0023 & 92.6 & 0.230 & 3.0 & 0.0033 & 89. \\
\hline WKI & 0.51 & 1.4 & 0.0017 & 93 & 0.374 & 2.4 & 0.0024 & 91.6 & 0.232 & 3.2 & 0.0034 & 88. \\
\hline $\mathrm{WKM}_{U, 50 \%}$ & 0.516 & 1.6 & 0.0018 & 93.3 & 0.376 & 2.6 & 0.0025 & 90.8 & 0.233 & 3.3 & 0.0035 & 88. \\
\hline $\mathrm{WKM}_{\mathcal{N}}$ & 1 & 0. & 42 & 77 & 5 & 0.5 & & 54.5 & 16 & 1.6 & 130 & 30.9 \\
\hline $\mathrm{WKM}_{\mathcal{N}(0.5)}$ & 0.507 & 0.7 & & 91.1 & 0.363 & 1.3 & & 90.4 & 221 & 2.1 & 0.0039 & 82. \\
\hline & & 1.1 & & 93.3 & 0.369 & 1.9 & & 92.3 & & 2.7 & 0.0033 & 88. \\
\hline & & 1. & & 92 & & 2. & & 91.3 & & 3.2 & 0.0035 & 88 \\
\hline $\mathrm{WKM}_{\mathcal{N}(5)}$ & 0.519 & 1.9 & 0.0019 & 92.7 & 0.378 & 2.8 & 0.0026 & 89.7 & 0.235 & 3.5 & 0.0036 & 87. \\
\hline
\end{tabular}

『 Censoring rate at the time of the true value of $S(t)$

* Average of 1000 point estimates

$\dagger$ Relative bias $(100 \times($ Bias $/ S(t))$

$\ddagger$ Mean square error

$\S$ Coverage rate of 100095 per cent confidence intervals 
Table 7. Monte Carlo results for estimating an hypothetical HIV-1 RNA reduction N(200). 30\% LOD=100 copies/ml and $\mathbf{7 0 \%} \mathrm{LOD}=\mathbf{2 0 0}$ copies $/ \mathrm{ml}$ leading to an overall censoring rate of $\mathbf{5 0 \%}$.

Estimators are derived using only $Z_{1}$ representing the baseline HIV-1 RNA

\begin{tabular}{|c|c|c|c|c|c|c|c|c|c|c|c|c|}
\hline \multirow[b]{2}{*}{ Method } & \multicolumn{4}{|c|}{$\begin{array}{c}\text { True value: } 0.5 \\
\text { Censoring rate }=30 \%\end{array}$} & \multicolumn{4}{|c|}{$\begin{array}{c}\text { True value: } 0.35 \\
\text { Censoring rate }=40 \%\end{array}$} & \multicolumn{4}{|c|}{$\begin{array}{c}\text { True value: } 0.2 \\
\text { Censoring rate }=47 \%\end{array}$} \\
\hline & Est * & $\mathrm{R}$ bias $^{\dagger}$ & $\mathrm{MSE}^{\ddagger}$ & $\mathrm{CR}^{\S}$ & Est & $\mathrm{R}$ bias & MSE & CR & Est & $\mathrm{R}$ bias & MSE & CR \\
\hline KM FO & 0.499 & -0.1 & 0.0013 & 94.1 & 0.349 & -0.1 & 0.0013 & 94.1 & 0.200 & 0.0 & 0.0009 & 93.9 \\
\hline KM PO & 0.525 & 2.5 & 0.0024 & 89.9 & 0.385 & 3.5 & 0.0034 & 89.5 & 0.240 & 4.0 & 0.0053 & 84.8 \\
\hline IPCW & 0.514 & 1.4 & 0.0039 & 83.6 & 0.374 & 2.4 & 0.0052 & 79.3 & 0.233 & 3.3 & 0.0079 & 77.8 \\
\hline KMIB & 0.516 & 1.6 & 0.0026 & 89.9 & 0.375 & 2.5 & 0.0037 & 87.7 & 0.232 & 3.2 & 0.0060 & 83.2 \\
\hline $\mathrm{WKM}_{2,1}$ & 0.513 & 1.3 & 0.0028 & 91.1 & 0.394 & 4.4 & 0.0082 & 65.5 & 0.314 & 11.4 & 0.0199 & 40.1 \\
\hline $\mathrm{WKM}_{4,1}$ & 0.533 & 3.3 & 0.0043 & 77.6 & 0.434 & 8.4 & 0.0116 & 51.3 & 0.369 & 16.9 & 0.0339 & 17.2 \\
\hline $\mathrm{WKM}_{6,1}$ & 0.543 & 4.3 & 0.0049 & 72.6 & 0.450 & 10.0 & 0.0136 & 42.7 & 0.390 & 19.0 & 0.0402 & 7.5 \\
\hline $\mathrm{WKM}_{8,1}$ & 0.550 & 5.0 & 0.0051 & 69.8 & 0.460 & 11.0 & 0.0153 & 32.7 & 0.404 & 20.4 & 0.0450 & 3.4 \\
\hline $\mathrm{WKM}_{10,1}$ & 0.555 & 5.5 & 0.0056 & 65.7 & 0.467 & 11.7 & 0.0167 & 27.6 & 0.412 & 21.2 & 0.0485 & 1.8 \\
\hline $\mathrm{WKM}_{12,1}$ & 0.559 & 5.9 & 0.0058 & 64.1 & 0.472 & 12.2 & 0.0178 & 21.4 & 0.419 & 21.9 & 0.0512 & 1.1 \\
\hline $\mathrm{WKM}_{D, 2.5 \%}$ & 0.509 & 0.9 & 0.0042 & 74.7 & 0.366 & 1.6 & 0.0070 & 52.9 & 0.224 & 2.4 & 0.0089 & 35.7 \\
\hline $\mathrm{WKM}_{D, 5 \%}$ & 0.509 & 0.9 & 0.0035 & 78.9 & 0.367 & 1.7 & 0.0054 & 59.1 & 0.224 & 2.4 & 0.0070 & 40.5 \\
\hline $\mathrm{WKM}_{D, 10 \%}$ & 0.510 & 1.0 & 0.0029 & 83.7 & 0.368 & 1.8 & 0.0042 & 66.4 & 0.226 & 2.6 & 0.0058 & 44.7 \\
\hline $\mathrm{WKM}_{D, 15 \%}$ & 0.511 & 1.1 & 0.0026 & 86.0 & 0.369 & 1.9 & 0.0037 & 70.7 & 0.227 & 2.7 & 0.0054 & 48.7 \\
\hline $\mathrm{WKM}_{D, 20 \%}$ & 0.512 & 1.2 & 0.0024 & 88.2 & 0.370 & 2.0 & 0.0035 & 73.2 & 0.228 & 2.8 & 0.0053 & 50.5 \\
\hline $\mathrm{WKM}_{D, 30 \%}$ & 0.513 & 1.3 & 0.0023 & 90.2 & 0.372 & 2.2 & 0.0033 & 75.1 & 0.230 & 3.0 & 0.0052 & 51.8 \\
\hline $\mathrm{WKM}_{D, 40 \%}$ & 0.515 & 1.5 & 0.0022 & 90.8 & 0.374 & 2.4 & 0.0032 & 76.7 & 0.231 & 3.1 & 0.0052 & 52.7 \\
\hline $\mathrm{WKM}_{D, 50 \%}$ & 0.516 & 1.6 & 0.0022 & 90.8 & 0.375 & 2.5 & 0.0032 & 76.7 & 0.232 & 3.2 & 0.0052 & 52.9 \\
\hline $\mathrm{WKM}_{R, 2.5 \%}$ & 0.509 & 0.9 & 0.0043 & 77.0 & 0.367 & 1.7 & 0.0072 & 59.7 & 0.225 & 2.5 & 0.0092 & 47.3 \\
\hline $\mathrm{WKM}_{R, 5 \%}$ & 0.509 & 0.9 & 0.0035 & 81.7 & 0.366 & 1.6 & 0.0055 & 67.6 & 0.225 & 2.5 & 0.0072 & 56.6 \\
\hline $\mathrm{WKM}_{R, 10 \%}$ & 0.510 & 1.0 & 0.0029 & 83.8 & 0.367 & 1.7 & 0.0043 & 73.4 & 0.227 & 2.7 & 0.0059 & 65.7 \\
\hline $\mathrm{WKM}_{R, 15 \%}$ & 0.510 & 1.0 & 0.0026 & 85.3 & 0.369 & 1.9 & 0.0038 & 77.8 & 0.228 & 2.8 & 0.0055 & 70.0 \\
\hline $\mathrm{WKM}_{R, 20 \%}$ & 0.511 & 1.1 & 0.0025 & 86.9 & 0.370 & 2.0 & 0.0035 & 78.8 & 0.229 & 2.9 & 0.0053 & 72.3 \\
\hline $\mathrm{WKM}_{R, 30 \%}$ & 0.513 & 1.3 & 0.0023 & 87.9 & 0.372 & 2.2 & 0.0033 & 81.8 & 0.230 & 3.0 & 0.0052 & 74.3 \\
\hline $\mathrm{WKM}_{R, 40 \%}$ & 0.514 & 1.4 & 0.0022 & 88.9 & 0.373 & 2.3 & 0.0032 & 83.2 & 0.231 & 3.1 & 0.0052 & 75.0 \\
\hline $\mathrm{WKM}_{R, 50 \%}$ & 0.515 & 1.5 & 0.0022 & 89.3 & 0.374 & 2.4 & 0.0032 & 83.1 & 0.232 & 3.2 & 0.0052 & 75.3 \\
\hline $\mathrm{WKM}_{U, 2.5 \%}$ & 0.509 & 0.9 & 0.0038 & 85.3 & 0.366 & 1.6 & 0.0061 & 75.2 & 0.225 & 2.5 & 0.0078 & 66.6 \\
\hline $\mathrm{WKM}_{U, 5 \%}$ & 0.509 & 0.9 & 0.0029 & 87.8 & 0.367 & 1.7 & 0.0044 & 83.8 & 0.226 & 2.6 & 0.0059 & 79.9 \\
\hline $\mathrm{WKM}_{U, 10 \%}$ & 0.510 & 1.0 & 0.0024 & 91.4 & 0.369 & 1.9 & 0.0034 & 88.4 & 0.229 & 2.9 & 0.0049 & 87.2 \\
\hline $\mathrm{WKM}_{U, 15 \%}$ & 0.512 & 1.2 & 0.0022 & 92.6 & 0.371 & 2.1 & 0.0030 & 89.6 & 0.231 & 3.1 & 0.0047 & 87.9 \\
\hline $\mathrm{WKM}_{U, 20 \%}$ & 0.513 & 1.3 & 0.0021 & 92.7 & 0.373 & 2.3 & 0.0029 & 89.6 & 0.232 & 3.2 & 0.0047 & 87.3 \\
\hline $\mathrm{WKM}_{U, 30 \%}$ & 0.516 & 1.6 & 0.0021 & 92.5 & 0.377 & 2.7 & 0.0029 & 90 & 0.235 & 3.5 & 0.0048 & 86.5 \\
\hline $\mathrm{WKM}_{U, 40 \%}$ & 0.519 & 1.9 & 0.0021 & 92.1 & 0.379 & 2.9 & 0.0030 & 89 & 0.236 & 3.6 & 0.0049 & 85.6 \\
\hline $\mathrm{WKM}_{U, 50 \%}$ & 0.521 & 2.1 & 0.0022 & 91.4 & 0.381 & 3.1 & 0.0031 & 88.9 & 0.238 & 3.8 & 0.005 & 85.5 \\
\hline $\mathrm{WKM}_{\mathcal{N}(0.1)}$ & 0.508 & 0.8 & 0.0068 & 67.6 & 0.363 & 1.3 & 0.0135 & 40.6 & 0.223 & 2.3 & 0.0208 & 27.2 \\
\hline $\mathrm{WKM}_{\mathcal{N}(0.5)}$ & 0.510 & 1.0 & 0.0024 & 89.4 & 0.367 & 1.7 & 0.0035 & 85.9 & 0.227 & 2.7 & 0.0058 & 78.0 \\
\hline $\mathrm{WKM}_{\mathcal{N}(1)}$ & 0.515 & 1.5 & 0.0021 & 92.5 & 0.374 & 2.4 & 0.0030 & 89.2 & 0.232 & 3.2 & 0.0049 & 86.5 \\
\hline $\mathrm{WKM}_{\mathcal{N}(2)}$ & 0.520 & 2.0 & 0.0022 & 91.8 & 0.380 & 3.0 & 0.0031 & 89.0 & 0.237 & 3.7 & 0.0050 & 86.3 \\
\hline $\mathrm{WKM}_{\mathcal{N}(5)}$ & 0.524 & 2.4 & 0.0023 & 90.2 & 0.384 & 3.4 & 0.0033 & 88.5 & 0.240 & 4.0 & 0.0052 & 85.1 \\
\hline $\begin{array}{l}\ddagger \text { Mean square error } \\
\text { § Coverage rate of } 1\end{array}$ & 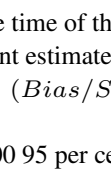 & & & & & & & & & & & \\
\hline
\end{tabular}




\section{Statistics}

\section{in Medicine}

Table 8. Monte Carlo results for estimating an hypothetical HIV-1 RNA reduction (N=200). $70 \%$ LOD=200 copies/ml and $\mathbf{3 0} \% \mathrm{LOD}=\mathbf{5 0 0}$ copies/ml leading to an overall censoring rate of $\mathbf{5 7 \%}$.

Estimators are derived using only $Z_{1}$ representing the baseline HIV-1 RNA

True value: 0.5

Censoring rate $=39 \%$ व

Method $\quad$ Est $^{*} \quad \mathrm{Rb}$ bias $^{\dagger} \mathrm{MSE}^{\ddagger} \mathrm{CR}^{\S}$
True value: 0.35

Censoring rate $=49 \%$ Est R bias MSE CR
True value: 0.2

Censoring rate $=56 \%$

\begin{tabular}{|c|c|c|c|c|c|c|c|c|c|c|c|c|}
\hline KM FO & 0.499 & -0.1 & 0.0013 & 93.8 & 0.348 & -0.2 & 0.0012 & 94.1 & 0.199 & -0.1 & 0.0009 & 93.3 \\
\hline KM PO & 0.535 & 3.5 & 0.0032 & 85.3 & 0.394 & 4.4 & 0.0047 & 84.6 & 0.250 & 5.0 & 0.0083 & 83.3 \\
\hline IPCW & 0.527 & 2.7 & 0.0031 & 86.5 & 0.386 & 3.6 & 0.0045 & 85.7 & 0.244 & 4.4 & 0.0084 & 83.3 \\
\hline KMIB & 0.526 & 2.6 & 0.0030 & 88.8 & 0.384 & 3.4 & 0.0044 & 87.6 & 0.243 & 4.3 & 0.0082 & 84.7 \\
\hline $\mathrm{WKM}_{2,1}$ & 0.526 & 2.6 & 0.0053 & 83.2 & 0.440 & 9.0 & 0.0147 & 47.3 & 0.353 & 15.3 & 0.0327 & 27.2 \\
\hline $\mathrm{WKM}_{4,1}$ & 0.558 & 5.8 & 0.0077 & 59.5 & 0.475 & 12.5 & 0.0210 & 30.9 & 0.424 & 22.4 & 0.0567 & 8.7 \\
\hline $\mathrm{WKM}_{6,1}$ & 0.576 & 7.6 & 0.0092 & 50.5 & 0.501 & 15.1 & 0.0269 & 17.7 & 0.457 & 25.7 & 0.0710 & 2.0 \\
\hline $\mathrm{WKM}_{8,1}$ & 0.584 & 8.4 & 0.0101 & 45.0 & 0.512 & 16.2 & 0.0298 & 11.9 & 0.472 & 27.2 & 0.0781 & 0.5 \\
\hline $\mathrm{WKM}_{10,1}$ & 0.592 & 9.2 & 0.0111 & 37.3 & 0.522 & 17.2 & 0.0327 & 6.3 & 0.485 & 28.5 & 0.0846 & 0.1 \\
\hline $\mathrm{WKM}_{12,1}$ & 0.596 & 9.6 & 0.0116 & 33.2 & 0.529 & 17.9 & 0.0345 & 3.6 & 0.493 & 29.3 & 0.0887 & 0.0 \\
\hline $\mathrm{WKM}_{D .2 .5 \%}$ & 0.512 & 1.2 & 0.0056 & 63.8 & 0.370 & 2.0 & 0.0083 & 47.5 & 0.230 & 3.0 & 0.0104 & 37.3 \\
\hline $\mathrm{WKM}_{D, 5 \%}$ & 0.513 & 1.3 & 0.0042 & 72.5 & 0.372 & 2.2 & 0.0059 & 56.0 & 0.232 & 3.2 & 0.0085 & 43.5 \\
\hline $\mathrm{WKM}_{D, 10 \%}$ & 0.515 & 1.5 & 0.0034 & 79.8 & 0.374 & 2.4 & 0.0047 & 63.3 & 0.234 & 3.4 & 0.0076 & 45.3 \\
\hline $\mathrm{WKM}_{D, 15 \%}$ & 0.517 & 1.7 & 0.0031 & 83.3 & 0.376 & 2.6 & 0.0043 & 66.2 & 0.236 & 3.6 & 0.0074 & 46.2 \\
\hline $\mathrm{WKM}_{D, 20 \%}$ & 0.518 & 1.8 & 0.0030 & 84.5 & 0.378 & 2.8 & 0.0041 & 69.3 & 0.237 & 3.7 & 0.0074 & 47.5 \\
\hline $\mathrm{WKM}_{D, 30 \%}$ & 0.520 & 2.0 & 0.0028 & 86.2 & 0.380 & 3.0 & 0.0040 & 70.2 & 0.238 & 3.8 & 0.0074 & 48.1 \\
\hline $\mathrm{WKM}_{D, 40 \%}$ & 0.522 & 2.2 & 0.0028 & 86.6 & 0.382 & 3.2 & 0.0041 & 70.9 & 0.240 & 4.0 & 0.0075 & 49.1 \\
\hline $\mathrm{WKM}_{D, 50 \%}$ & 0.524 & 2.4 & 0.0028 & 86.7 & 0.383 & 3.3 & 0.0041 & 70.8 & 0.240 & 4.0 & 0.0076 & 49.4 \\
\hline $\mathrm{WKM}_{R, 2.5 \%}$ & 0.512 & 1.2 & 0.0058 & 67.3 & 0.369 & 1.9 & 0.0087 & 50.1 & 0.23 & 3.0 & 0.0107 & 45.9 \\
\hline $\mathrm{WKM}_{R, 5 \%}$ & 0.513 & 1.3 & 0.0043 & 77.0 & 0.371 & 2.1 & 0.0061 & 64.0 & 0.232 & 3.2 & 0.0085 & 61.2 \\
\hline $\mathrm{WKM}_{R .10 \%}$ & 0.515 & 1.5 & 0.0034 & 82.7 & 0.373 & 2.3 & 0.0048 & 74.2 & 0.234 & 3.4 & 0.0076 & 69.7 \\
\hline $\mathrm{WKM}_{R, 15 \%}$ & 0.516 & 1.6 & 0.0032 & 83.3 & 0.375 & 2.5 & 0.0043 & 78.1 & 0.236 & 3.6 & 0.0074 & 72.7 \\
\hline $\mathrm{WKM}_{R, 20 \%}$ & 0.517 & 1.7 & 0.0030 & 84.1 & 0.377 & 2.7 & 0.0041 & 78.6 & 0.237 & 3.7 & 0.0073 & 74.9 \\
\hline $\mathrm{WKM}_{R, 30 \%}$ & 0.520 & 2.0 & 0.0028 & 85.2 & 0.379 & 2.9 & 0.0040 & 80.3 & 0.238 & 3.8 & 0.0074 & 77.0 \\
\hline $\mathrm{WKM}_{R, 40 \%}$ & 0.521 & 2.1 & 0.0028 & 85.1 & 0.381 & 3.1 & 0.0040 & 81.2 & 0.239 & 3.9 & 0.0074 & 77.4 \\
\hline $\mathrm{WKM}_{R, 50 \%}$ & 0.523 & 2.3 & 0.0028 & 85.7 & 0.382 & 3.2 & 0.0041 & 81.2 & 0.240 & 4.0 & 0.0075 & 77.8 \\
\hline $\mathrm{WKM}_{U, 2.5 \%}$ & 0.512 & 1.2 & 0.0051 & 79.8 & 0.370 & 2.0 & 0.0073 & 69.8 & 0.231 & 3.1 & 0.0096 & 67.6 \\
\hline $\mathrm{WKM}_{U, 5 \%}$ & 0.514 & 1.4 & 0.0038 & 85.9 & 0.372 & 2.2 & 0.0052 & 83.8 & 0.233 & 3.3 & 0.0078 & 82.6 \\
\hline $\mathrm{WKM}_{U, 10 \%}$ & 0.517 & 1.7 & 0.0031 & 89.0 & 0.375 & 2.5 & 0.0042 & 88.3 & 0.236 & 3.6 & 0.0072 & 86.4 \\
\hline $\mathrm{WKM}_{U, 15 \%}$ & 0.519 & 1.9 & 0.0029 & 89.7 & 0.378 & 2.8 & 0.0039 & 88.3 & 0.239 & 3.9 & 0.0072 & 86.4 \\
\hline $\mathrm{WKM}_{U, 20 \%}$ & 0.521 & 2.1 & 0.0027 & 89.8 & 0.381 & 3.1 & 0.0038 & 88.8 & 0.241 & 4.1 & 0.0073 & 86.4 \\
\hline $\mathrm{WKM}_{U, 30 \%}$ & 0.524 & 2.4 & 0.0027 & 89.1 & 0.385 & 3.5 & 0.0039 & 87.6 & 0.244 & 4.4 & 0.0075 & 86.0 \\
\hline $\mathrm{WKM}_{U, 40 \%}$ & 0.528 & 2.8 & 0.0028 & 88.0 & 0.388 & 3.8 & 0.0041 & 85.6 & 0.246 & 4.6 & 0.0077 & 85.2 \\
\hline $\mathrm{WKM}_{U, 50 \%}$ & 0.530 & 3.0 & 0.0029 & 87.3 & 0.390 & 4.0 & 0.0043 & 85.8 & 0.247 & 4.7 & 0.0079 & 84.9 \\
\hline $\mathrm{WKM}_{\mathcal{N}(0.1)}$ & 0.510 & 1.0 & 0.0078 & 62.7 & 0.365 & 1.5 & 0.0143 & 41.3 & 0.230 & 3.0 & 0.0224 & 26.7 \\
\hline $\mathrm{WKM}_{\mathcal{N}(0.5)}$ & 0.517 & 1.7 & 0.0032 & 88.1 & 0.375 & 2.5 & 0.0047 & 84.8 & 0.236 & 3.6 & 0.0083 & 79.8 \\
\hline $\mathrm{WKM}_{\mathcal{N}(1)}$ & 0.523 & 2.3 & 0.0028 & 89.2 & 0.382 & 3.2 & 0.0040 & 87.9 & 0.241 & 4.1 & 0.0075 & 85.2 \\
\hline $\mathrm{WKM}_{\mathcal{N}(2)}$ & 0.530 & 3.0 & 0.0029 & 87.0 & 0.389 & 3.9 & 0.0043 & 85.8 & 0.247 & 4.7 & 0.0079 & 84.8 \\
\hline $\mathrm{WKM}_{\mathcal{N}(5)}$ & 0.534 & 3.4 & 0.0032 & 85.4 & 0.393 & 4.3 & 0.0046 & 84.9 & 0.249 & 4.9 & 0.0082 & 84.2 \\
\hline
\end{tabular}

ब Censoring rate at the time of the true value of $S(t)$

* Average of 1000 point estimates

$\dagger$ Relative bias $(100 \times($ Bias $/ S(t))$

$\ddagger$ Mean square error

$\S$ Coverage rate of 100095 per cent confidence intervals 
Table 9. Monte Carlo results for estimating an hypothetical HIV-1 RNA reduction (N=200). 30\% LOD=200 copies/ml and $70 \% \mathrm{LOD}=\mathbf{5 0 0}$ copies/ $\mathrm{ml}$ leading to an overall censoring rate of $\mathbf{6 4 \%}$.

Estimators are derived using only $Z_{1}$ representing the baseline HIV-1 RNA

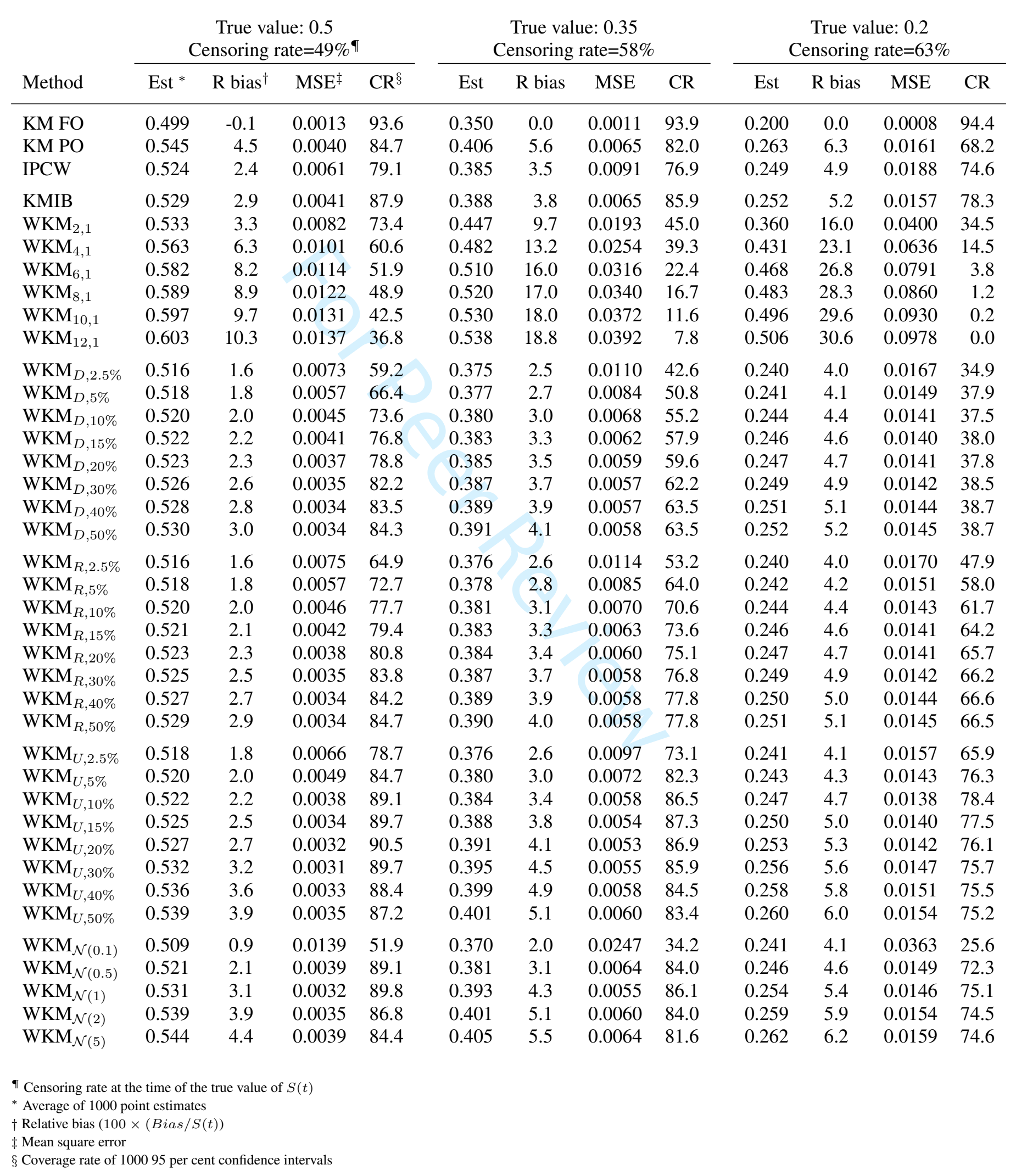




\section{Statistics}

\section{in Medicine}

Table 10. Monte Carlo results for estimating classical survival curve with with dependent censoring $(\mathbf{N}=\mathbf{2 0 0})$.

Overall censoring rate $=35 \%$ and the link functions correctly specified.

\begin{tabular}{|c|c|c|c|c|c|c|c|c|c|c|c|c|}
\hline \multirow[b]{2}{*}{ Method } & \multicolumn{4}{|c|}{$\begin{array}{c}\text { True value: } 0.5 \\
\text { Censoring rate }=26 \%\end{array}$} & \multicolumn{4}{|c|}{$\begin{array}{c}\text { True value: } 0.35 \\
\text { Censoring rate }=29 \%\end{array}$} & \multicolumn{4}{|c|}{$\begin{array}{c}\text { True value: } 0.2 \\
\text { Censoring rate }=32 \%\end{array}$} \\
\hline & Est ${ }^{*}$ & $\mathrm{R}_{\text {bias }^{\dagger}}$ & $\mathrm{MSE}^{\ddagger}$ & $\mathrm{CR}^{\S}$ & Est & $\mathrm{R}$ bias & MSE & $\mathrm{CR}$ & Est & $\mathrm{R}$ bias & MSE & $\mathrm{CR}$ \\
\hline KM FO & 0.499 & -0.1 & 0.0012 & 94.5 & 0.350 & 0.0 & 0.0012 & 93.9 & 0.198 & -0.2 & 0.0008 & 93.4 \\
\hline KM PO & 0.565 & 6.5 & 0.0059 & 60.6 & 0.425 & 7.5 & 0.0074 & 55.3 & 0.268 & 6.8 & 0.0062 & 60.0 \\
\hline IPCW & 0.500 & 0.0 & 0.0018 & 93.0 & 0.352 & 0.2 & 0.0018 & 94.4 & 0.201 & 0.1 & 0.0013 & 94.2 \\
\hline KMIB & 0.510 & 1.0 & 0.0018 & 94.0 & 0.364 & 1.4 & 0.0018 & 93.4 & 0.212 & 1.2 & 0.0013 & 94.3 \\
\hline $\mathrm{WKM}_{4,1}$ & 0.505 & 0.5 & 0.0018 & 94.3 & 0.357 & 0.7 & 0.0017 & 93.4 & 0.211 & 1.1 & 0.0014 & 92.9 \\
\hline $\mathrm{WKM}_{4,2}$ & 0.509 & 0.9 & 0.0019 & 93.2 & 0.365 & 1.5 & 0.0020 & 91.7 & 0.221 & 2.1 & 0.0019 & 88.6 \\
\hline $\mathrm{WKM}_{4,4}$ & 0.516 & 1.6 & 0.0020 & 92.2 & 0.376 & 2.6 & 0.0025 & 87.9 & 0.237 & 3.7 & 0.0029 & 80.2 \\
\hline $\mathrm{WKM}_{8,1}$ & 0.504 & 0.4 & 0.0018 & 94.0 & 0.360 & 1.0 & 0.0019 & 91.9 & 0.217 & 1.7 & 0.0017 & 90.6 \\
\hline $\mathrm{WKM}_{8,2}$ & 0.513 & 1.3 & 0.0019 & 92.2 & 0.374 & 2.4 & 0.0024 & 87.9 & 0.236 & 3.6 & 0.0028 & 80.6 \\
\hline $\mathrm{WKM}_{16,1}$ & 0.510 & 1.0 & 0.0019 & 92.4 & 0.371 & 2.1 & 0.0023 & 89.1 & 0.233 & 3.3 & 0.0026 & 82.7 \\
\hline $\mathrm{WKM}_{D, 2.5 \%}$ & 0.499 & -0.1 & 0.0018 & 92.0 & 0.350 & 0.0 & 0.0017 & 90.2 & 0.200 & 0.0 & 0.0011 & 88.1 \\
\hline $\mathrm{WKM}_{D, 5 \%}$ & 0.501 & 0.1 & 0.0017 & 92.6 & 0.352 & 0.2 & 0.0016 & 90.1 & 0.201 & 0.1 & 0.0011 & 88.7 \\
\hline $\mathrm{WKM}_{D, 10 \%}$ & 0.505 & 0.5 & 0.0017 & 93.1 & 0.355 & 0.5 & 0.0017 & 90.4 & 0.204 & 0.4 & 0.0011 & 88.6 \\
\hline $\mathrm{WKM}_{D, 15 \%}$ & 0.507 & 0.7 & 0.0018 & 93.0 & 0.358 & 0.8 & 0.0017 & 90.1 & 0.206 & 0.6 & 0.0012 & 88.5 \\
\hline $\mathrm{WKM}_{D, 20 \%}$ & 0.510 & 1.0 & 0.0018 & 93.2 & 0.361 & 1.1 & 0.0018 & 90.2 & 0.209 & 0.9 & 0.0012 & 88.1 \\
\hline $\mathrm{WKM}_{D, 30 \%}$ & 0.514 & 1.4 & 0.0019 & 92.5 & 0.366 & 1.6 & 0.0019 & 89.3 & 0.212 & 1.2 & 0.0014 & 86.8 \\
\hline $\mathrm{WKM}_{D, 40 \%}$ & 0.518 & 1.8 & 0.0020 & 91.7 & 0.370 & 2.0 & 0.0021 & 88.3 & 0.216 & 1.6 & 0.0015 & 86.1 \\
\hline $\mathrm{WKM}_{D, 50 \%}$ & 0.522 & 2.2 & 0.0022 & 90.6 & 0.373 & 2.3 & 0.0022 & 87.8 & 0.218 & 1.8 & 0.0016 & 84.9 \\
\hline $\mathrm{WKM}_{R, 2.5 \%}$ & 0.500 & 0.0 & 0.0018 & 92.6 & 0.351 & 0.1 & 0.0016 & 91.3 & 0.200 & 0.0 & 0.0011 & 89.2 \\
\hline $\mathrm{WKM}_{R, 5 \%}$ & 0.502 & 0.2 & 0.0017 & 92.7 & 0.352 & 0.2 & 0.0016 & 91.3 & 0.201 & 0.1 & 0.0011 & 90.6 \\
\hline $\mathrm{WKM}_{R, 10 \%}$ & 0.505 & 0.5 & 0.0017 & 93.1 & 0.355 & 0.5 & 0.0016 & 91.3 & 0.203 & 0.3 & 0.0011 & 91.7 \\
\hline $\mathrm{WKM}_{R, 15 \%}$ & 0.507 & 0.7 & 0.0017 & 93.5 & 0.358 & 0.8 & 0.0017 & 91.2 & 0.206 & 0.6 & 0.0012 & 91.9 \\
\hline $\mathrm{WKM}_{R, 20 \%}$ & 0.509 & 0.9 & 0.0018 & 92.4 & 0.360 & 1.0 & 0.0017 & 91.7 & 0.208 & 0.8 & 0.0012 & 91.4 \\
\hline $\mathrm{WKM}_{R, 30 \%}$ & 0.513 & 1.3 & 0.0018 & 92.3 & 0.364 & 1.4 & 0.0018 & 91.5 & 0.212 & 1.2 & 0.0013 & 91.2 \\
\hline $\mathrm{WKM}_{R, 40 \%}$ & 0.517 & 1.7 & 0.0019 & 91.5 & 0.368 & 1.8 & 0.0020 & 91.2 & 0.215 & 1.5 & 0.0014 & 90.2 \\
\hline $\mathrm{WKM}_{R, 50 \%}$ & 0.520 & 2.0 & 0.0020 & 90.8 & 0.372 & 2.2 & 0.0021 & 90.3 & 0.218 & 1.8 & 0.0015 & 88.9 \\
\hline $\mathrm{WKM}_{U, 2.5 \%}$ & 0.501 & 0.1 & 0.0017 & 92.8 & 0.352 & 0.2 & 0.0016 & 92.3 & 0.201 & 0.1 & 0.0011 & 92.2 \\
\hline $\mathrm{WKM}_{U, 5 \%}$ & 0.504 & 0.4 & 0.0017 & 93.7 & 0.355 & 0.5 & 0.0016 & 92.7 & 0.203 & 0.3 & 0.0011 & 93.5 \\
\hline $\mathrm{WKM}_{U, 10 \%}$ & 0.510 & 1.0 & 0.0018 & 93.7 & 0.361 & 1.1 & 0.0017 & 93.3 & 0.209 & 0.9 & 0.0012 & 93.5 \\
\hline $\mathrm{WKM}_{U, 15 \%}$ & 0.516 & 1.6 & 0.0019 & 92.9 & 0.367 & 1.7 & 0.0019 & 92.8 & 0.214 & 1.4 & 0.0014 & 92.9 \\
\hline $\mathrm{WKM}_{U, 20 \%}$ & 0.521 & 2.1 & 0.0021 & 91.6 & 0.372 & 2.2 & 0.0021 & 92.0 & 0.219 & 1.9 & 0.0016 & 91.2 \\
\hline $\mathrm{WKM}_{U, 30 \%}$ & 0.531 & 3.1 & 0.0026 & 87.6 & 0.383 & 3.3 & 0.0027 & 87.9 & 0.230 & 3.0 & 0.0022 & 87.2 \\
\hline $\mathrm{WKM}_{U, 40 \%}$ & 0.539 & 3.9 & 0.0032 & 83.5 & 0.393 & 4.3 & 0.0036 & 80.6 & 0.239 & 3.9 & 0.0029 & 82.9 \\
\hline $\mathrm{WKM}_{U, 50 \%}$ & 0.547 & 4.7 & 0.0038 & 77.7 & 0.402 & 5.2 & 0.0044 & 74.1 & 0.247 & 4.7 & 0.0036 & 76.7 \\
\hline $\mathrm{WKM}_{\mathcal{N}(0.1)}$ & 0.497 & -0.3 & 0.0018 & 93.2 & 0.347 & -0.3 & 0.0017 & 91.6 & 0.197 & -0.3 & 0.0012 & 90.5 \\
\hline $\mathrm{WKM}_{\mathcal{N}(0.5)}$ & 0.509 & 0.9 & 0.0017 & 93.9 & 0.360 & 1.0 & 0.0017 & 93.5 & 0.206 & 0.6 & 0.0012 & 94.0 \\
\hline $\mathrm{WKM}_{\mathcal{N}(1)}$ & 0.529 & 2.9 & 0.0025 & 88.1 & 0.381 & 3.1 & 0.0026 & 88.3 & 0.224 & 2.4 & 0.0019 & 88.9 \\
\hline $\mathrm{WKM}_{\mathcal{N}(2)}$ & 0.550 & 5.0 & 0.0041 & 74.5 & 0.405 & 5.5 & 0.0048 & 71.5 & 0.248 & 4.8 & 0.0037 & 76.1 \\
\hline $\mathrm{WKM}_{\mathcal{N}(5)}$ & 0.562 & 6.2 & 0.0055 & 64.2 & 0.421 & 7.1 & 0.0068 & 59.0 & 0.264 & 6.4 & 0.0056 & 61.5 \\
\hline
\end{tabular}

『 Censoring rate at the time of the true value of $S(t)$

* Average of 1000 point estimates

$\dagger$ Relative bias $(100 \times($ Bias $/ S(t))$

$\ddagger$ Mean square error

$\S$ Coverage rate of 100095 per cent confidence intervals 
Table 11. Monte Carlo results for estimating classical survival curve with dependent censoring $(\mathbf{N}=\mathbf{2 0 0})$.

Censoring rate $=51 \%$ and the link functions uncorrectly specified.

\begin{tabular}{|c|c|c|c|c|c|c|c|c|c|c|c|c|}
\hline \multirow[b]{2}{*}{ Method } & \multicolumn{4}{|c|}{$\begin{array}{c}\text { True value: } 0.5 \\
\text { Censoring rate }=34 \%\end{array}$} & \multicolumn{4}{|c|}{$\begin{array}{c}\text { True value: } 0.35 \\
\text { Censoring rate }=40 \%\end{array}$} & \multicolumn{4}{|c|}{$\begin{array}{c}\text { True value: } 0.2 \\
\text { Censoring rate }=46 \%\end{array}$} \\
\hline & Est * & $\mathrm{R}$ bias $^{\dagger}$ & $\mathrm{MSE}^{\ddagger}$ & $\mathrm{CR}^{\S}$ & Est & $\mathrm{R}$ bias & MSE & $\mathrm{CR}$ & Est & $\mathrm{R}$ bias & MSE & $\mathrm{CR}$ \\
\hline KM FO & 0.498 & -0.2 & 0.0012 & 94.8 & 0.349 & -0.1 & 0.0011 & 94.9 & 0.199 & -0.1 & 0.0008 & 94.3 \\
\hline KM PO & 0.603 & 10.3 & 0.0121 & 29.6 & 0.470 & 12.0 & 0.0163 & 24.3 & 0.318 & 11.8 & 0.0163 & 29.6 \\
\hline IPCW & 0.489 & -1.1 & 0.0066 & 81.7 & 0.334 & -1.6 & 0.0073 & 77.1 & 0.186 & -1.4 & 0.0053 & 81.3 \\
\hline KMIB & 0.521 & 2.1 & 0.0024 & 91.5 & 0.377 & 2.7 & 0.0029 & 90.3 & 0.23 & 3.0 & 0.0029 & 89.0 \\
\hline $\mathrm{WKM}_{4,1}$ & 0.515 & 1.5 & 0.0026 & 90.4 & 0.374 & 2.4 & 0.0034 & 88.1 & 0.243 & 4.3 & 0.0046 & 81.2 \\
\hline $\mathrm{WKM}_{4,2}$ & 0.522 & 2.2 & 0.0029 & 88.5 & 0.389 & 3.9 & 0.0043 & 81.9 & 0.266 & 6.6 & 0.0071 & 65.7 \\
\hline $\mathrm{WKM}_{4,4}$ & 0.535 & 3.5 & 0.0035 & 82.8 & 0.409 & 5.9 & 0.0061 & 66.5 & 0.294 & 9.4 & 0.0116 & 38.3 \\
\hline $\mathrm{WKM}_{8,1}$ & 0.518 & 1.8 & 0.0027 & 89.2 & 0.382 & 3.2 & 0.0038 & 85.1 & 0.257 & 5.7 & 0.0060 & 69.2 \\
\hline $\mathrm{WKM}_{8,2}$ & 0.532 & 3.2 & 0.0033 & 83.8 & 0.406 & 5.6 & 0.0058 & 68.8 & 0.291 & 9.1 & 0.0109 & 40.5 \\
\hline $\mathrm{WKM}_{16,1}$ & 0.529 & 2.9 & 0.0031 & 84.4 & 0.402 & 5.2 & 0.0053 & 70.7 & 0.286 & 8.6 & 0.0099 & 43.9 \\
\hline $\mathrm{WKM}_{D .2 .5 \%}$ & 0.505 & 0.5 & 0.0023 & 89.5 & 0.356 & 0.6 & 0.0025 & 82.0 & 0.208 & 0.8 & 0.0022 & 75.4 \\
\hline $\mathrm{WKM}_{D, 5 \%}$ & 0.507 & 0.7 & 0.0022 & 90.0 & 0.358 & 0.8 & 0.0024 & 83.5 & 0.211 & 1.1 & 0.0021 & 77.1 \\
\hline $\mathrm{WKM}_{D, 10 \%}$ & 0.512 & 1.2 & 0.0022 & 90.2 & 0.363 & 1.3 & 0.0024 & 83.6 & 0.216 & 1.6 & 0.0022 & 76.0 \\
\hline $\mathrm{WKM}_{D, 15 \%}$ & 0.516 & 1.6 & 0.0023 & 89.9 & 0.368 & 1.8 & 0.0025 & 82.8 & 0.222 & 2.2 & 0.0023 & 74.5 \\
\hline $\mathrm{WKM}_{D, 20 \%}$ & 0.519 & 1.9 & 0.0024 & 89.2 & 0.373 & 2.3 & 0.0027 & 81.4 & 0.226 & 2.6 & 0.0026 & 72.8 \\
\hline $\mathrm{WKM}_{D, 30 \%}$ & 0.526 & 2.6 & 0.0026 & 86.7 & 0.381 & 3.1 & 0.0031 & 78.8 & 0.233 & 3.3 & 0.0030 & 69.7 \\
\hline $\mathrm{WKM}_{D, 40 \%}$ & 0.532 & 3.2 & 0.0030 & 84.8 & 0.387 & 3.7 & 0.0035 & 75.5 & 0.238 & 3.8 & 0.0034 & 66.5 \\
\hline $\mathrm{WKM}_{D, 50 \%}$ & 0.538 & 3.8 & 0.0033 & 82.7 & 0.392 & 4.2 & 0.0040 & 72.0 & 0.242 & 4.2 & 0.0038 & 62.7 \\
\hline $\mathrm{WKM}_{R, 2.5 \%}$ & 0.505 & 0.5 & 0.0023 & 89.3 & 0.356 & 0.6 & 0.0025 & 84.0 & 0.208 & 0.8 & 0.0022 & 80.5 \\
\hline $\mathrm{WKM}_{R, 5 \%}$ & 0.507 & 0.7 & 0.0022 & 89.9 & 0.359 & 0.9 & 0.0024 & 85.0 & 0.211 & 1.1 & 0.0021 & 82.1 \\
\hline $\mathrm{WKM}_{R, 10 \%}$ & 0.511 & 1.1 & 0.0022 & 89.7 & 0.363 & 1.3 & 0.0024 & 86.9 & 0.216 & 1.6 & 0.0021 & 83.5 \\
\hline $\mathrm{WKM}_{R, 15 \%}$ & 0.515 & 1.5 & 0.0022 & 89.8 & 0.368 & 1.8 & 0.0025 & 86.7 & 0.221 & 2.1 & 0.0023 & 83.7 \\
\hline $\mathrm{WKM}_{R, 20 \%}$ & 0.518 & 1.8 & 0.0023 & 89.6 & 0.372 & 2.2 & 0.0026 & 85.6 & 0.225 & 2.5 & 0.0025 & 83.3 \\
\hline $\mathrm{WKM}_{R, 30 \%}$ & 0.524 & 2.4 & 0.0025 & 87.3 & 0.379 & 2.9 & 0.0029 & 84.4 & 0.232 & 3.2 & 0.0029 & 80.7 \\
\hline $\mathrm{WKM}_{R, 40 \%}$ & 0.530 & 3.0 & 0.0028 & 85.1 & 0.385 & 3.5 & 0.0033 & 80.9 & 0.238 & 3.8 & 0.0033 & 77.2 \\
\hline $\mathrm{WKM}_{R, 50 \%}$ & 0.535 & 3.5 & 0.0031 & 82.8 & 0.390 & 4.0 & 0.0037 & 77.9 & 0.242 & 4.2 & 0.0036 & 75.4 \\
\hline $\mathrm{WKM}_{U, 2.5 \%}$ & 0.506 & 0.6 & 0.0022 & 90.7 & 0.358 & 0.8 & 0.0024 & 87.9 & 0.210 & 1.0 & 0.0021 & 86.6 \\
\hline $\mathrm{WKM}_{U, 5 \%}$ & 0.511 & 1.1 & 0.0021 & 92.1 & 0.363 & 1.3 & 0.0023 & 90.6 & 0.216 & 1.6 & 0.0021 & 89.6 \\
\hline $\mathrm{WKM}_{U, 10 \%}$ & 0.519 & 1.9 & 0.0023 & 91.8 & 0.373 & 2.3 & 0.0026 & 90.4 & 0.227 & 2.7 & 0.0024 & 89.2 \\
\hline $\mathrm{WKM}_{U, 15 \%}$ & 0.527 & 2.7 & 0.0027 & 88.1 & 0.382 & 3.2 & 0.0031 & 87.8 & 0.238 & 3.8 & 0.0031 & 85.2 \\
\hline $\mathrm{WKM}_{U, 20 \%}$ & 0.535 & 3.5 & 0.0031 & 85.9 & 0.391 & 4.1 & 0.0037 & 83.5 & 0.248 & 4.8 & 0.0041 & 80.0 \\
\hline $\mathrm{WKM}_{U, 30 \%}$ & 0.549 & 4.9 & 0.0042 & 79.1 & 0.409 & 5.9 & 0.0055 & 71.5 & 0.266 & 6.6 & 0.0062 & 65.7 \\
\hline $\mathrm{WKM}_{U, 40 \%}$ & 0.562 & 6.2 & 0.0056 & 68.8 & 0.425 & 7.5 & 0.0076 & 58.9 & 0.280 & 8.0 & 0.0084 & 54.3 \\
\hline $\mathrm{WKM}_{U, 50 \%}$ & 0.574 & 7.4 & 0.0072 & 58.0 & 0.438 & 8.8 & 0.0098 & 48.3 & 0.291 & 9.1 & 0.0105 & 46.5 \\
\hline $\mathrm{WKM}_{\mathcal{N}(0.1)}$ & 0.500 & 0.0 & 0.0025 & 89.3 & 0.350 & 0.0 & 0.0027 & 85.2 & 0.203 & 0.3 & 0.0027 & 79.2 \\
\hline $\mathrm{WKM}_{\mathcal{N}(0.5)}$ & 0.520 & 2.0 & 0.0023 & 90.4 & 0.372 & 2.2 & 0.0026 & 90.1 & 0.220 & 2.0 & 0.0024 & 88.5 \\
\hline $\mathrm{WKM}_{\mathcal{N}(1)}$ & 0.550 & 5.0 & 0.0043 & 77.5 & 0.406 & 5.6 & 0.0053 & 73.7 & 0.253 & 5.3 & 0.0049 & 77.1 \\
\hline $\mathrm{WKM}_{\mathcal{N}(2)}$ & 0.581 & 8.1 & 0.0082 & 51.6 & 0.442 & 9.2 & 0.0106 & 45.5 & 0.289 & 8.9 & 0.0102 & 49.1 \\
\hline $\mathrm{WKM}_{\mathcal{N}(5)}$ & 0.598 & 9.8 & 0.0113 & 33.1 & 0.464 & 11.4 & 0.0151 & 27.7 & 0.312 & 11.2 & 0.0149 & 32.5 \\
\hline $\begin{array}{l}* \text { Average of } 1000 \mathrm{p} \\
\dagger \text { Relative bias }(100 \\
\ddagger \text { Mean square error }\end{array}$ & $\begin{array}{l}\text { ime of } \\
\text { estima } \\
\text { Bias / }\end{array}$ & . & ) & & & & & & & & & \\
\hline
\end{tabular}




\section{Statistics}

\section{in Medicine}

Table 12. Monte Carlo results for estimating classical survival curve with independent censoring $(\mathbf{N}=\mathbf{2 0 0})$.

Censoring rate $=40 \%$ and the link functions correctly specified.

\begin{tabular}{|c|c|c|c|c|c|c|c|c|c|c|c|c|}
\hline \multirow[b]{2}{*}{ Method } & \multicolumn{4}{|c|}{$\begin{array}{c}\text { True value: } 0.5 \\
\text { Censoring rate }=35 \%\end{array}$} & \multicolumn{4}{|c|}{$\begin{array}{c}\text { True value: } 0.35 \\
\text { Censoring rate }=37 \%\end{array}$} & \multicolumn{4}{|c|}{$\begin{array}{c}\text { True value: } 0.2 \\
\text { Censoring rate }=39 \%\end{array}$} \\
\hline & Est * & $\mathrm{R}$ bias $^{\dagger}$ & $\mathrm{MSE}^{\ddagger}$ & $\mathrm{CR}^{\S}$ & Est & $\mathrm{R}$ bias & MSE & $\mathrm{CR}$ & Est & $\mathrm{R}$ bias & MSE & $\mathrm{CR}$ \\
\hline KM FO & 0.499 & -0.1 & 0.0013 & 94.2 & 0.349 & -0.1 & 0.0012 & 93.5 & 0.199 & -0.1 & 0.0008 & 93.2 \\
\hline KM PO & 0.500 & 0.0 & 0.0019 & 95.6 & 0.348 & -0.2 & 0.0018 & 94.1 & 0.199 & -0.1 & 0.0014 & 94.2 \\
\hline IPCW & 0.500 & 0.0 & 0.0017 & 94.5 & 0.348 & -0.2 & 0.0017 & 93.4 & 0.198 & -0.2 & 0.0013 & 94.9 \\
\hline KMIB & 0.501 & 0.1 & 0.0018 & 94.5 & 0.349 & -0.1 & 0.0018 & 92.8 & 0.199 & -0.1 & 0.0013 & 93.2 \\
\hline $\mathrm{WKM}_{4.1}$ & 0.499 & -0.1 & 0.0018 & 94.6 & 0.348 & -0.2 & 0.0018 & 93.9 & 0.199 & -0.1 & 0.0013 & 93.9 \\
\hline $\mathrm{WKM}_{4.2}$ & 0.499 & -0.1 & 0.0018 & 95.1 & 0.348 & -0.2 & 0.0018 & 92.8 & 0.199 & -0.1 & 0.0013 & 93.3 \\
\hline $\mathrm{WKM}_{4.4}$ & 0.500 & 0.0 & 0.0018 & 94.3 & 0.350 & 0.0 & 0.0019 & 92.1 & 0.203 & 0.3 & 0.0014 & 92.4 \\
\hline $\mathrm{WKM}_{8.1}$ & 0.499 & -0.1 & 0.0018 & 94.6 & 0.349 & -0.1 & 0.0018 & 93.0 & 0.201 & 0.1 & 0.0013 & 92.9 \\
\hline $\mathrm{WKM}_{8.2}$ & 0.500 & 0.0 & 0.0018 & 94.3 & 0.350 & 0.0 & 0.0018 & 91.9 & 0.203 & 0.3 & 0.0014 & 91.4 \\
\hline $\mathrm{WKM}_{16.1}$ & 0.500 & 0.0 & 0.0018 & 94.1 & 0.351 & 0.1 & 0.0019 & 92.0 & 0.205 & 0.5 & 0.0014 & 92.4 \\
\hline $\mathrm{WKM}_{D .2 .5 \%}$ & 0.500 & 0.0 & 0.0019 & 90.9 & 0.349 & -0.1 & 0.002 & 87.7 & 0.199 & -0.1 & 0.0014 & 84.6 \\
\hline $\mathrm{WKM}_{D .5 \%}$ & 0.500 & 0.0 & 0.0019 & 91.8 & 0.349 & -0.1 & 0.0019 & 88.0 & 0.199 & -0.1 & 0.0014 & 85.7 \\
\hline $\mathrm{WKM}_{D .10 \%}$ & 0.500 & 0.0 & 0.0019 & 92.1 & 0.349 & -0.1 & 0.0019 & 88.0 & 0.198 & -0.2 & 0.0014 & 86.5 \\
\hline $\mathrm{WKM}_{D .15 \%}$ & 0.500 & 0.0 & 0.0019 & 92.2 & 0.349 & -0.1 & 0.0019 & 88.3 & 0.198 & -0.2 & 0.0013 & 86.3 \\
\hline $\mathrm{WKM}_{D .20 \%}$ & 0.501 & 0.1 & 0.0019 & 92.3 & 0.348 & -0.2 & 0.0019 & 88.5 & 0.197 & -0.3 & 0.0013 & 86.3 \\
\hline $\mathrm{WKM}_{D .30 \%}$ & 0.501 & 0.1 & 0.0019 & 92.7 & 0.348 & -0.2 & 0.0019 & 88.9 & 0.197 & -0.3 & 0.0013 & 86.4 \\
\hline $\mathrm{WKM}_{D .40 \%}$ & 0.501 & 0.1 & 0.0019 & 92.4 & 0.348 & -0.2 & 0.0019 & 89.2 & 0.196 & -0.4 & 0.0013 & 86.3 \\
\hline $\mathrm{WKM}_{D .50 \%}$ & 0.501 & 0.1 & 0.0018 & 92.3 & 0.348 & -0.2 & 0.0018 & 89.1 & 0.196 & -0.4 & 0.0013 & 86.4 \\
\hline $\mathrm{WKM}_{R .2 .5 \%}$ & 0.500 & 0.0 & 0.0019 & 90.6 & 0.349 & -0.1 & 0.0019 & 88.8 & 0.199 & -0.1 & 0.0014 & 87.3 \\
\hline $\mathrm{WKM}_{R .5 \%}$ & 0.500 & 0.0 & 0.0019 & 91.2 & 0.349 & -0.1 & 0.0019 & 89.5 & 0.199 & -0.1 & 0.0014 & 88.9 \\
\hline $\mathrm{WKM}_{R .10 \%}$ & 0.500 & 0.0 & 0.0018 & 91.9 & 0.349 & -0.1 & 0.0019 & 90.0 & 0.198 & -0.2 & 0.0013 & 90.1 \\
\hline $\mathrm{WKM}_{R .15 \%}$ & 0.500 & 0.0 & 0.0018 & 92.2 & 0.348 & -0.2 & 0.0018 & 90.3 & 0.198 & -0.2 & 0.0013 & 90.2 \\
\hline $\mathrm{WKM}_{R .20 \%}$ & 0.500 & 0.0 & 0.0018 & 92.5 & 0.348 & -0.2 & 0.0018 & 90.7 & 0.197 & -0.3 & 0.0013 & 90.5 \\
\hline $\mathrm{WKM}_{R .30 \%}$ & 0.501 & 0.1 & 0.0018 & 93.0 & 0.348 & -0.2 & 0.0018 & 91.4 & 0.197 & -0.3 & 0.0013 & 91.0 \\
\hline $\mathrm{WKM}_{R .40 \%}$ & 0.501 & 0.1 & 0.0018 & 93.4 & 0.348 & -0.2 & 0.0018 & 91.6 & 0.196 & -0.4 & 0.0013 & 91.3 \\
\hline $\mathrm{WKM}_{R .50 \%}$ & 0.501 & 0.1 & 0.0018 & 93.5 & 0.348 & -0.2 & 0.0018 & 92.0 & 0.196 & -0.4 & 0.0013 & 91.5 \\
\hline $\mathrm{WKM}_{U .2 .5 \%}$ & 0.500 & 0.0 & 0.0019 & 93.2 & 0.349 & -0.1 & 0.0019 & 90.7 & 0.199 & -0.1 & 0.0014 & 90.1 \\
\hline $\mathrm{WKM}_{U .5 \%}$ & 0.499 & -0.1 & 0.0018 & 94.5 & 0.348 & -0.2 & 0.0019 & 91.9 & 0.198 & -0.2 & 0.0013 & 92.0 \\
\hline $\mathrm{WKM}_{U .10 \%}$ & 0.500 & 0.0 & 0.0018 & 94.5 & 0.348 & -0.2 & 0.0018 & 92.8 & 0.197 & -0.3 & 0.0013 & 92.9 \\
\hline $\mathrm{WKM}_{U .15 \%}$ & 0.501 & 0.1 & 0.0018 & 94.8 & 0.348 & -0.2 & 0.0018 & 93.4 & 0.196 & -0.4 & 0.0013 & 93.2 \\
\hline $\mathrm{WKM}_{U .20 \%}$ & 0.501 & 0.1 & 0.0018 & 94.7 & 0.348 & -0.2 & 0.0018 & 93.6 & 0.195 & -0.5 & 0.0013 & 93.5 \\
\hline $\mathrm{WKM}_{U .30 \%}$ & 0.502 & 0.2 & 0.0018 & 94.6 & 0.347 & -0.3 & 0.0018 & 93.8 & 0.194 & -0.6 & 0.0014 & 93.5 \\
\hline $\mathrm{WKM}_{U .40 \%}$ & 0.502 & 0.2 & 0.0019 & 94.8 & 0.347 & -0.3 & 0.0018 & 93.8 & 0.194 & -0.6 & 0.0014 & 93.3 \\
\hline $\mathrm{WKM}_{U .50 \%}$ & 0.502 & 0.2 & 0.0019 & 95.4 & 0.347 & -0.3 & 0.0018 & 93.8 & 0.194 & -0.6 & 0.0014 & 93.4 \\
\hline $\mathrm{WKM}_{\mathcal{N}(0.1)}$ & 0.499 & -0.1 & 0.0018 & 93.6 & 0.349 & -0.1 & 0.0019 & 90.8 & 0.199 & -0.1 & 0.0014 & 90.3 \\
\hline $\mathrm{WKM}_{\mathcal{N}(0.5)}$ & 0.500 & 0.0 & 0.0018 & 94.7 & 0.348 & -0.2 & 0.0018 & 93.3 & 0.197 & -0.3 & 0.0013 & 92.8 \\
\hline $\mathrm{WKM}_{\mathcal{N}(1)}$ & 0.501 & 0.1 & 0.0018 & 94.7 & 0.348 & -0.2 & 0.0018 & 94.1 & 0.196 & -0.4 & 0.0013 & 94.0 \\
\hline $\mathrm{WKM}_{\mathcal{N}(2)}$ & 0.501 & 0.1 & 0.0018 & 95.9 & 0.348 & -0.2 & 0.0018 & 93.5 & 0.197 & -0.3 & 0.0013 & 94.1 \\
\hline $\mathrm{WKM}_{\mathcal{N}(5)}$ & 0.500 & 0.0 & 0.0019 & 95.4 & 0.348 & -0.2 & 0.0018 & 93.8 & 0.198 & -0.2 & 0.0014 & 93.3 \\
\hline
\end{tabular}

ฯ Censoring rate at the time of the true value of $S(t)$

* Average of 1000 point estimates

$\dagger$ Relative bias $(100 \times($ Bias $/ S(t))$

$\ddagger$ Mean square error

$\S$ Coverage rate of 100095 per cent confidence intervals 
Table 13. Monte Carlo results for estimating classical survival curve with with dependent censoring $(\mathbf{N}=\mathbf{2 0 0})$.

Working failure model mis-specified (using only $Z_{1}, Z_{2}$ and $Z_{3}$ )

Overall censoring rate $=35 \%$ and the link functions correctly specified.

\begin{tabular}{|c|c|c|c|c|c|c|c|c|c|c|c|c|}
\hline \multirow[b]{2}{*}{ Method } & \multicolumn{4}{|c|}{$\begin{array}{c}\text { True value: } 0.5 \\
\text { Censoring rate }=26 \%\end{array}$} & \multicolumn{4}{|c|}{$\begin{array}{c}\text { True value: } 0.35 \\
\text { Censoring rate }=29 \%\end{array}$} & \multicolumn{4}{|c|}{$\begin{array}{c}\text { True value: } 0.2 \\
\text { Censoring rate }=32 \%\end{array}$} \\
\hline & Est * & $\mathrm{R}$ bias $^{\dagger}$ & $\mathrm{MSE}^{\ddagger}$ & $\mathrm{CR}^{\S}$ & Est & $\mathrm{R}$ bias & MSE & $\mathrm{CR}$ & Est & $\mathrm{R}$ bias & MSE & $\mathrm{CR}$ \\
\hline KM FO & 0.499 & -0.1 & 0.0012 & 94.5 & 0.350 & 0.0 & 0.0012 & 93.9 & 0.198 & -0.2 & 0.0008 & 93.4 \\
\hline KM PO & 0.565 & 6.5 & 0.0059 & 60.6 & 0.425 & 7.5 & 0.0074 & 55.3 & 0.268 & 6.8 & 0.0062 & 60.0 \\
\hline IPCW & 0.535 & 3.5 & 0.0030 & 83.4 & 0.387 & 3.7 & 0.0033 & 83.0 & 0.229 & 2.9 & 0.0026 & 86.7 \\
\hline $\mathrm{WKM}_{4.1}$ & 0.521 & 2.1 & 0.0022 & 91.4 & 0.372 & 2.2 & 0.0023 & 91.7 & 0.221 & 2.1 & 0.0018 & 92.8 \\
\hline $\mathrm{WKM}_{4.2}$ & 0.515 & 1.5 & 0.0019 & 93.1 & 0.370 & 2.0 & 0.0021 & 91.3 & 0.225 & 2.5 & 0.0020 & 89.6 \\
\hline $\mathrm{WKM}_{4.4}$ & 0.518 & 1.8 & 0.0020 & 92.4 & 0.378 & 2.8 & 0.0025 & 87.8 & 0.239 & 3.9 & 0.0030 & 79.1 \\
\hline $\mathrm{WKM}_{8.1}$ & 0.519 & 1.9 & 0.0022 & 91.2 & 0.374 & 2.4 & 0.0024 & 91.3 & 0.226 & 2.6 & 0.0022 & 88.6 \\
\hline $\mathrm{WKM}_{8.2}$ & 0.518 & 1.8 & 0.0021 & 90.8 & 0.379 & 2.9 & 0.0027 & 86.2 & 0.240 & 4.0 & 0.0031 & 78.9 \\
\hline $\mathrm{WKM}_{16.1}$ & 0.523 & 2.3 & 0.0024 & 88.8 & 0.382 & 3.2 & 0.0029 & 84.9 & 0.241 & 4.1 & 0.0033 & 76.9 \\
\hline $\mathrm{WKM}_{D .2 .5 \%}$ & 0.515 & 1.5 & 0.0021 & 90.4 & 0.365 & 1.5 & 0.0020 & 87.7 & 0.211 & 1.1 & 0.0014 & 86.2 \\
\hline $\mathrm{WKM}_{D .5 \%}$ & 0.516 & 1.6 & 0.0021 & 90.3 & 0.367 & 1.7 & 0.0020 & 88.5 & 0.213 & 1.3 & 0.0015 & 85.5 \\
\hline $\mathrm{WKM}_{D .10 \%}$ & 0.518 & 1.8 & 0.0021 & 90.2 & 0.369 & 1.9 & 0.0021 & 88.4 & 0.215 & 1.5 & 0.0015 & 84.6 \\
\hline $\mathrm{WKM}_{D .15 \%}$ & 0.520 & 2.0 & 0.0021 & 89.8 & 0.371 & 2.1 & 0.0022 & 87.3 & 0.217 & 1.7 & 0.0016 & 84.9 \\
\hline $\mathrm{WKM}_{D .20 \%}$ & 0.522 & 2.2 & 0.0022 & 89.3 & 0.373 & 2.3 & 0.0023 & 86.6 & 0.219 & 1.9 & 0.0017 & 83.9 \\
\hline $\mathrm{WKM}_{D .30 \%}$ & 0.525 & 2.5 & 0.0023 & 88.4 & 0.377 & 2.7 & 0.0024 & 84.6 & 0.223 & 2.3 & 0.0018 & 82.3 \\
\hline $\mathrm{WKM}_{D .40 \%}$ & 0.528 & 2.8 & 0.0025 & 87.2 & 0.380 & 3.0 & 0.0026 & 83.0 & 0.225 & 2.5 & 0.0020 & 80.6 \\
\hline $\mathrm{WKM}_{D .50 \%}$ & 0.531 & 3.1 & 0.0026 & 86.1 & 0.383 & 3.3 & 0.0028 & 81.1 & 0.228 & 2.8 & 0.0021 & 80.2 \\
\hline $\mathrm{WKM}_{R .2 .5 \%}$ & 0.515 & 1.5 & 0.0021 & 90.0 & 0.365 & 1.5 & 0.0020 & 89.0 & 0.211 & 1.1 & 0.0014 & 88.7 \\
\hline $\mathrm{WKM}_{R, 5 \%}$ & 0.516 & 1.6 & 0.0020 & 89.6 & 0.366 & 1.6 & 0.0020 & 89.8 & 0.213 & 1.3 & 0.0014 & 88.9 \\
\hline $\mathrm{WKM}_{R .10 \%}$ & 0.518 & 1.8 & 0.0021 & 89.7 & 0.369 & 1.9 & 0.0020 & 90.0 & 0.215 & 1.5 & 0.0015 & 88.9 \\
\hline $\mathrm{WKM}_{R .15 \%}$ & 0.520 & 2.0 & 0.0021 & 89.3 & 0.371 & 2.1 & 0.0021 & 90.2 & 0.217 & 1.7 & 0.0015 & 88.8 \\
\hline $\mathrm{WKM}_{R .20 \%}$ & 0.521 & 2.1 & 0.0022 & 88.8 & 0.372 & 2.2 & 0.0022 & 89.9 & 0.219 & 1.9 & 0.0016 & 88.1 \\
\hline $\mathrm{WKM}_{R .30 \%}$ & 0.524 & 2.4 & 0.0023 & 87.7 & 0.376 & 2.6 & 0.0023 & 88.5 & 0.222 & 2.2 & 0.0018 & 87.4 \\
\hline $\mathrm{WKM}_{R .40 \%}$ & 0.527 & 2.7 & 0.0024 & 86.7 & 0.379 & 2.9 & 0.0025 & 86.8 & 0.224 & 2.4 & 0.0019 & 86.5 \\
\hline $\mathrm{WKM}_{R .50 \%}$ & 0.529 & 2.9 & 0.0025 & 86.0 & 0.382 & 3.2 & 0.0027 & 85.1 & 0.227 & 2.7 & 0.0020 & 85.3 \\
\hline $\mathrm{WKM}_{U .2}$ & 0.515 & 1.5 & 0.0020 & 91.0 & 0.366 & 1.6 & 0.0020 & 91.4 & 0.212 & 1.2 & 0.0014 & 91.4 \\
\hline $\mathrm{WKM}_{U .5}$ & 0.517 & 1.7 & 0.0020 & 91.2 & 0.368 & 1.8 & 0.0020 & 91.9 & 0.214 & 1.4 & 0.0015 & 91.9 \\
\hline $\mathrm{WKM}_{U .10 \%}$ & 0.522 & 2.2 & 0.0022 & 90.4 & 0.373 & 2.3 & 0.0022 & 91.8 & 0.219 & 1.9 & 0.0016 & 91.5 \\
\hline $\mathrm{WKM}_{U .15 \%}$ & 0.526 & 2.6 & 0.0023 & 89.5 & 0.378 & 2.8 & 0.0024 & 91.4 & 0.224 & 2.4 & 0.0018 & 90.2 \\
\hline $\mathrm{WKM}_{U .20 \%}$ & 0.529 & 2.9 & 0.0025 & 87.9 & 0.382 & 3.2 & 0.0027 & 88.7 & 0.228 & 2.8 & 0.0021 & 88.3 \\
\hline $\mathrm{WKM}_{U .30 \%}$ & 0.536 & 3.6 & 0.0030 & 84.5 & 0.391 & 4.1 & 0.0033 & 82.7 & 0.237 & 3.7 & 0.0027 & 83.8 \\
\hline $\mathrm{WKM}_{U .40 \%}$ & 0.543 & 4.3 & 0.0035 & 80.5 & 0.399 & 4.9 & 0.0041 & 76.9 & 0.244 & 4.4 & 0.0034 & 78.7 \\
\hline $\mathrm{WKM}_{U .50 \%}$ & 0.549 & 4.9 & 0.0040 & 75.3 & 0.406 & 5.6 & 0.0048 & 70.8 & 0.251 & 5.1 & 0.0040 & 74.0 \\
\hline $\mathrm{WKM}_{\mathcal{N}(\mathrm{s}}$ & 0.514 & 1.4 & 0.0021 & 90.7 & 0.364 & 1.4 & 0.0020 & 90.6 & 0.210 & 1.0 & 0.0014 & 90.8 \\
\hline $\mathrm{WKM}_{\mathcal{N}(0.5)}$ & 0.522 & 2.2 & 0.0022 & 89.2 & 0.373 & 2.3 & 0.0022 & 91.4 & 0.218 & 1.8 & 0.0016 & 91.0 \\
\hline $\mathrm{WKM}_{\mathcal{N}(1)}$ & 0.537 & 3.7 & 0.0030 & 84.5 & 0.390 & 4.0 & 0.0033 & 82.7 & 0.233 & 3.3 & 0.0025 & 85.0 \\
\hline $\mathrm{WKM}_{\mathcal{N}(2)}$ & 0.553 & 5.3 & 0.0045 & 71.7 & 0.410 & 6.0 & 0.0053 & 68.0 & 0.252 & 5.2 & 0.0042 & 72.6 \\
\hline $\mathrm{WKM}_{\mathcal{N}(5)}$ & 0.563 & 6.3 & 0.0056 & 62.9 & 0.422 & 7.2 & 0.0069 & 58.0 & 0.265 & 6.5 & 0.0058 & 60.7 \\
\hline
\end{tabular}

I Censoring rate at the time of the true value of $S(t)$

* Average of 1000 point estimates

$\dagger$ Relative bias $(100 \times($ Bias $/ S(t))$

$\ddagger$ Mean square error

$\S$ Coverage rate of 100095 per cent confidence intervals 


\section{Statistics}

\section{in Medicine}

Table 14. Monte Carlo results for estimating classical survival curve with dependent censoring ( $\mathbf{N}=\mathbf{2 0 0})$.

Working failure model mis-specified (using only $Z_{1}, Z_{2}$ and $Z_{3}$ )

Censoring rate $=51 \%$ and the link functions uncorrectly specified.

True value: 0.5

Censoring rate $=34 \%$ व

Method

KM FO

KM PO

IPCW

$\mathrm{WKM}_{4.1}$

$\mathrm{WKM}_{4.2}$

$\mathrm{WKM}_{4.4}$

$\mathrm{WKM}_{8.1}$

$\mathrm{WKM}_{8.2}$

$\mathrm{WKM}_{16.1}$

$\mathrm{WKM}_{D .2 .5 \%}$

$\mathrm{WKM}_{D .5 \%}$

$\mathrm{WKM}_{D .10 \%}$

$\mathrm{WKM}_{D .15 \%}$

$\mathrm{WKM}_{D .20 \%}$

$\mathrm{WKM}_{D .30 \%}$

$\mathrm{WKM}_{D .40 \%}$

$\mathrm{WKM}_{D .50 \%}$

$\mathrm{WKM}_{R .2 .5 \%}$

$\mathrm{WKM}_{R .5 \%}$

$\mathrm{WKM}_{R .10 \%}$

$\mathrm{WKM}_{R .15 \%}$

$\mathrm{WKM}_{R .20 \%}$

$\mathrm{WKM}_{R .30 \%}$

$\mathrm{WKM}_{R .40 \%}$

$\mathrm{WKM}_{R .50 \%}$

$\mathrm{WKM}_{U .2 .5 \%}$

WKM $_{U .5 \%}$

$\mathrm{WKM}_{U .10 \%}$

$\mathrm{WKM}_{U .15 \%}$

$\mathrm{WKM}_{U .20 \%}$

$\mathrm{WKM}_{U .30 \%}$

$\mathrm{WKM}_{U .40 \%}$

$\mathrm{WKM}_{U .50 \%}$

$\mathrm{WKM}_{\mathcal{N}(0.1)}$

$\mathrm{WKM}_{\mathcal{N}(0.5)}$

$\mathrm{WKM}_{\mathcal{N}(1)}$

$\mathrm{WKM}_{\mathcal{N}(2)}$

$\mathrm{WKM}_{\mathcal{N}(5)}$

Est ${ }^{*}$ Cen
0.498
0.603
0.566

\subsection{5}

0.528

0.537

0.535

0.537

0.542

0.525

0.526

0.530

0.533

0.536

0.541

0.545

0.549

0.525

0.527

0.530

0.532

0.535

0.540

0.544

0.547

0.526

0.529

0.536

0.542

0.548

0.559

0.569

0.579

0.524

0.539

0.563

0.586

0.600
0.0065

3.5

2.5

2.6

3.0

3.3

0.003

3.6

0.0032

4.1

0.0036

4.9

0.0043

2.5

2.7

0.0028

0.0028

3.0

0.0029

3.2

0.003

3.5

0.0032

4.0

0.0035

4.4

0.0038

4.7

0.0041

2.6

0.002

2.9

0.0028

0.0032

3.6

4.8

0.004

5.9

0.0052

6.9

0.0065

7.9

0.0079

\section{4}

$$
3.9
$$

6.3

8.6

0.0034

10.0
True value: 0.35

Censoring rate $=40 \%$

Est R bias MSE CR

$\begin{array}{llll}0.349 & -0.1 & 0.0011 & 94.9\end{array}$

$0.0012 \quad 94.8$

$\begin{array}{ll}0.0121 & 29.6\end{array}$

62.5

$0.0033 \quad 86.6$

$\begin{array}{lll}2.8 & 0.0030 & 86.8\end{array}$

$\begin{array}{lll}3.7 & 0.0035 & 80.9\end{array}$

$\begin{array}{lll}3.5 & 0.0033 & 85.6\end{array}$

$\begin{array}{lll}3.7 & 0.0035 & 82.0\end{array}$

$\begin{array}{lll}4.2 & 0.0039 & 79.4\end{array}$

$0.0028 \quad 86.3$

$0.0028 \quad 86.6$

$0.0029 \quad 85.7$

84.8

83.5

$0.0039 \quad 78.4$

75.6

85.7

85.5

85.0

81.0

77.6

87.3

87.8

$0.0036 \quad 82.1$

78.8

71.8

62.2

$0.0029 \quad 87.0$

83.8

$0.0057 \quad 67.1$

$0.0092 \quad 44.9$

$0.0115 \quad 32.1$

0.349
0.470

0.418

12.0

0.0011

0.392

0.394

4.2

24.3
63.0

0.411

0.397

4.4

$\begin{array}{ll}0.0044 & 82.0\end{array}$

0.411

6.1

0.0046

79.1

$\begin{array}{ll}0.0063 & 66.2 \\ 0.0047 & 77.4\end{array}$

$\begin{array}{lll}6.1 & 0.0062 & 67.0\end{array}$

0.412

6.2

0.0063

65.1

0.376

2.6

$0.0033 \quad 77.4$

0.379

2.9

$0.0033 \quad 78.0$

0.383

3.3

$0.0034 \quad 77.1$

0.387

3.7

$0.0036 \quad 75.5$

0.390

4.0

$0.0038 \quad 73.5$

0.396

4.6

0.0043

70.8

0.406

5.6

0.004966 .8

$0.376 \quad 2.6$

$0.0053 \quad 63.9$

$0.379-2.9$

0.0033

0.0033

80.6

0.383

3.3

0.0034

0.386

3.6

0.0035

80.9

0.389

3.9

0.0037

0.395

4.5

0.0042

0.400

5.0
5.4

0.0047

0.404

5.4

0.0051

0.378

2.8

0.0033

0.383

3.3

0.0033

0.391

4.1

0.0038

0.398

4.8
5.6

0.0044

7.0

0.0069

0.433

8.3

0.0088

0.443

9.3

0.0107

0.375

0.42

4.

0.0035

0.449

7.0

$0.0071 \quad 62.8$

0.466

9.9
11.6

$0.0119 \quad 38.7$

$0.0154 \quad 26.6$

『 Censoring rate at the time of the true value of $S(t)$

* Average of 1000 point estimates

$\dagger$ Relative bias $(100 \times($ Bias $/ S(t))$

$\ddagger$ Mean square error

$\S$ Coverage rate of 100095 per cent confidence intervals

True value: 0.2 
Table 15. Monte Carlo results for estimating classical survival curve with independent censoring $(\mathbf{N}=\mathbf{2 0 0})$.

Working failure model mis-specified (using only $Z_{1}, Z_{2}$ and $Z_{3}$ )

Censoring rate $=40 \%$ and the link functions correctly specified.

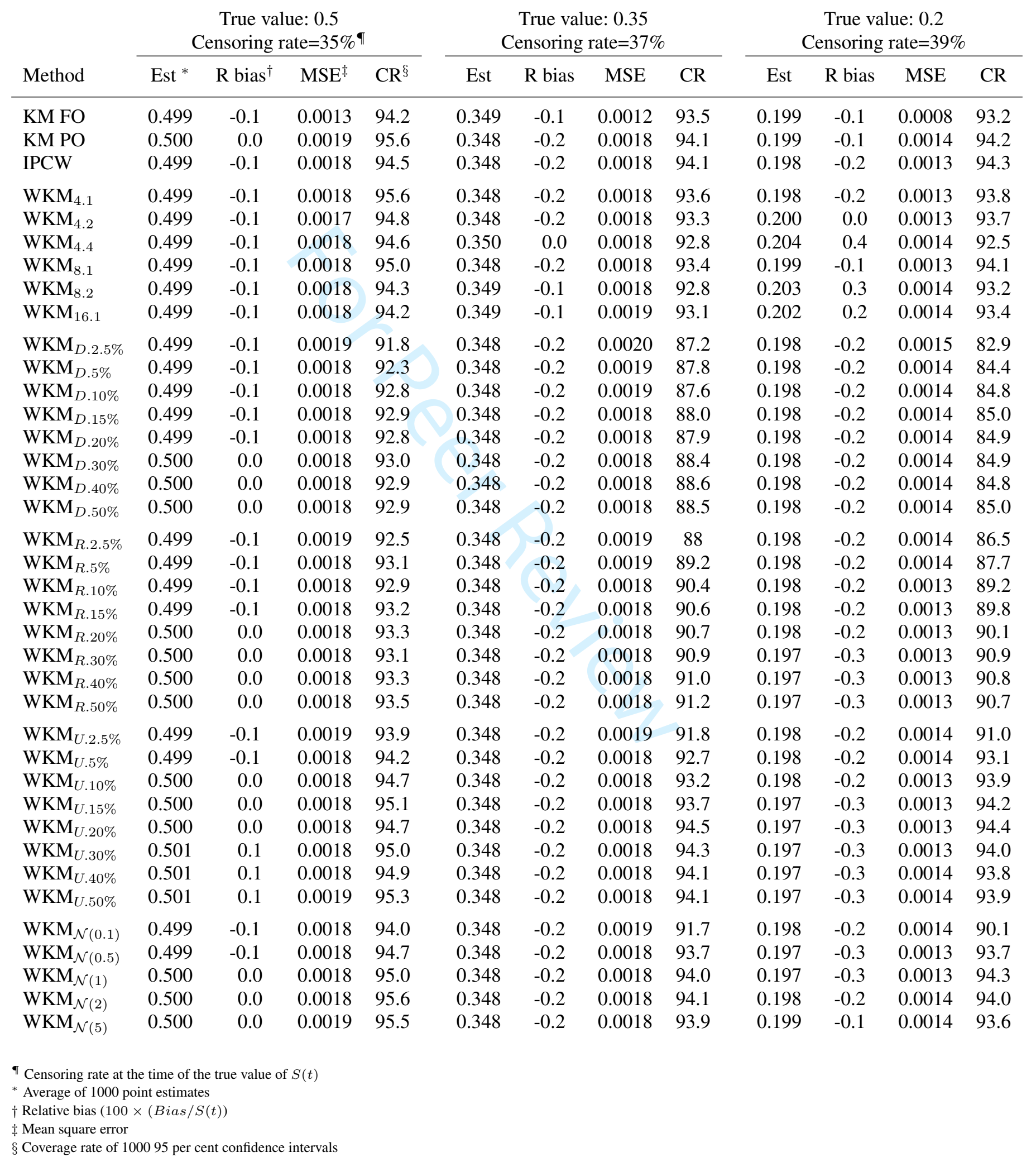




\section{Statistics \\ in Medicine}

Table 16. Monte Carlo results for estimating an hypothetical HIV-1 RNA reduction $(\mathbf{N}=100)$. $70 \%$ LOD=100 copies/ml and $\mathbf{3 0} \% \mathrm{LOD}=\mathbf{2 0 0}$ copies/ml leading to an overall censoring rate of $\mathbf{4 5 \%}$.

Estimators are derived using the 5 covariates.

\begin{tabular}{|c|c|c|c|c|c|c|c|c|c|c|c|c|}
\hline \multirow[b]{2}{*}{ Method } & \multicolumn{4}{|c|}{$\begin{array}{c}\text { True value: } 0.5 \\
\text { Censoring rate }=24 \%\end{array}$} & \multicolumn{4}{|c|}{$\begin{array}{c}\text { True value: } 0.35 \\
\text { Censoring rate }=34 \%\end{array}$} & \multicolumn{4}{|c|}{$\begin{array}{c}\text { True value: } 0.2 \\
\text { Censoring rate }=42 \%\end{array}$} \\
\hline & Est * & $\mathrm{R}$ bias $^{\dagger}$ & $\mathrm{MSE}^{\ddagger}$ & $\mathrm{CR}^{\S}$ & Est & $\mathrm{R}$ bias & MSE & $\mathrm{CR}$ & Est & $\mathrm{R}$ bias & MSE & $\mathrm{CR}$ \\
\hline KM FO & 0.497 & -0.3 & 0.0026 & 93.9 & 0.350 & 0.0 & 0.0023 & 94.7 & 0.201 & 0.1 & 0.0017 & 93.7 \\
\hline KM PO & 0.521 & 2.1 & 0.0037 & 93.3 & 0.382 & 3.2 & 0.0046 & 92.0 & 0.235 & 3.5 & 0.0062 & 90.6 \\
\hline $\mathrm{WKM}_{4.1}$ & 0.491 & -0.9 & 0.0047 & 88.5 & 0.359 & 0.9 & 0.0056 & 86.6 & 0.258 & 5.8 & 0.0100 & 75.2 \\
\hline $\mathrm{WKM}_{4.2}$ & 0.526 & 2.6 & 0.0049 & 86.2 & 0.424 & 7.4 & 0.0100 & 69.7 & 0.353 & 15.3 & 0.0280 & 25.7 \\
\hline $\mathrm{WKM}_{8.1}$ & 0.500 & 0.0 & 0.0043 & 90.8 & 0.380 & 3.0 & 0.0056 & 85.4 & 0.292 & 9.2 & 0.0136 & 60.3 \\
\hline $\mathrm{WKM}_{D .3 \%}$ & 0.487 & -1.3 & 0.0048 & 88.2 & 0.334 & -1.6 & 0.0062 & 76.4 & 0.188 & -1.2 & 0.0063 & 66.1 \\
\hline $\mathrm{WKM}_{D .5 \%}$ & 0.488 & -1.2 & 0.0045 & 87.9 & 0.337 & -1.3 & 0.0056 & 79.5 & 0.191 & -0.9 & 0.0058 & 69.7 \\
\hline $\mathrm{WKM}_{D .10 \%}$ & 0.490 & -1.0 & 0.0042 & 89.6 & 0.341 & -0.9 & 0.0049 & 82.1 & 0.196 & -0.4 & 0.0052 & 73.9 \\
\hline $\mathrm{WKM}_{D .20 \%}$ & 0.493 & -0.7 & 0.0038 & 91.4 & 0.346 & -0.4 & 0.0044 & 84.3 & 0.203 & 0.3 & 0.0049 & 75.3 \\
\hline $\mathrm{WKM}_{D .30 \%}$ & 0.496 & -0.4 & 0.0037 & 92.3 & 0.351 & 0.1 & 0.0042 & 85.7 & 0.206 & 0.6 & 0.0049 & 75.7 \\
\hline $\mathrm{WKM}_{D .40 \%}$ & 0.499 & -0.1 & 0.0036 & 92.0 & 0.354 & 0.4 & 0.0041 & 87.4 & 0.209 & 0.9 & 0.0050 & 76.4 \\
\hline $\mathrm{WKM}_{D .50 \%}$ & 0.501 & 0.1 & 0.0035 & 92.4 & 0.356 & 0.6 & 0.0041 & 87.4 & 0.210 & 1.0 & 0.0050 & 76.2 \\
\hline $\mathrm{WKM}_{R .3 \%}$ & 0.487 & -1.3 & 0.0048 & 87.5 & 0.335 & -1.5 & 0.0061 & 79.2 & 0.188 & -1.2 & 0.0063 & 73.2 \\
\hline $\mathrm{WKM}_{R .5 \%}$ & 0.488 & -1.2 & 0.0045 & 88.0 & 0.337 & -1.3 & 0.0055 & 82.2 & 0.191 & -0.9 & 0.0056 & 78.0 \\
\hline $\mathrm{WKM}_{R .10 \%}$ & 0.490 & -1.0 & 0.0041 & 89.5 & 0.341 & -0.9 & 0.0048 & 85.6 & 0.196 & -0.4 & 0.0051 & 82.1 \\
\hline $\mathrm{WKM}_{R .20 \%}$ & 0.493 & -0.7 & 0.0038 & 90.1 & 0.346 & -0.4 & 0.0043 & 87.8 & 0.202 & 0.2 & 0.0048 & 85.6 \\
\hline $\mathrm{WKM}_{R .30 \%}$ & 0.495 & -0.5 & 0.0037 & 91.1 & 0.350 & 0.0 & 0.0041 & 89.3 & 0.205 & 0.5 & 0.0048 & 86.5 \\
\hline $\mathrm{WKM}_{R .40 \%}$ & 0.498 & -0.2 & 0.0036 & 91.0 & 0.353 & 0.3 & 0.0040 & 90.0 & 0.208 & 0.8 & 0.0048 & 87.2 \\
\hline $\mathrm{WKM}_{R .50 \%}$ & 0.500 & 0.0 & 0.0035 & 91.1 & 0.355 & 0.5 & 0.0040 & 90.7 & 0.209 & 0.9 & 0.0048 & 87.7 \\
\hline $\mathrm{WKM}_{U .3 \%}$ & 0.488 & -1.2 & 0.0046 & 89.0 & 0.336 & -1.4 & 0.0057 & 83.1 & 0.190 & -1.0 & 0.0058 & 80.1 \\
\hline $\mathrm{WKM}_{U .5 \%}$ & 0.489 & -1.1 & 0.0042 & 89.7 & 0.339 & -1.1 & 0.0050 & 87.6 & 0.194 & -0.6 & 0.0051 & 85.5 \\
\hline $\mathrm{WKM}_{U .10 \%}$ & 0.493 & -0.7 & 0.0038 & 91.7 & 0.346 & -0.4 & 0.0042 & 91.0 & 0.202 & 0.2 & 0.0047 & 89.6 \\
\hline $\mathrm{WKM}_{U .20 \%}$ & 0.498 & -0.2 & 0.0035 & 92.3 & 0.355 & 0.5 & 0.0038 & 93.1 & 0.213 & 1.3 & 0.0047 & 92.4 \\
\hline $\mathrm{WKM}_{U .30 \%}$ & 0.504 & 0.4 & 0.0034 & 93.1 & 0.363 & 1.3 & 0.0038 & 94.1 & 0.220 & 2.0 & 0.0050 & 92.2 \\
\hline $\mathrm{WKM}_{U .40 \%}$ & 0.508 & 0.8 & 0.0034 & 93.2 & 0.369 & 1.9 & 0.0039 & 94.0 & 0.225 & 2.5 & 0.0053 & 91.9 \\
\hline $\mathrm{WKM}_{U .50 \%}$ & 0.512 & 1.2 & 0.0034 & 93.2 & 0.373 & 2.3 & 0.0041 & 93.3 & 0.229 & 2.9 & 0.0056 & 90.9 \\
\hline $\mathrm{WKM}_{\mathcal{N}(0.1)}$ & 0.483 & -1.7 & 0.0058 & 85.6 & 0.327 & -2.3 & 0.0083 & 74.3 & 0.177 & -2.3 & 0.0109 & 57.8 \\
\hline $\mathrm{WKM}_{\mathcal{N}(0.5)}$ & 0.491 & -0.9 & 0.0039 & 91.4 & 0.341 & -0.9 & 0.0047 & 89.3 & 0.192 & -0.8 & 0.0059 & 82.8 \\
\hline $\mathrm{WKM}_{\mathcal{N}(1)}$ & 0.502 & 0.2 & 0.0034 & 92.8 & 0.358 & 0.8 & 0.0039 & 93.1 & 0.211 & 1.1 & 0.0049 & 90.6 \\
\hline $\mathrm{WKM}_{\mathcal{N}(2)}$ & 0.513 & 1.3 & 0.0035 & 92.8 & 0.372 & 2.2 & 0.0042 & 93.0 & 0.225 & 2.5 & 0.0054 & 91.7 \\
\hline $\mathrm{WKM}_{\mathcal{N}(5)}$ & 0.519 & 1.9 & 0.0036 & 92.5 & 0.380 & 3.0 & 0.0045 & 91.4 & 0.233 & 3.3 & 0.0060 & 90.5 \\
\hline
\end{tabular}

ฯ Censoring rate at the time of the true value of $S(t)$

* Average of 1000 point estimates

$\dagger$ Relative bias $(100 \times($ Bias $/ S(t))$

$\ddagger$ Mean square error

$\S$ Coverage rate of 100095 per cent confidence intervals 
Table 17. Monte Carlo results for estimating an hypothetical HIV-1 RNA reduction ( $\mathbf{N = 1 0 0 ) . ~ 3 0 \% ~ L O D = 1 0 0 ~ c o p i e s / m l ~}$ and $\mathbf{7 0} \% \mathrm{LOD}=\mathbf{2 0 0}$ copies $/ \mathbf{m l}$ leading to an overall censoring rate of $\mathbf{5 0 \%}$.

Estimators are derived using the 5 covariates.

\begin{tabular}{|c|c|c|c|c|c|c|c|c|c|c|c|c|}
\hline \multirow[b]{2}{*}{ Method } & \multicolumn{4}{|c|}{$\begin{array}{c}\text { True value: } 0.5 \\
\text { Censoring rate }=30 \%\end{array}$} & \multicolumn{4}{|c|}{$\begin{array}{c}\text { True value: } 0.35 \\
\text { Censoring rate }=40 \%\end{array}$} & \multicolumn{4}{|c|}{$\begin{array}{c}\text { True value: } 0.2 \\
\text { Censoring rate }=47 \%\end{array}$} \\
\hline & Est * & $\mathrm{R} \operatorname{bias}^{\dagger}$ & $\mathrm{MSE}^{\ddagger}$ & $\mathrm{CR}^{\S}$ & Est & $\mathrm{R}$ bias & MSE & $\mathrm{CR}$ & Est & $\mathrm{R}$ bias & MSE & $\mathrm{CR}$ \\
\hline KM FO & 0.497 & -0.3 & 0.0026 & 93.9 & 0.350 & 0.0 & 0.0023 & 94.7 & 0.201 & 0.1 & 0.0017 & 93.7 \\
\hline KM PO & 0.525 & 2.5 & 0.0040 & 92.0 & 0.386 & 3.6 & 0.0053 & 90.7 & 0.239 & 3.9 & 0.0081 & 87.9 \\
\hline $\mathrm{WKM}_{4.1}$ & 0.492 & -0.8 & 0.0055 & 87.7 & 0.367 & 1.7 & 0.0072 & 82.3 & 0.276 & 7.6 & 0.0139 & 69.0 \\
\hline $\mathrm{WKM}_{4.2}$ & 0.536 & 3.6 & 0.0058 & 83.9 & 0.442 & 9.2 & 0.0132 & 60.4 & 0.380 & 18 & 0.0372 & 16.5 \\
\hline $\mathrm{WKM}_{8.1}$ & 0.504 & 0.4 & 0.0048 & 88.5 & 0.391 & 4.1 & 0.0074 & 80.8 & 0.313 & 11.3 & 0.0192 & 51.0 \\
\hline $\mathrm{WKM}_{D .3 \%}$ & 0.484 & -1.6 & 0.0057 & 84.9 & 0.332 & -1.8 & 0.0073 & 72.9 & 0.193 & -0.7 & 0.0084 & 62.2 \\
\hline $\mathrm{WKM}_{D .5 \%}$ & 0.485 & -1.5 & 0.0052 & 86.1 & 0.334 & -1.6 & 0.0066 & 74.9 & 0.195 & -0.5 & 0.0077 & 63.8 \\
\hline $\mathrm{WKM}_{D .10 \%}$ & 0.487 & -1.3 & 0.0047 & 88.1 & 0.339 & -1.1 & 0.0057 & 79.6 & 0.199 & -0.1 & 0.0070 & 66.9 \\
\hline $\mathrm{WKM}_{D .20 \%}$ & 0.492 & -0.8 & 0.0043 & 89.8 & 0.345 & -0.5 & 0.0049 & 82.9 & 0.205 & 0.5 & 0.0066 & 70.1 \\
\hline $\mathrm{WKM}_{D .30 \%}$ & 0.495 & -0.5 & 0.0041 & 90.8 & 0.350 & 0.0 & 0.0046 & 84.7 & 0.209 & 0.9 & 0.0066 & 71.8 \\
\hline $\mathrm{WKM}_{D .40 \%}$ & 0.498 & -0.2 & 0.0039 & 91.5 & 0.354 & 0.4 & 0.0046 & 85.5 & 0.211 & 1.1 & 0.0066 & 72.2 \\
\hline $\mathrm{WKM}_{D .50 \%}$ & 0.501 & 0.1 & 0.0039 & 91.6 & 0.356 & 0.6 & 0.0045 & 85.8 & 0.213 & 1.3 & 0.0067 & 71.8 \\
\hline $\mathrm{WKM}_{R .3 \%}$ & 0.484 & -1.6 & 0.0056 & 85.4 & 0.332 & -1.8 & 0.0073 & 75.2 & 0.193 & -0.7 & 0.0083 & 68.5 \\
\hline $\mathrm{WKM}_{R .5 \%}$ & 0.485 & -1.5 & 0.0051 & 86.4 & 0.334 & -1.6 & 0.0065 & 78.1 & 0.195 & -0.5 & 0.0076 & 73.7 \\
\hline $\mathrm{WKM}_{R .10 \%}$ & 0.487 & -1.3 & 0.0047 & 88.0 & 0.338 & -1.2 & 0.0056 & 83.4 & 0.199 & -0.1 & 0.0068 & 79.1 \\
\hline $\mathrm{WKM}_{R .20 \%}$ & 0.491 & -0.9 & 0.0043 & 89.3 & 0.345 & -0.5 & 0.0049 & 86.4 & 0.205 & 0.5 & 0.0065 & 84.2 \\
\hline $\mathrm{WKM}_{R .30 \%}$ & 0.495 & -0.5 & 0.0040 & 90.1 & 0.349 & -0.1 & 0.0046 & 88.3 & 0.209 & 0.9 & 0.0064 & 85.3 \\
\hline $\mathrm{WKM}_{R .40 \%}$ & 0.497 & -0.3 & 0.0039 & 90.5 & 0.353 & 0.3 & 0.0045 & 89.2 & 0.211 & 1.1 & 0.0065 & 86.3 \\
\hline $\mathrm{WKM}_{R .50 \%}$ & 0.500 & 0.0 & 0.0038 & 90.6 & 0.355 & 0.5 & 0.0045 & 89.6 & 0.213 & 1.3 & 0.0065 & 86.7 \\
\hline $\mathrm{WKM}_{U .3 \%}$ & 0.484 & -1.6 & 0.0053 & 87.6 & 0.334 & -1.6 & 0.0068 & 81.1 & 0.194 & -0.6 & 0.0079 & 76.0 \\
\hline $\mathrm{WKM}_{U .5 \%}$ & 0.486 & -1.4 & 0.0048 & 89.3 & 0.337 & -1.3 & 0.0059 & 85.9 & 0.197 & -0.3 & 0.0071 & 82.7 \\
\hline $\mathrm{WKM}_{U .10 \%}$ & 0.491 & -0.9 & 0.0043 & 91.4 & 0.344 & -0.6 & 0.0049 & 89.9 & 0.205 & 0.5 & 0.0063 & 89.6 \\
\hline $\mathrm{WKM}_{U .20 \%}$ & 0.498 & -0.2 & 0.0039 & 92.4 & 0.355 & 0.5 & 0.0042 & 93.4 & 0.216 & 1.6 & 0.0062 & 91.9 \\
\hline $\mathrm{WKM}_{U .30 \%}$ & 0.505 & 0.5 & 0.0037 & 92.2 & 0.365 & 1.5 & 0.0042 & 93.6 & 0.223 & 2.3 & 0.0066 & 92.2 \\
\hline $\mathrm{WKM}_{U .40 \%}$ & 0.511 & 1.1 & 0.0036 & 93.0 & 0.371 & 2.1 & 0.0044 & 93.0 & 0.228 & 2.8 & 0.0070 & 91.2 \\
\hline $\mathrm{WKM}_{U .50 \%}$ & 0.515 & 1.5 & 0.0037 & 92.9 & 0.376 & 2.6 & 0.0046 & 92.2 & 0.232 & 3.2 & 0.0073 & 90.7 \\
\hline $\mathrm{WKM}_{\mathcal{N}(0.1)}$ & 0.479 & -2.1 & 0.0072 & 82.1 & 0.323 & -2.7 & 0.0104 & 69.6 & 0.180 & -2.0 & 0.0139 & 55.4 \\
\hline $\mathrm{WKM}_{\mathcal{N}(0.5)}$ & 0.489 & -1.1 & 0.0044 & 90.6 & 0.339 & -1.1 & 0.0055 & 89.4 & 0.194 & -0.6 & 0.0079 & 82.4 \\
\hline $\mathrm{WKM}_{\mathcal{N}(1)}$ & 0.503 & 0.3 & 0.0037 & 92.4 & 0.359 & 0.9 & 0.0044 & 93.4 & 0.214 & 1.4 & 0.0067 & 90.6 \\
\hline $\mathrm{WKM}_{\mathcal{N}(2)}$ & 0.516 & 1.6 & 0.0038 & 92.6 & 0.375 & 2.5 & 0.0047 & 92.5 & 0.229 & 2.9 & 0.0073 & 91.1 \\
\hline $\mathrm{WKM}_{\mathcal{N}(5)}$ & 0.523 & 2.3 & 0.0040 & 91.6 & 0.384 & 3.4 & 0.0052 & 91.0 & 0.237 & 3.7 & 0.0079 & 89.4 \\
\hline
\end{tabular}

I Censoring rate at the time of the true value of $S(t)$

* Average of 1000 point estimates

$\dagger$ Relative bias $(100 \times($ Bias $/ S(t))$

$\ddagger$ Mean square error

$\S$ Coverage rate of 100095 per cent confidence intervals 


\section{Statistics \\ in Medicine}

Table 18. Monte Carlo results for estimating an hypothetical HIV-1 RNA reduction $(\mathbf{N}=\mathbf{1 0 0})$. $70 \%$ LOD=200 copies/ml and $\mathbf{3 0} \% \mathrm{LOD}=\mathbf{5 0 0}$ copies $/ \mathbf{m l}$ leading to an overall censoring rate of $\mathbf{5 7 \%}$.

Estimators are derived using the 5 covariates.

\begin{tabular}{|c|c|c|c|c|c|c|c|c|c|c|c|c|}
\hline \multirow[b]{2}{*}{ Method } & \multicolumn{4}{|c|}{$\begin{array}{c}\text { True value: } 0.5 \\
\text { Censoring rate }=39 \%\end{array}$} & \multicolumn{4}{|c|}{$\begin{array}{c}\text { True value: } 0.35 \\
\text { Censoring rate }=49 \%\end{array}$} & \multicolumn{4}{|c|}{$\begin{array}{c}\text { True value: } 0.2 \\
\text { Censoring rate }=56 \%\end{array}$} \\
\hline & Est * & $\mathrm{R}$ bias $^{\dagger}$ & $\mathrm{MSE}^{\ddagger}$ & $\mathrm{CR}^{\S}$ & Est & $\mathrm{R}$ bias & MSE & $\mathrm{CR}$ & Est & $\mathrm{R}$ bias & MSE & $\mathrm{CR}$ \\
\hline KM FO & 0.497 & -0.3 & 0.0026 & 93.9 & 0.350 & 0.0 & 0.0023 & 94.7 & 0.201 & 0.1 & 0.0017 & 93.7 \\
\hline KM PO & 0.534 & 3.4 & 0.0051 & 90.5 & 0.396 & 4.6 & 0.0072 & 88.9 & 0.252 & 5.2 & 0.0140 & 79.4 \\
\hline $\mathrm{WKM}_{4.1}$ & 0.498 & -0.2 & 0.0074 & 82.6 & 0.384 & 3.4 & 0.0101 & 78.5 & 0.312 & 11.2 & 0.0234 & 59.5 \\
\hline $\mathrm{WKM}_{4.2}$ & 0.561 & 6.1 & 0.0088 & 73.9 & 0.481 & 13.1 & 0.0228 & 43.0 & 0.432 & 23.2 & 0.0600 & 8.1 \\
\hline $\mathrm{WKM}_{8.1}$ & 0.515 & 1.5 & 0.0063 & 85.0 & 0.413 & 6.3 & 0.0110 & 74.4 & 0.354 & 15.4 & 0.0317 & 34.5 \\
\hline $\mathrm{WKM}_{D .3 \%}$ & 0.481 & -1.9 & 0.0077 & 78.2 & 0.332 & -1.8 & 0.0098 & 65.7 & 0.200 & 0.0 & 0.0126 & 55.4 \\
\hline $\mathrm{WKM}_{D .5 \%}$ & 0.482 & -1.8 & 0.0069 & 80.5 & 0.334 & -1.6 & 0.0086 & 68.6 & 0.203 & 0.3 & 0.0118 & 58.1 \\
\hline $\mathrm{WKM}_{D .10 \%}$ & 0.485 & -1.5 & 0.0061 & 84.1 & 0.339 & -1.1 & 0.0073 & 73.9 & 0.208 & 0.8 & 0.0110 & 60.5 \\
\hline $\mathrm{WKM}_{D .20 \%}$ & 0.491 & -0.9 & 0.0054 & 86.4 & 0.347 & -0.3 & 0.0063 & 78.3 & 0.215 & 1.5 & 0.0108 & 62.2 \\
\hline $\mathrm{WKM}_{D .30 \%}$ & 0.496 & -0.4 & 0.0050 & 88.2 & 0.353 & 0.3 & 0.0060 & 81.1 & 0.219 & 1.9 & 0.0109 & 61.8 \\
\hline $\mathrm{WKM}_{D .40 \%}$ & 0.500 & 0.0 & 0.0048 & 89.8 & 0.357 & 0.7 & 0.0059 & 82.0 & 0.222 & 2.2 & 0.0111 & 62.2 \\
\hline $\mathrm{WKM}_{D .50 \%}$ & 0.503 & 0.3 & 0.0047 & 90.3 & 0.360 & 1.0 & 0.0059 & 82.8 & 0.223 & 2.3 & 0.0112 & 62.4 \\
\hline $\mathrm{WKM}_{R .3 \%}$ & 0.481 & -1.9 & 0.0076 & 79.5 & 0.333 & -1.7 & 0.0096 & 70.3 & 0.201 & 0.1 & 0.0125 & 63.3 \\
\hline $\mathrm{WKM}_{R .5 \%}$ & 0.482 & -1.8 & 0.0069 & 82.1 & 0.335 & -1.5 & 0.0084 & 75.3 & 0.204 & 0.4 & 0.0117 & 68.2 \\
\hline $\mathrm{WKM}_{R .10 \%}$ & 0.486 & -1.4 & 0.0061 & 84.2 & 0.340 & -1.0 & 0.0072 & 80.7 & 0.209 & 0.9 & 0.0109 & 73.7 \\
\hline $\mathrm{WKM}_{R .20 \%}$ & 0.491 & -0.9 & 0.0054 & 87.1 & 0.347 & -0.3 & 0.0062 & 84.9 & 0.215 & 1.5 & 0.0106 & 77.8 \\
\hline $\mathrm{WKM}_{R .30 \%}$ & 0.495 & -0.5 & 0.0050 & 88.0 & 0.353 & 0.3 & 0.0059 & 87.3 & 0.219 & 1.9 & 0.0108 & 78.2 \\
\hline $\mathrm{WKM}_{R .40 \%}$ & 0.499 & -0.1 & 0.0048 & 89.2 & 0.357 & 0.7 & 0.0058 & 88.2 & 0.221 & 2.1 & 0.0109 & 78.4 \\
\hline $\mathrm{WKM}_{R .50 \%}$ & 0.502 & 0.2 & 0.0047 & 89.8 & 0.359 & 0.9 & 0.0058 & 88.4 & 0.223 & 2.3 & 0.0110 & 78.6 \\
\hline $\mathrm{WKM}_{U .3 \%}$ & 0.482 & -1.8 & 0.0071 & 83.5 & 0.334 & -1.6 & 0.0089 & 77.8 & 0.202 & 0.2 & 0.0119 & 71.3 \\
\hline $\mathrm{WKM}_{U .5 \%}$ & 0.485 & -1.5 & 0.0062 & 87.0 & 0.338 & -1.2 & 0.0075 & 84.4 & 0.207 & 0.7 & 0.0110 & 79.1 \\
\hline $\mathrm{WKM}_{U .10 \%}$ & 0.490 & -1.0 & 0.0054 & 89.1 & 0.346 & -0.4 & 0.0062 & 88.6 & 0.215 & 1.5 & 0.0103 & 84.2 \\
\hline $\mathrm{WKM}_{U .20 \%}$ & 0.500 & 0.0 & 0.0047 & 91.0 & 0.360 & 1.0 & 0.0054 & 92.9 & 0.226 & 2.6 & 0.0107 & 86.4 \\
\hline $\mathrm{WKM}_{U .30 \%}$ & 0.509 & 0.9 & 0.0044 & 92.2 & 0.371 & 2.1 & 0.0055 & 93.1 & 0.234 & 3.4 & 0.0115 & 85.5 \\
\hline $\mathrm{WKM}_{U .40 \%}$ & 0.516 & 1.6 & 0.0044 & 91.6 & 0.378 & 2.8 & 0.0058 & 92.5 & 0.240 & 4.0 & 0.0121 & 85.0 \\
\hline $\mathrm{WKM}_{U .50 \%}$ & 0.522 & 2.2 & 0.0045 & 90.9 & 0.384 & 3.4 & 0.0061 & 91.5 & 0.244 & 4.4 & 0.0127 & 84.5 \\
\hline $\mathrm{WKM}_{\mathcal{N}(0.1)}$ & 0.475 & -2.5 & 0.0105 & 75.4 & 0.320 & -3.0 & 0.0149 & 63.2 & 0.187 & -1.3 & 0.0203 & 49.7 \\
\hline $\mathrm{WKM}_{\mathcal{N}(0.5)}$ & 0.488 & -1.2 & 0.0058 & 88.4 & 0.339 & -1.1 & 0.0073 & 86.7 & 0.203 & 0.3 & 0.0123 & 78.3 \\
\hline $\mathrm{WKM}_{\mathcal{N}(1)}$ & 0.507 & 0.7 & 0.0045 & 91.8 & 0.364 & 1.4 & 0.0056 & 92.7 & 0.225 & 2.5 & 0.0113 & 84.5 \\
\hline $\mathrm{WKM}_{\mathcal{N}(2)}$ & 0.524 & 2.4 & 0.0046 & 90.8 & 0.384 & 3.4 & 0.0062 & 91.6 & 0.242 & 4.2 & 0.0126 & 84.7 \\
\hline $\mathrm{WKM}_{\mathcal{N}(5)}$ & 0.532 & 3.2 & 0.0050 & 89.6 & 0.393 & 4.3 & 0.0070 & 89.1 & 0.250 & 5.0 & 0.0137 & 83.1 \\
\hline
\end{tabular}

ฯ Censoring rate at the time of the true value of $S(t)$

* Average of 1000 point estimates

$\dagger$ Relative bias $(100 \times($ Bias $/ S(t))$

$\ddagger$ Mean square error

$\S$ Coverage rate of 100095 per cent confidence intervals 
Table 19. Monte Carlo results for estimating an hypothetical HIV-1 RNA reduction $(\mathbf{N}=100)$. $30 \%$ LOD=200 copies/ml and $\mathbf{7 0 \%}$ LOD=500 copies/ml leading to an overall censoring rate of $\mathbf{6 4 \%}$.

Estimators are derived using the 5 covariates.

\begin{tabular}{|c|c|c|c|c|c|c|c|c|c|c|c|c|}
\hline \multirow[b]{2}{*}{ Method } & \multicolumn{4}{|c|}{$\begin{array}{c}\text { True value: } 0.5 \\
\text { Censoring rate }=49 \%\end{array}$} & \multicolumn{4}{|c|}{$\begin{array}{c}\text { True value: } 0.35 \\
\text { Censoring rate }=58 \%\end{array}$} & \multicolumn{4}{|c|}{$\begin{array}{c}\text { True value: } 0.2 \\
\text { Censoring rate }=63 \%\end{array}$} \\
\hline & Est * & $\mathrm{R}$ bias $^{\dagger}$ & $\mathrm{MSE}^{\ddagger}$ & $\mathrm{CR}^{\S}$ & Est & $\mathrm{R}$ bias & MSE & $\mathrm{CR}$ & Est & $\mathrm{R}$ bias & MSE & $\mathrm{CR}$ \\
\hline KM FO & 0.497 & -0.3 & 0.0026 & 93 & 0.350 & 0.0 & 0.0023 & & 0.201 & 0.1 & 0.0017 & 93.7 \\
\hline KM PO & 0.544 & 4.4 & 0.0065 & 86.8 & 0.403 & 5.3 & 0.0098 & 87.8 & 0.268 & 6.8 & 0.0232 & 67.5 \\
\hline $\mathrm{WKM}_{4.1}$ & 0.506 & 0.6 & 0.0105 & 75.4 & 0.400 & 5.0 & 0.0156 & 71.5 & 0.344 & 14.4 & 0.0361 & 49.7 \\
\hline $\mathrm{WKM}_{4.2}$ & 0.582 & 8.2 & 0.0128 & 62.4 & 0.509 & 15.9 & 0.0325 & 32.6 & 0.471 & 27.1 & 0.0817 & 5.5 \\
\hline $\mathrm{WKM}_{8.1}$ & 0.528 & 2.8 & 0.0090 & 77.4 & 0.438 & 8.8 & 0.0174 & 64.9 & 0.393 & 19.3 & 0.0483 & 25.8 \\
\hline $\mathrm{WKM}_{D .3 \%}$ & 0.480 & -2.0 & 0.0098 & 73.1 & 0.331 & -1.9 & 0.0129 & 61.0 & 0.216 & 1.6 & 0.0193 & 52.0 \\
\hline $\mathrm{WKM}_{D .5 \%}$ & 0.482 & -1.8 & 0.0089 & 75.8 & 0.334 & -1.6 & 0.0116 & 63.4 & 0.219 & 1.9 & 0.0184 & 53.7 \\
\hline $\mathrm{WKM}_{D .10 \%}$ & 0.487 & -1.3 & 0.0078 & 80.7 & 0.341 & -0.9 & 0.0100 & 68.4 & 0.224 & 2.4 & 0.0177 & 55.2 \\
\hline $\mathrm{WKM}_{D .20 \%}$ & 0.495 & -0.5 & 0.0067 & 84.4 & 0.350 & 0.0 & 0.0088 & 72.8 & 0.231 & 3.1 & 0.0177 & 54.9 \\
\hline $\mathrm{WKM}_{D .30 \%}$ & 0.500 & 0.0 & 0.0062 & 85.9 & 0.357 & 0.7 & 0.0083 & 74.9 & 0.235 & 3.5 & 0.0180 & 54.3 \\
\hline $\mathrm{WKM}_{D .40 \%}$ & 0.505 & 0.5 & 0.0060 & 86.7 & 0.361 & 1.1 & 0.0082 & 75.8 & 0.238 & 3.8 & 0.0183 & 53.6 \\
\hline $\mathrm{WKM}_{D .50 \%}$ & 0.508 & 0.8 & 0.0059 & 87.0 & 0.364 & 1.4 & 0.0082 & 76.4 & 0.240 & 4.0 & 0.0186 & 53.5 \\
\hline $\mathrm{WKM}_{R .3 \%}$ & 0.480 & -2.0 & 0.0098 & 75.1 & 0.331 & -1.9 & 0.0127 & 67.7 & 0.216 & 1.6 & 0.0192 & 60.8 \\
\hline $\mathrm{WKM}_{R .5 \%}$ & 0.482 & -1.8 & 0.0088 & 77.9 & 0.334 & -1.6 & 0.0113 & 71.6 & 0.219 & 1.9 & 0.0182 & 65.8 \\
\hline $\mathrm{WKM}_{R .10 \%}$ & 0.487 & -1.3 & 0.0077 & 82.0 & 0.341 & -0.9 & 0.0098 & 77.1 & 0.224 & 2.4 & 0.0175 & 69.9 \\
\hline $\mathrm{WKM}_{R .20 \%}$ & 0.494 & -0.6 & 0.0068 & 84.5 & 0.350 & 0.0 & 0.0086 & 82.3 & 0.230 & 3.0 & 0.0175 & 73.1 \\
\hline $\mathrm{WKM}_{R .30 \%}$ & 0.499 & -0.1 & 0.0063 & 86.1 & 0.355 & 0.5 & 0.0082 & 84.9 & 0.234 & 3.4 & 0.0178 & 73.2 \\
\hline $\mathrm{WKM}_{R .40 \%}$ & 0.503 & 0.3 & 0.0060 & 87.0 & 0.360 & 1.0 & 0.0081 & 86.0 & 0.237 & 3.7 & 0.0181 & 73.9 \\
\hline $\mathrm{WKM}_{R .50 \%}$ & 0.506 & 0.6 & 0.0058 & 87.1 & 0.362 & 1.2 & 0.0080 & 86.4 & 0.239 & 3.9 & 0.0183 & 74.2 \\
\hline $\mathrm{WKM}_{U .3 \%}$ & 0.482 & -1.8 & 0.0093 & 80.5 & 0.333 & -1.7 & 0.0117 & 74.4 & 0.218 & 1.8 & 0.0186 & 69.1 \\
\hline $\mathrm{WKM}_{U .5 \%}$ & 0.485 & -1.5 & 0.0083 & 84.1 & 0.338 & -1.2 & 0.0103 & 81.7 & 0.222 & 2.2 & 0.0176 & 76.1 \\
\hline $\mathrm{WKM}_{U .10 \%}$ & 0.493 & -0.7 & 0.0070 & 87.5 & 0.349 & -0.1 & 0.0087 & 87.3 & 0.230 & 3.0 & 0.0173 & 80.4 \\
\hline $\mathrm{WKM}_{U .20 \%}$ & 0.505 & 0.5 & 0.0059 & 89.5 & 0.365 & 1.5 & 0.0077 & 91.0 & 0.242 & 4.2 & 0.0181 & 81.6 \\
\hline $\mathrm{WKM}_{U .30 \%}$ & 0.515 & 1.5 & 0.0055 & 90.1 & 0.377 & 2.7 & 0.0078 & 91.2 & 0.250 & 5.0 & 0.0193 & 80.2 \\
\hline $\mathrm{WKM}_{U .40 \%}$ & 0.523 & 2.3 & 0.0055 & 89.9 & 0.385 & 3.5 & 0.0081 & 90.6 & 0.256 & 5.6 & 0.0204 & 79.1 \\
\hline $\mathrm{WKM}_{U .50 \%}$ & 0.530 & 3.0 & 0.0057 & 89.1 & 0.390 & 4.0 & 0.0086 & 90.4 & 0.26 & 6.0 & 0.0212 & 78.4 \\
\hline $\mathrm{WKM}_{\mathcal{N}(0.1)}$ & 0.471 & -2.9 & 0.0138 & 71.3 & 0.315 & -3.5 & 0.0212 & 57.1 & 0.202 & 0.2 & 0.0277 & 53.1 \\
\hline $\mathrm{WKM}_{\mathcal{N}(0.5)}$ & 0.490 & -1.0 & 0.0074 & 86.9 & 0.341 & -0.9 & 0.0105 & 82.8 & 0.221 & 2.1 & 0.0192 & 75.3 \\
\hline $\mathrm{WKM}_{\mathcal{N}(1)}$ & 0.513 & 1.3 & 0.0057 & 89.9 & 0.369 & 1.9 & 0.0080 & 89.4 & 0.242 & 4.2 & 0.0190 & 79.4 \\
\hline $\mathrm{WKM}_{\mathcal{N}(2)}$ & 0.532 & 3.2 & 0.0059 & 89.1 & 0.390 & 4.0 & 0.0087 & 89.5 & 0.259 & 5.9 & 0.0212 & 78.6 \\
\hline $\mathrm{WKM}_{\mathcal{N}(5)}$ & 0.542 & 4.2 & 0.0064 & 87.1 & 0.400 & 5.0 & 0.0096 & 88.3 & 0.267 & 6.7 & 0.0228 & 77.8 \\
\hline
\end{tabular}

I Censoring rate at the time of the true value of $S(t)$

* Average of 1000 point estimates

$\dagger$ Relative bias $(100 \times($ Bias $/ S(t))$

$\ddagger$ Mean square error

$\S$ Coverage rate of 100095 per cent confidence intervals 


\section{Statistics \\ in Medicine}

Table 20. Monte Carlo results for estimating an hypothetical HIV-1 RNA reduction $(\mathbf{N}=100)$. $70 \%$ LOD=100 copies/ml and $\mathbf{3 0} \% \mathrm{LOD}=\mathbf{2 0 0}$ copies/ml leading to an overall censoring rate of $\mathbf{4 5 \%}$.

Estimators are derived using only $Z_{1}$ representing the baseline HIV-1 RNA

\begin{tabular}{|c|c|c|c|c|c|c|c|c|c|c|c|c|}
\hline \multirow[b]{2}{*}{ Method } & \multicolumn{4}{|c|}{$\begin{array}{c}\text { True value: } 0.5 \\
\text { Censoring rate }=24 \%\end{array}$} & \multicolumn{4}{|c|}{$\begin{array}{c}\text { True value: } 0.35 \\
\text { Censoring rate }=34 \%\end{array}$} & \multicolumn{4}{|c|}{$\begin{array}{c}\text { True value: } 0.2 \\
\text { Censoring rate }=42 \%\end{array}$} \\
\hline & Est * & $\mathrm{R}$ bias $^{\dagger}$ & $\mathrm{MSE}^{\ddagger}$ & $\mathrm{CR}^{\S}$ & Est & $\mathrm{R}$ bias & MSE & $\mathrm{CR}$ & Est & $\mathrm{R}$ bias & MSE & $\mathrm{CR}$ \\
\hline KM FO & 0.497 & -0.3 & 0.0026 & 93.9 & 0.350 & 0.0 & 0.0023 & 94.7 & 0.201 & 0.1 & 0.0017 & 93.7 \\
\hline KM PO & 0.521 & 2.1 & 0.0037 & 93.3 & 0.382 & 3.2 & 0.0046 & 92.0 & 0.235 & 3.5 & 0.0062 & 90.6 \\
\hline $\mathrm{WKM}_{4.1}$ & 0.513 & 1.3 & 0.0039 & 92.6 & 0.391 & 4.1 & 0.0086 & 78.3 & 0.299 & 9.9 & 0.0183 & 53.3 \\
\hline $\mathrm{WKM}_{4.2}$ & 0.528 & 2.8 & 0.0052 & 86.7 & 0.423 & 7.3 & 0.0114 & 67.0 & 0.349 & 14.9 & 0.0287 & 34.9 \\
\hline $\mathrm{WKM}_{8.1}$ & 0.545 & 4.5 & 0.0059 & 81.6 & 0.450 & 10 & 0.0146 & 53.3 & 0.386 & 18.6 & 0.0394 & 11.9 \\
\hline $\mathrm{WKM}_{D .3 \%}$ & 0.508 & 0.8 & 0.0055 & 85.6 & 0.366 & 1.6 & 0.0079 & 67.1 & 0.219 & 1.9 & 0.0091 & 55.9 \\
\hline $\mathrm{WKM}_{D .5 \%}$ & 0.508 & 0.8 & 0.0049 & 87.0 & 0.367 & 1.7 & 0.0066 & 73.8 & 0.219 & 1.9 & 0.0075 & 60.8 \\
\hline $\mathrm{WKM}_{D .10 \%}$ & 0.509 & 0.9 & 0.0043 & 90.4 & 0.368 & 1.8 & 0.0054 & 79.9 & 0.221 & 2.1 & 0.0062 & 66.5 \\
\hline $\mathrm{WKM}_{D .20 \%}$ & 0.510 & 1.0 & 0.0038 & 92.4 & 0.370 & 2.0 & 0.0047 & 85.3 & 0.224 & 2.4 & 0.0058 & 69.7 \\
\hline $\mathrm{WKM}_{D .30 \%}$ & 0.511 & 1.1 & 0.0037 & 93.7 & 0.372 & 2.2 & 0.0045 & 86.5 & 0.226 & 2.6 & 0.0058 & 70.7 \\
\hline $\mathrm{WKM}_{D .40 \%}$ & 0.512 & 1.2 & 0.0036 & 93.9 & 0.373 & 2.3 & 0.0044 & 86.9 & 0.227 & 2.7 & 0.0058 & 70.7 \\
\hline $\mathrm{WKM}_{D .50 \%}$ & 0.513 & 1.3 & 0.0036 & 93.6 & 0.374 & 2.4 & 0.0045 & 87.2 & 0.227 & 2.7 & 0.0058 & 71.0 \\
\hline $\mathrm{WKM}_{R .3 \%}$ & 0.508 & 0.8 & 0.0056 & 86.9 & 0.366 & 1.6 & 0.0082 & 71.6 & 0.219 & 1.9 & 0.0094 & 60.5 \\
\hline $\mathrm{WKM}_{R .5 \%}$ & 0.508 & 0.8 & 0.0049 & 87.8 & 0.367 & 1.7 & 0.0067 & 77.0 & 0.220 & 2.0 & 0.0077 & 70.0 \\
\hline $\mathrm{WKM}_{R .10 \%}$ & 0.509 & 0.9 & 0.0043 & 89.5 & 0.368 & 1.8 & 0.0055 & 83.5 & 0.222 & 2.2 & 0.0064 & 78.1 \\
\hline $\mathrm{WKM}_{R .20 \%}$ & 0.510 & 1.0 & 0.0038 & 90.1 & 0.370 & 2.0 & 0.0047 & 86.7 & 0.224 & 2.4 & 0.0058 & 83.2 \\
\hline $\mathrm{WKM}_{R .30 \%}$ & 0.511 & 1.1 & 0.0037 & 90.6 & 0.371 & 2.1 & 0.0045 & 88.0 & 0.226 & 2.6 & 0.0058 & 84.8 \\
\hline $\mathrm{WKM}_{R .40 \%}$ & 0.512 & 1.2 & 0.0036 & 91.5 & 0.372 & 2.2 & 0.0045 & 88.4 & 0.227 & 2.7 & 0.0058 & 85.4 \\
\hline $\mathrm{WKM}_{R .50 \%}$ & 0.513 & 1.3 & 0.0036 & 92.0 & 0.373 & 2.3 & 0.0044 & 89.1 & 0.227 & 2.7 & 0.0058 & 85.9 \\
\hline $\mathrm{WKM}_{U .3 \%}$ & 0.508 & 0.8 & 0.0052 & 89.5 & 0.366 & 1.6 & 0.0074 & 80.0 & 0.219 & 1.9 & 0.0085 & 71.1 \\
\hline $\mathrm{WKM}_{U .5 \%}$ & 0.508 & 0.8 & 0.0046 & 89.8 & 0.367 & 1.7 & 0.0061 & 85.7 & 0.221 & 2.1 & 0.0068 & 81.8 \\
\hline $\mathrm{WKM}_{U .10 \%}$ & 0.509 & 0.9 & 0.0040 & 90.6 & 0.369 & 1.9 & 0.0049 & 90.0 & 0.223 & 2.3 & 0.0058 & 88.8 \\
\hline $\mathrm{WKM}_{U .20 \%}$ & 0.511 & 1.1 & 0.0036 & 92.7 & 0.372 & 2.2 & 0.0043 & 92.0 & 0.227 & 2.7 & 0.0056 & 91.2 \\
\hline $\mathrm{WKM}_{U .30 \%}$ & 0.513 & 1.3 & 0.0035 & 93.4 & 0.374 & 2.4 & 0.0042 & 93.0 & 0.230 & 3.0 & 0.0057 & 91.6 \\
\hline $\mathrm{WKM}_{U .40 \%}$ & 0.515 & 1.5 & 0.0035 & 93.1 & 0.377 & 2.7 & 0.0043 & 92.2 & 0.231 & 3.1 & 0.0058 & 91.2 \\
\hline $\mathrm{WKM}_{U .50 \%}$ & 0.517 & 1.7 & 0.0035 & 93.0 & 0.378 & 2.8 & 0.0044 & 91.7 & 0.233 & 3.3 & 0.0059 & 90.8 \\
\hline $\mathrm{WKM}_{\mathcal{N}(0.1)}$ & 0.506 & 0.6 & 0.0081 & 79.6 & 0.363 & 1.3 & 0.0133 & 54.6 & 0.216 & 1.6 & 0.0192 & 36.9 \\
\hline $\mathrm{WKM}_{\mathcal{N}(0.5)}$ & 0.508 & 0.8 & 0.0041 & 90.9 & 0.367 & 1.7 & 0.0054 & 88.1 & 0.220 & 2.0 & 0.0073 & 80.6 \\
\hline $\mathrm{WKM}_{\mathcal{N}(1)}$ & 0.511 & 1.1 & 0.0035 & 93.1 & 0.372 & 2.2 & 0.0044 & 91.8 & 0.226 & 2.6 & 0.0059 & 89.4 \\
\hline $\mathrm{WKM}_{\mathcal{N}(2)}$ & 0.516 & 1.6 & 0.0035 & 92.8 & 0.377 & 2.7 & 0.0044 & 91.9 & 0.231 & 3.1 & 0.0059 & 91.2 \\
\hline $\mathrm{WKM}_{\mathcal{N}(5)}$ & 0.520 & 2.0 & 0.0036 & 92.6 & 0.381 & 3.1 & 0.0046 & 91.2 & 0.234 & 3.4 & 0.0061 & 90.4 \\
\hline
\end{tabular}

ฯ Censoring rate at the time of the true value of $S(t)$

* Average of 1000 point estimates

$\dagger$ Relative bias $(100 \times($ Bias $/ S(t))$

$\ddagger$ Mean square error

$\S$ Coverage rate of 100095 per cent confidence intervals 
Table 21. Monte Carlo results for estimating an hypothetical HIV-1 RNA reduction ( $\mathbf{N = 1 0 0 ) . ~ 3 0 \% ~ L O D = 1 0 0 ~ c o p i e s / m l ~}$ and $\mathbf{7 0} \% \mathbf{L O D}=\mathbf{2 0 0}$ copies $/ \mathbf{m l}$ leading to an overall censoring rate pf $\mathbf{5 0 \%}$.

Estimators are derived using only $Z_{1}$ representing the baseline HIV-1 RNA

\begin{tabular}{|c|c|c|c|c|c|c|c|c|c|c|c|c|}
\hline \multirow[b]{2}{*}{ Method } & \multicolumn{4}{|c|}{$\begin{array}{c}\text { True value: } 0.5 \\
\text { Censoring rate }=30 \%\end{array}$} & \multicolumn{4}{|c|}{$\begin{array}{c}\text { True value: } 0.35 \\
\text { Censoring rate }=40 \%\end{array}$} & \multicolumn{4}{|c|}{$\begin{array}{c}\text { True value: } 0.2 \\
\text { Censoring rate }=47 \%\end{array}$} \\
\hline & Est * & $\mathrm{R} \operatorname{bias}^{\dagger}$ & $\mathrm{MSE}^{\ddagger}$ & $\mathrm{CR}^{\S}$ & Est & $\mathrm{R}$ bias & MSE & $\mathrm{CR}$ & Est & $\mathrm{R}$ bias & MSE & $\mathrm{CR}$ \\
\hline KM FO & 0.497 & -0.3 & 0.0026 & 93.9 & 0.350 & 0.0 & 0.0023 & 94.7 & 0.201 & 0.1 & 0.0017 & 93.7 \\
\hline KM PO & 0.525 & 2.5 & 0.0040 & 92.0 & 0.386 & 3.6 & 0.0053 & 90.7 & 0.239 & 3.9 & 0.0081 & 87.9 \\
\hline $\mathrm{WKM}_{4.1}$ & 0.516 & 1.6 & 0.0050 & 90.9 & 0.402 & 5.2 & 0.0113 & 68.5 & 0.310 & 11.0 & 0.0234 & 50.0 \\
\hline $\mathrm{WKM}_{4.2}$ & 0.537 & 3.7 & 0.0066 & 81.1 & 0.436 & 8.6 & 0.0145 & 61.3 & 0.366 & 16.6 & 0.0363 & 32.1 \\
\hline $\mathrm{WKM}_{8.1}$ & 0.555 & 5.5 & 0.0073 & 75.6 & 0.465 & 11.5 & 0.0183 & 46.6 & 0.407 & 20.7 & 0.0485 & 9.5 \\
\hline $\mathrm{WKM}_{D .3 \%}$ & 0.508 & 0.8 & 0.0072 & 78.9 & 0.365 & 1.5 & 0.0107 & 59.9 & 0.223 & 2.3 & 0.0127 & 47.0 \\
\hline $\mathrm{WKM}_{D .5 \%}$ & 0.509 & 0.9 & 0.0062 & 84.0 & 0.367 & 1.7 & 0.0087 & 67.6 & 0.223 & 2.3 & 0.0107 & 51.7 \\
\hline $\mathrm{WKM}_{D .10 \%}$ & 0.509 & 0.9 & 0.0051 & 88.5 & 0.369 & 1.9 & 0.0067 & 74.1 & 0.225 & 2.5 & 0.0087 & 59.5 \\
\hline $\mathrm{WKM}_{D .20 \%}$ & 0.511 & 1.1 & 0.0043 & 90.7 & 0.371 & 2.1 & 0.0055 & 80.2 & 0.227 & 2.7 & 0.0080 & 63.8 \\
\hline $\mathrm{WKM}_{D .30 \%}$ & 0.513 & 1.3 & 0.0041 & 91.8 & 0.374 & 2.4 & 0.0052 & 83.2 & 0.229 & 2.9 & 0.0079 & 65.0 \\
\hline $\mathrm{WKM}_{D .40 \%}$ & 0.515 & 1.5 & 0.0040 & 92.8 & 0.375 & 2.5 & 0.0051 & 84.2 & 0.230 & 3.0 & 0.0079 & 65.6 \\
\hline $\mathrm{WKM}_{D .50 \%}$ & 0.516 & 1.6 & 0.0040 & 92.8 & 0.376 & 2.6 & 0.0051 & 84.5 & 0.231 & 3.1 & 0.0079 & 65.7 \\
\hline $\mathrm{WKM}_{R .3 \%}$ & 0.509 & 0.9 & 0.0073 & 82.5 & 0.365 & 1.5 & 0.0107 & 64.8 & 0.223 & 2.3 & 0.0127 & 56.0 \\
\hline $\mathrm{WKM}_{R .5 \%}$ & 0.509 & 0.9 & 0.0062 & 85.0 & 0.366 & 1.6 & 0.0088 & 71.6 & 0.223 & 2.3 & 0.0107 & 64.7 \\
\hline $\mathrm{WKM}_{R .10 \%}$ & 0.510 & 1.0 & 0.0051 & 87.3 & 0.368 & 1.8 & 0.0068 & 78.0 & 0.225 & 2.5 & 0.0088 & 74.7 \\
\hline $\mathrm{WKM}_{R .20 \%}$ & 0.511 & 1.1 & 0.0044 & 89.1 & 0.371 & 2.1 & 0.0056 & 83.8 & 0.227 & 2.7 & 0.0080 & 81.3 \\
\hline $\mathrm{WKM}_{R .30 \%}$ & 0.513 & 1.3 & 0.0041 & 89.7 & 0.373 & 2.3 & 0.0052 & 86.6 & 0.229 & 2.9 & 0.0078 & 83.2 \\
\hline $\mathrm{WKM}_{R .40 \%}$ & 0.514 & 1.4 & 0.0040 & 90.2 & 0.375 & 2.5 & 0.0051 & 87.8 & 0.230 & 3.0 & 0.0078 & 83.6 \\
\hline $\mathrm{WKM}_{R .50 \%}$ & 0.516 & 1.6 & 0.0040 & 90.2 & 0.376 & 2.6 & 0.0051 & 88.4 & 0.231 & 3.1 & 0.0078 & 83.7 \\
\hline $\mathrm{WKM}_{U .3 \%}$ & 0.509 & 0.9 & 0.0066 & 87.9 & 0.366 & 1.6 & 0.0096 & 76.5 & 0.222 & 2.2 & 0.0114 & 68.0 \\
\hline $\mathrm{WKM}_{U .5 \%}$ & 0.510 & 1.0 & 0.0055 & 89.0 & 0.368 & 1.8 & 0.0075 & 81.8 & 0.224 & 2.4 & 0.0094 & 79.0 \\
\hline $\mathrm{WKM}_{U .10 \%}$ & 0.511 & 1.1 & 0.0045 & 90.7 & 0.370 & 2.0 & 0.0057 & 88.1 & 0.226 & 2.6 & 0.0078 & 87.9 \\
\hline $\mathrm{WKM}_{U .20 \%}$ & 0.514 & 1.4 & 0.0039 & 92.2 & 0.374 & 2.4 & 0.0048 & 91.4 & 0.231 & 3.1 & 0.0074 & 89.7 \\
\hline $\mathrm{WKM}_{U .30 \%}$ & 0.516 & 1.6 & 0.0038 & 92.4 & 0.378 & 2.8 & 0.0048 & 92.0 & 0.233 & 3.3 & 0.0076 & 89.7 \\
\hline $\mathrm{WKM}_{U .40 \%}$ & 0.519 & 1.9 & 0.0038 & 92.1 & 0.380 & 3.0 & 0.0049 & 91.6 & 0.235 & 3.5 & 0.0077 & 90.1 \\
\hline $\mathrm{WKM}_{U .50 \%}$ & 0.521 & 2.1 & 0.0038 & 92.1 & 0.382 & 3.2 & 0.0050 & 91.4 & 0.236 & 3.6 & 0.0078 & 90.0 \\
\hline $\mathrm{WKM}_{\mathcal{N}(0.1)}$ & 0.506 & 0.6 & 0.0104 & 73.2 & 0.361 & 1.1 & 0.0176 & 48.2 & 0.216 & 1.6 & 0.0247 & 35.9 \\
\hline $\mathrm{WKM}_{\mathcal{N}(0.5)}$ & 0.510 & 1.0 & 0.0045 & 90.6 & 0.368 & 1.8 & 0.0063 & 86.9 & 0.224 & 2.4 & 0.0096 & 79.8 \\
\hline $\mathrm{WKM}_{\mathcal{N}(1)}$ & 0.514 & 1.4 & 0.0038 & 92.4 & 0.375 & 2.5 & 0.0050 & 91.5 & 0.230 & 3.0 & 0.0078 & 88.4 \\
\hline $\mathrm{WKM}_{\mathcal{N}(2)}$ & 0.520 & 2.0 & 0.0039 & 92.1 & 0.381 & 3.1 & 0.0050 & 91.3 & 0.235 & 3.5 & 0.0078 & 89.8 \\
\hline $\mathrm{WKM}_{\mathcal{N}(5)}$ & 0.524 & 2.4 & 0.0040 & 91.5 & 0.385 & 3.5 & 0.0052 & 90.8 & 0.238 & 3.8 & 0.0080 & 89.2 \\
\hline
\end{tabular}

ฯ Censoring rate at the time of the true value of $S(t)$

* Average of 1000 point estimates

$\dagger$ Relative bias $(100 \times($ Bias $/ S(t))$

$\ddagger$ Mean square error

$\S$ Coverage rate of 100095 per cent confidence intervals 


\section{Statistics \\ in Medicine}

Table 22. Monte Carlo results for estimating an hypothetical HIV-1 RNA reduction $(\mathbf{N}=\mathbf{1 0 0})$. $70 \%$ LOD=200 copies/ml and $\mathbf{3 0} \%$ LOD $=\mathbf{5 0 0}$ copies $/ \mathbf{m l}$ leading to an overall censoring rate of $\mathbf{5 7 \%}$.

Estimators are derived using only $Z_{1}$ representing the baseline HIV-1 RNA

\begin{tabular}{|c|c|c|c|c|c|c|c|c|c|c|c|c|}
\hline \multirow[b]{2}{*}{ Method } & \multicolumn{4}{|c|}{$\begin{array}{c}\text { True value: } 0.5 \\
\text { Censoring rate }=39 \%\end{array}$} & \multicolumn{4}{|c|}{$\begin{array}{c}\text { True value: } 0.35 \\
\text { Censoring rate }=49 \%\end{array}$} & \multicolumn{4}{|c|}{$\begin{array}{c}\text { True value: } 0.2 \\
\text { Censoring rate }=56 \%\end{array}$} \\
\hline & Est * & $\mathrm{R}$ bias $^{\dagger}$ & $\mathrm{MSE}^{\ddagger}$ & $\mathrm{CR}^{\S}$ & Est & $\mathrm{R}$ bias & MSE & $\mathrm{CR}$ & Est & $\mathrm{R}$ bias & MSE & $\mathrm{CR}$ \\
\hline KM FO & 0.497 & -0.3 & 0.0026 & 93.9 & 0.350 & 0.0 & 0.0023 & 94.7 & 0.201 & 0.1 & 0.0017 & 93.7 \\
\hline KM PO & 0.534 & 3.4 & 0.0051 & 90.5 & 0.396 & 4.6 & 0.0072 & 88.9 & 0.252 & 5.2 & 0.0140 & 79.4 \\
\hline $\mathrm{WKM}_{4.1}$ & 0.532 & 3.2 & 0.0073 & 85.9 & 0.442 & 9.2 & 0.0178 & 58.0 & 0.352 & 15.2 & 0.0365 & 40.6 \\
\hline $\mathrm{WKM}_{4.2}$ & 0.563 & 6.3 & 0.0099 & 71.3 & 0.482 & 13.2 & 0.0248 & 42.4 & 0.428 & 22.8 & 0.0609 & 15.5 \\
\hline $\mathrm{WKM}_{8.1}$ & 0.589 & 8.9 & 0.0120 & 60.4 & 0.517 & 16.7 & 0.0328 & 22.7 & 0.476 & 27.6 & 0.0816 & 1.4 \\
\hline $\mathrm{WKM}_{D .3 \%}$ & 0.513 & 1.3 & 0.0090 & 72.8 & 0.369 & 1.9 & 0.0127 & 55.6 & 0.231 & 3.1 & 0.0168 & 45.9 \\
\hline $\mathrm{WKM}_{D .5 \%}$ & 0.514 & 1.4 & 0.0072 & 78.9 & 0.373 & 2.3 & 0.0100 & 62.9 & 0.233 & 3.3 & 0.0148 & 47.9 \\
\hline $\mathrm{WKM}_{D .10 \%}$ & 0.515 & 1.5 & 0.0058 & 85.1 & 0.376 & 2.6 & 0.0078 & 69.6 & 0.236 & 3.6 & 0.0135 & 50.1 \\
\hline $\mathrm{WKM}_{D .20 \%}$ & 0.517 & 1.7 & 0.0051 & 88.3 & 0.379 & 2.9 & 0.0068 & 75.5 & 0.239 & 3.9 & 0.0130 & 51.7 \\
\hline $\mathrm{WKM}_{D .30 \%}$ & 0.520 & 2.0 & 0.0049 & 89.8 & 0.382 & 3.2 & 0.0067 & 77.0 & 0.241 & 4.1 & 0.0131 & 52.3 \\
\hline $\mathrm{WKM}_{D .40 \%}$ & 0.522 & 2.2 & 0.0048 & 91.0 & 0.384 & 3.4 & 0.0066 & 77.9 & 0.242 & 4.2 & 0.0132 & 52.5 \\
\hline $\mathrm{WKM}_{D .50 \%}$ & 0.523 & 2.3 & 0.0048 & 91.1 & 0.385 & 3.5 & 0.0067 & 78.6 & 0.243 & 4.3 & 0.0133 & 52.9 \\
\hline $\mathrm{WKM}_{R .3 \%}$ & 0.514 & 1.4 & 0.0092 & 75.6 & 0.370 & 2.0 & 0.0134 & 58.9 & 0.233 & 3.3 & 0.0176 & 51.4 \\
\hline $\mathrm{WKM}_{R .5 \%}$ & 0.515 & 1.5 & 0.0074 & 81.7 & 0.373 & 2.3 & 0.0105 & 68.8 & 0.234 & 3.4 & 0.0152 & 59.1 \\
\hline $\mathrm{WKM}_{R .10 \%}$ & 0.515 & 1.5 & 0.0059 & 86.0 & 0.375 & 2.5 & 0.0081 & 76.8 & 0.236 & 3.6 & 0.0136 & 67.8 \\
\hline $\mathrm{WKM}_{R .20 \%}$ & 0.517 & 1.7 & 0.0051 & 87.5 & 0.379 & 2.9 & 0.0069 & 83.0 & 0.239 & 3.9 & 0.0130 & 73.7 \\
\hline $\mathrm{WKM}_{R .30 \%}$ & 0.519 & 1.9 & 0.0049 & 88.8 & 0.381 & 3.1 & 0.0067 & 85.0 & 0.241 & 4.1 & 0.0130 & 75.9 \\
\hline $\mathrm{WKM}_{R .40 \%}$ & 0.521 & 2.1 & 0.0048 & 89.1 & 0.383 & 3.3 & 0.0066 & 86.3 & 0.242 & 4.2 & 0.0131 & 76.4 \\
\hline $\mathrm{WKM}_{R .50 \%}$ & 0.522 & 2.2 & 0.0048 & 89.2 & 0.384 & 3.4 & 0.0067 & 86.7 & 0.243 & 4.3 & 0.0132 & 76.7 \\
\hline $\mathrm{WKM}_{U .3 \%}$ & 0.513 & 1.3 & 0.0083 & 83.9 & 0.370 & 2.0 & 0.0118 & 70.8 & 0.232 & 3.2 & 0.0161 & 62.3 \\
\hline $\mathrm{WKM}_{U .5 \%}$ & 0.515 & 1.5 & 0.0066 & 86.7 & 0.374 & 2.4 & 0.0092 & 80.3 & 0.234 & 3.4 & 0.0141 & 75.2 \\
\hline $\mathrm{WKM}_{U .10 \%}$ & 0.516 & 1.6 & 0.0053 & 90.0 & 0.377 & 2.7 & 0.0071 & 88.0 & 0.238 & 3.8 & 0.0129 & 82.4 \\
\hline $\mathrm{WKM}_{U .20 \%}$ & 0.520 & 2.0 & 0.0047 & 91.1 & 0.382 & 3.2 & 0.0063 & 91.4 & 0.242 & 4.2 & 0.0127 & 84.1 \\
\hline $\mathrm{WKM}_{U .30 \%}$ & 0.523 & 2.3 & 0.0046 & 90.8 & 0.386 & 3.6 & 0.0064 & 91.3 & 0.245 & 4.5 & 0.0130 & 84.0 \\
\hline $\mathrm{WKM}_{U .40 \%}$ & 0.527 & 2.7 & 0.0047 & 90.8 & 0.389 & 3.9 & 0.0066 & 90.2 & 0.247 & 4.7 & 0.0133 & 83.9 \\
\hline $\mathrm{WKM}_{U .50 \%}$ & 0.529 & 2.9 & 0.0048 & 91.1 & 0.391 & 4.1 & 0.0068 & 90.0 & 0.249 & 4.9 & 0.0135 & 83.7 \\
\hline $\mathrm{WKM}_{\mathcal{N}(0.1)}$ & 0.512 & 1.2 & 0.0144 & 65.0 & 0.371 & 2.1 & 0.0238 & 42.8 & 0.238 & 3.8 & 0.0348 & 28.7 \\
\hline $\mathrm{WKM}_{\mathcal{N}(0.5)}$ & 0.515 & 1.5 & 0.0056 & 89.5 & 0.376 & 2.6 & 0.0082 & 84.6 & 0.237 & 3.7 & 0.0152 & 75.7 \\
\hline $\mathrm{WKM}_{\mathcal{N}(1)}$ & 0.522 & 2.2 & 0.0047 & 91.6 & 0.384 & 3.4 & 0.0066 & 90.5 & 0.243 & 4.3 & 0.0134 & 83.2 \\
\hline $\mathrm{WKM}_{\mathcal{N}(2)}$ & 0.529 & 2.9 & 0.0048 & 90.8 & 0.391 & 4.1 & 0.0068 & 89.7 & 0.248 & 4.8 & 0.0136 & 83.2 \\
\hline $\mathrm{WKM}_{\mathcal{N}(5)}$ & 0.533 & 3.3 & 0.0051 & 89.6 & 0.395 & 4.5 & 0.0071 & 89.2 & 0.251 & 5.1 & 0.0139 & 83.2 \\
\hline
\end{tabular}

T Censoring rate at the time of the true value of $S(t)$

* Average of 1000 point estimates

$\dagger$ Relative bias $(100 \times($ Bias $/ S(t))$

$\ddagger$ Mean square error

$\S$ Coverage rate of 100095 per cent confidence intervals 
Table 23. Monte Carlo results for estimating an hypothetical HIV-1 RNA reduction ( $\mathbf{N = 1 0 0 ) . ~ 3 0 \% ~ L O D = 2 0 0 ~ c o p i e s / m l ~}$ and $70 \% \mathrm{LOD}=\mathbf{5 0 0}$ copies $/ \mathrm{ml}$ leading to an overall censoring rate of $64 \%$.

Estimators are derived using only $Z_{1}$ representing the baseline HIV-1 RNA

\begin{tabular}{|c|c|c|c|c|c|c|c|c|c|c|c|c|}
\hline \multirow[b]{2}{*}{ Method } & \multicolumn{4}{|c|}{$\begin{array}{c}\text { True value: } 0.5 \\
\text { Censoring rate }=49 \%\end{array}$} & \multicolumn{4}{|c|}{$\begin{array}{c}\text { True value: } 0.35 \\
\text { Censoring rate }=58 \%\end{array}$} & \multicolumn{4}{|c|}{$\begin{array}{c}\text { True value: } 0.2 \\
\text { Censoring rate }=63 \%\end{array}$} \\
\hline & Est * & $\mathrm{R}$ bias $^{\dagger}$ & $\mathrm{MSE}^{\ddagger}$ & $\mathrm{CR}^{\S}$ & Est & $\mathrm{R}$ bias & MSE & $\mathrm{CR}$ & Est & $\mathrm{R}$ bias & MSE & $\mathrm{CR}$ \\
\hline KM FO & 0.497 & -0.3 & 0.0026 & 93.9 & 0.35 & 0.0 & 0.0023 & 94.7 & 0.201 & 0.1 & 0.0017 & 93.7 \\
\hline KM PO & 0.544 & 4.4 & 0.0065 & 86.8 & 0.403 & 5.3 & 0.0098 & 87.8 & 0.268 & 6.8 & 0.0232 & 67.5 \\
\hline $\mathrm{WKM}_{4.1}$ & 0.544 & 4.4 & 0.0121 & 72.3 & 0.457 & 10.7 & 0.0252 & 51.7 & 0.378 & 17.8 & 0.0501 & 42.7 \\
\hline $\mathrm{WKM}_{4.2}$ & 0.578 & 7.8 & 0.0136 & 65.3 & 0.499 & 14.9 & 0.0325 & 42.5 & 0.454 & 25.4 & 0.0764 & 15.1 \\
\hline $\mathrm{WKM}_{8.1}$ & 0.603 & 10.3 & 0.0161 & 54.0 & 0.537 & 18.7 & 0.0415 & 20.9 & 0.504 & 30.4 & 0.0994 & 2.2 \\
\hline $\mathrm{WKM}_{D .3 \%}$ & 0.519 & 1.9 & 0.0122 & 66.0 & 0.376 & 2.6 & 0.0180 & 48.0 & 0.248 & 4.8 & 0.0270 & 39.7 \\
\hline $\mathrm{WKM}_{D .5 \%}$ & 0.520 & 2.0 & 0.0103 & 69.7 & 0.378 & 2.8 & 0.0151 & 54.0 & 0.250 & 5.0 & 0.0248 & 42.1 \\
\hline $\mathrm{WKM}_{D .10 \%}$ & 0.521 & 2.1 & 0.0083 & 77.0 & 0.380 & 3.0 & 0.0121 & 60.7 & 0.252 & 5.2 & 0.0230 & 42.9 \\
\hline $\mathrm{WKM}_{D .20 \%}$ & 0.524 & 2.4 & 0.0070 & 81.2 & 0.384 & 3.4 & 0.0104 & 67.2 & 0.255 & 5.5 & 0.0222 & 43.1 \\
\hline $\mathrm{WKM}_{D .30 \%}$ & 0.527 & 2.7 & 0.0065 & 84.4 & 0.387 & 3.7 & 0.0099 & 69.5 & 0.257 & 5.7 & 0.0222 & 42.7 \\
\hline $\mathrm{WKM}_{D .40 \%}$ & 0.529 & 2.9 & 0.0063 & 86.4 & 0.389 & 3.9 & 0.0098 & 70.5 & 0.258 & 5.8 & 0.0223 & 43.4 \\
\hline $\mathrm{WKM}_{D .50 \%}$ & 0.530 & 3.0 & 0.0062 & 86.7 & 0.390 & 4.0 & 0.0097 & 71.5 & 0.259 & 5.9 & 0.0224 & 43.4 \\
\hline $\mathrm{WKM}_{R .3 \%}$ & 0.519 & 1.9 & 0.0124 & 70.7 & 0.375 & 2.5 & 0.0182 & 55.6 & 0.247 & 4.7 & 0.0271 & 48.6 \\
\hline $\mathrm{WKM}_{R .5 \%}$ & 0.519 & 1.9 & 0.0104 & 75.6 & 0.377 & 2.7 & 0.0153 & 65.2 & 0.249 & 4.9 & 0.0249 & 54.5 \\
\hline $\mathrm{WKM}_{R .10 \%}$ & 0.521 & 2.1 & 0.0084 & 78.9 & 0.380 & 3.0 & 0.0124 & 73.1 & 0.252 & 5.2 & 0.0230 & 60.5 \\
\hline $\mathrm{WKM}_{R .20 \%}$ & 0.524 & 2.4 & 0.0070 & 81.9 & 0.383 & 3.3 & 0.0105 & 79.9 & 0.255 & 5.5 & 0.0222 & 64.9 \\
\hline $\mathrm{WKM}_{R .30 \%}$ & 0.526 & 2.6 & 0.0065 & 84.0 & 0.386 & 3.6 & 0.0100 & 81.6 & 0.257 & 5.7 & 0.0221 & 67.0 \\
\hline $\mathrm{WKM}_{R .40 \%}$ & 0.528 & 2.8 & 0.0063 & 85.2 & 0.388 & 3.8 & 0.0098 & 82.3 & 0.258 & 5.8 & 0.0222 & 67.5 \\
\hline $\mathrm{WKM}_{R .50 \%}$ & 0.530 & 3.0 & 0.0062 & 85.6 & 0.389 & 3.9 & 0.0098 & 82.7 & 0.259 & 5.9 & 0.0222 & 67.9 \\
\hline $\mathrm{WKM}_{U .3 \%}$ & 0.519 & 1.9 & 0.0111 & 79.7 & 0.377 & 2.7 & 0.0166 & 69.1 & 0.249 & 4.9 & 0.0260 & 58.8 \\
\hline $\mathrm{WKM}_{U .5 \%}$ & 0.520 & 2.0 & 0.0091 & 83.5 & 0.378 & 2.8 & 0.0135 & 79.3 & 0.251 & 5.1 & 0.0237 & 69.4 \\
\hline $\mathrm{WKM}_{U .10 \%}$ & 0.523 & 2.3 & 0.0071 & 86.7 & 0.382 & 3.2 & 0.0105 & 85.4 & 0.255 & 5.5 & 0.0219 & 75.8 \\
\hline $\mathrm{WKM}_{U .20 \%}$ & 0.528 & 2.8 & 0.0061 & 87.7 & 0.389 & 3.9 & 0.0091 & 88.9 & 0.259 & 5.9 & 0.0216 & 77.6 \\
\hline $\mathrm{WKM}_{U .30 \%}$ & 0.532 & 3.2 & 0.0059 & 88.2 & 0.393 & 4.3 & 0.0091 & 89.3 & 0.262 & 6.2 & 0.0220 & 77.7 \\
\hline $\mathrm{WKM}_{U .40 \%}$ & 0.536 & 3.6 & 0.0059 & 88.1 & 0.396 & 4.6 & 0.0092 & 89.2 & 0.264 & 6.4 & 0.0222 & 77.9 \\
\hline $\mathrm{WKM}_{U .50 \%}$ & 0.538 & 3.8 & 0.0061 & 87.8 & 0.398 & 4.8 & 0.0093 & 88.7 & 0.265 & 6.5 & 0.0225 & 77.4 \\
\hline $\mathrm{WKM}_{\mathcal{N}(0.1)}$ & 0.518 & 1.8 & 0.0202 & 59.1 & 0.373 & 2.3 & 0.0350 & 34.9 & 0.243 & 4.3 & 0.0455 & 33.9 \\
\hline $\mathrm{WKM}_{\mathcal{N}(0.5)}$ & 0.523 & 2.3 & 0.0074 & 87.6 & 0.381 & 3.1 & 0.0128 & 81.3 & 0.252 & 5.2 & 0.0245 & 69.1 \\
\hline $\mathrm{WKM}_{\mathcal{N}(1)}$ & 0.531 & 3.1 & 0.0060 & 88.3 & 0.390 & 4.0 & 0.0095 & 87.5 & 0.260 & 6.0 & 0.0222 & 77.2 \\
\hline $\mathrm{WKM}_{\mathcal{N}(2)}$ & 0.538 & 3.8 & 0.0061 & 87.7 & 0.398 & 4.8 & 0.0094 & 88.7 & 0.265 & 6.5 & 0.0226 & 77.6 \\
\hline $\mathrm{WKM}_{\mathcal{N}(5)}$ & 0.543 & 4.3 & 0.0064 & 86.9 & 0.402 & 5.2 & 0.0097 & 88.1 & 0.268 & 6.8 & 0.0231 & 77.3 \\
\hline
\end{tabular}

ฯ Censoring rate at the time of the true value of $S(t)$

* Average of 1000 point estimates

$\dagger$ Relative bias $(100 \times($ Bias $/ S(t))$

$\ddagger$ Mean square error

$\S$ Coverage rate of 100095 per cent confidence intervals 


\section{Statistics}

\section{in Medicine}

Table 24. Monte Carlo results for estimating classical survival curve with with dependent censoring $(\mathbf{N}=\mathbf{1 0 0})$.

Overall censoring rate $=35 \%$ and the link functions correctly specified.

\begin{tabular}{|c|c|c|c|c|c|c|c|c|c|c|c|c|}
\hline \multirow[b]{2}{*}{ Method } & \multicolumn{4}{|c|}{$\begin{array}{c}\text { True value: } 0.5 \\
\text { Censoring rate }=26 \%\end{array}$} & \multicolumn{4}{|c|}{$\begin{array}{c}\text { True value: } 0.35 \\
\text { Censoring rate }=29 \%\end{array}$} & \multicolumn{4}{|c|}{$\begin{array}{c}\text { True value: } 0.2 \\
\text { Censoring rate }=32 \%\end{array}$} \\
\hline & Est * & $\mathrm{R}$ bias $^{\dagger}$ & $\mathrm{MSE}^{\ddagger}$ & $\mathrm{CR}^{\S}$ & Est & $\mathrm{R}$ bias & MSE & $\mathrm{CR}$ & Est & $\mathrm{R}$ bias & MSE & $\mathrm{CR}$ \\
\hline KM FO & 0.502 & 0.2 & 0.0024 & 94.0 & 0.352 & 0.2 & 0.0023 & 94.1 & 0.201 & 0.1 & 0.0016 & 93.5 \\
\hline KM PO & 0.569 & 6.9 & 0.0080 & 76.6 & 0.429 & 7.9 & 0.0098 & 73.6 & 0.272 & 7.2 & 0.0083 & 77.2 \\
\hline IPCW & 0.505 & 0.5 & 0.0041 & 90.8 & 0.356 & 0.6 & 0.0038 & 92.2 & 0.204 & 0.4 & 0.0026 & 93.7 \\
\hline KMIB & 0.516 & 1.6 & 0.0037 & 92.7 & 0.368 & 1.8 & 0.0036 & 90.2 & 0.215 & 1.5 & 0.0026 & 93.8 \\
\hline $\mathrm{WKM}_{4.1}$ & 0.511 & 1.1 & 0.0037 & 92.6 & 0.365 & 1.5 & 0.0035 & 90.4 & 0.220 & 2.0 & 0.0029 & 92.8 \\
\hline $\mathrm{WKM}_{4.2}$ & 0.519 & 1.9 & 0.0039 & 91.0 & 0.378 & 2.8 & 0.0042 & 93.1 & 0.238 & 3.8 & 0.0044 & 87.2 \\
\hline $\mathrm{WKM}_{8.1}$ & 0.514 & 1.4 & 0.0039 & 91.0 & 0.374 & 2.4 & 0.0041 & 90.3 & 0.234 & 3.4 & 0.0041 & 87.7 \\
\hline $\mathrm{WKM}_{D .3 \%}$ & 0.507 & 0.7 & 0.0038 & 90.4 & 0.355 & 0.5 & 0.0034 & 90.0 & 0.202 & 0.2 & 0.0023 & 88.5 \\
\hline $\mathrm{WKM}_{D .5 \%}$ & 0.508 & 0.8 & 0.0037 & 91.1 & 0.356 & 0.6 & 0.0034 & 89.6 & 0.203 & 0.3 & 0.0022 & 88.6 \\
\hline $\mathrm{WKM}_{D .10 \%}$ & 0.511 & 1.1 & 0.0037 & 90.6 & 0.360 & 1.0 & 0.0034 & 89.4 & 0.206 & 0.6 & 0.0023 & 89.4 \\
\hline $\mathrm{WKM}_{D .20 \%}$ & 0.517 & 1.7 & 0.0038 & 89.9 & 0.366 & 1.6 & 0.0036 & 88.1 & 0.212 & 1.2 & 0.0024 & 88.3 \\
\hline $\mathrm{WKM}_{D .30 \%}$ & 0.521 & 2.1 & 0.0040 & 89.3 & 0.371 & 2.1 & 0.0038 & 87.7 & 0.216 & 1.6 & 0.0026 & 86.8 \\
\hline $\mathrm{WKM}_{D .40 \%}$ & 0.525 & 2.5 & 0.0042 & 89.2 & 0.375 & 2.5 & 0.0040 & 86.7 & 0.220 & 2.0 & 0.0028 & 86.6 \\
\hline $\mathrm{WKM}_{D .50 \%}$ & 0.529 & 2.9 & 0.0043 & 88.8 & 0.379 & 2.9 & 0.0043 & 90.3 & 0.223 & 2.3 & 0.0030 & 86.1 \\
\hline $\mathrm{WKM}_{R .3 \%}$ & 0.507 & 0.7 & 0.0037 & 90.1 & 0.355 & 0.5 & 0.0034 & 90.6 & 0.202 & 0.2 & 0.0023 & 89.5 \\
\hline $\mathrm{WKM}_{R .5 \%}$ & 0.508 & 0.8 & 0.0037 & 90.3 & 0.357 & 0.7 & 0.0033 & 91.0 & 0.203 & 0.3 & 0.0023 & 90.4 \\
\hline $\mathrm{WKM}_{R .10 \%}$ & 0.511 & 1.1 & 0.0037 & 90.0 & 0.360 & 1.0 & 0.0033 & 90.7 & 0.206 & 0.6 & 0.0023 & 91.0 \\
\hline $\mathrm{WKM}_{R .20 \%}$ & 0.516 & 1.6 & 0.0038 & 89.9 & 0.366 & 1.6 & 0.0035 & 89.9 & 0.212 & 1.2 & 0.0024 & 90.8 \\
\hline $\mathrm{WKM}_{R .30 \%}$ & 0.521 & 2.1 & 0.0039 & 89.5 & 0.370 & 2.0 & 0.0037 & 89.0 & 0.216 & 1.6 & 0.0026 & 90.2 \\
\hline $\mathrm{WKM}_{R .40 \%}$ & 0.524 & 2.4 & 0.0040 & 89.1 & 0.375 & 2.5 & 0.0039 & 89.0 & 0.220 & 2.0 & 0.0028 & 90.1 \\
\hline $\mathrm{WKM}_{R .50 \%}$ & 0.527 & 2.7 & 0.0042 & 88.6 & 0.378 & 2.8 & 0.0041 & 91.6 & 0.223 & 2.3 & 0.0030 & 90.2 \\
\hline $\mathrm{WKM}_{U .3 \%}$ & 0.507 & 0.7 & 0.0037 & 90.9 & 0.356 & 0.6 & 0.0034 & 91.6 & 0.203 & 0.3 & 0.0023 & 91.0 \\
\hline $\mathrm{WKM}_{U .5 \%}$ & 0.510 & 1.0 & 0.0037 & 91.3 & 0.359 & 0.9 & 0.0033 & 92.1 & 0.205 & 0.5 & 0.0022 & 92.3 \\
\hline $\mathrm{WKM}_{U .10 \%}$ & 0.516 & 1.6 & 0.0038 & 91.1 & 0.365 & 1.5 & 0.0034 & 91.1 & 0.211 & 1.1 & 0.0024 & 93.0 \\
\hline $\mathrm{WKM}_{U .20 \%}$ & 0.526 & 2.6 & 0.0042 & 90.1 & 0.376 & 2.6 & 0.0040 & 89.8 & 0.222 & 2.2 & 0.0029 & 91.4 \\
\hline $\mathrm{WKM}_{U .30 \%}$ & 0.535 & 3.5 & 0.0047 & 88.4 & 0.387 & 3.7 & 0.0047 & 87.2 & 0.233 & 3.3 & 0.0037 & 89.5 \\
\hline $\mathrm{WKM}_{U .40 \%}$ & 0.544 & 4.4 & 0.0053 & 85.9 & 0.398 & 4.8 & 0.0057 & 83.6 & 0.242 & 4.2 & 0.0045 & 87.3 \\
\hline $\mathrm{WKM}_{U .50 \%}$ & 0.551 & 5.1 & 0.0059 & 83.6 & 0.406 & 5.6 & 0.0066 & 89.9 & 0.250 & 5.0 & 0.0054 & 84.7 \\
\hline $\mathrm{WKM}_{\mathcal{N}(0.1)}$ & 0.502 & 0.2 & 0.0037 & 90.5 & 0.350 & 0.0 & 0.0035 & 92.0 & 0.198 & -0.2 & 0.0024 & 90.7 \\
\hline $\mathrm{WKM}_{\mathcal{N}(0.5)}$ & 0.513 & 1.3 & 0.0036 & 91.9 & 0.362 & 1.2 & 0.0034 & 90.6 & 0.207 & 0.7 & 0.0023 & 93.1 \\
\hline $\mathrm{WKM}_{\mathcal{N}(1)}$ & 0.533 & 3.3 & 0.0044 & 88.9 & 0.384 & 3.4 & 0.0045 & 82.7 & 0.226 & 2.6 & 0.0033 & 90.4 \\
\hline $\mathrm{WKM}_{\mathcal{N}(2)}$ & 0.554 & 5.4 & 0.0062 & 82.5 & 0.409 & 5.9 & 0.0070 & 74.2 & 0.251 & 5.1 & 0.0055 & 84.7 \\
\hline $\mathrm{WKM}_{\mathcal{N}(5)}$ & 0.566 & 6.6 & 0.0076 & 77.0 & 0.425 & 7.5 & 0.0092 & 92.6 & 0.267 & 6.7 & 0.0077 & 77.4 \\
\hline
\end{tabular}


Table 25. Monte Carlo results for estimating classical survival curve with dependent censoring $(\mathbf{N}=\mathbf{1 0 0})$. Censoring rate $=51 \%$ and the link functions uncorrectly specified.

\begin{tabular}{|c|c|c|c|c|c|c|c|c|c|c|c|c|}
\hline \multirow[b]{2}{*}{ Method } & \multicolumn{4}{|c|}{$\begin{array}{c}\text { True value: } 0.5 \\
\text { Censoring rate }=34 \%\end{array}$} & \multicolumn{4}{|c|}{$\begin{array}{c}\text { True value: } 0.35 \\
\text { Censoring rate }=40 \%\end{array}$} & \multicolumn{4}{|c|}{$\begin{array}{c}\text { True value: } 0.2 \\
\text { Censoring rate }=46 \%\end{array}$} \\
\hline & Est * & $\mathrm{R}$ bias $^{\dagger}$ & $\mathrm{MSE}^{\ddagger}$ & $\mathrm{CR}^{\S}$ & Est & $\mathrm{R}$ bias & MSE & $\mathrm{CR}$ & Est & $\mathrm{R}$ bias & MSE & $\mathrm{CR}$ \\
\hline KM FO & 0.502 & 0.2 & 0.0026 & 93.8 & 0.353 & 0.3 & 0.0025 & 92.0 & 0.202 & 0.2 & 0.0017 & 93.0 \\
\hline KM PO & 0.607 & 10.7 & 0.0148 & 51.8 & 0.474 & 12.4 & 0.0195 & 49.5 & 0.317 & 11.7 & 0.0186 & 38.8 \\
\hline IPCW & 0.502 & 0.2 & 0.0090 & 83.0 & 0.354 & 0.4 & 0.0089 & 83.9 & 0.202 & 0.2 & 0.0069 & 86.8 \\
\hline KMIB & 0.527 & 2.7 & 0.0047 & 92.3 & 0.383 & 3.3 & 0.0054 & 90.0 & 0.235 & 3.5 & 0.0050 & 89.9 \\
\hline $\mathrm{WKM}_{4.1}$ & 0.524 & 2.4 & 0.0053 & 88.9 & 0.390 & 4.0 & 0.0067 & 86.0 & 0.261 & 6.1 & 0.0089 & 78.0 \\
\hline $\mathrm{WKM}_{4.2}$ & 0.539 & 3.9 & 0.0061 & 84.0 & 0.415 & 6.5 & 0.0094 & 75.2 & 0.299 & 9.9 & 0.0150 & 59.2 \\
\hline $\mathrm{WKM}_{8.1}$ & 0.533 & 3.3 & 0.0055 & 86.8 & 0.407 & 5.7 & 0.0083 & 79.2 & 0.286 & 8.6 & 0.0124 & 64.2 \\
\hline $\mathrm{WKM}_{D .3 \%}$ & 0.511 & 1.1 & 0.0047 & 90.2 & 0.362 & 1.2 & 0.0049 & 83.3 & 0.213 & 1.3 & 0.0043 & 75.9 \\
\hline $\mathrm{WKM}_{D .5 \%}$ & 0.514 & 1.4 & 0.0045 & 90.5 & 0.365 & 1.5 & 0.0048 & 83.8 & 0.216 & 1.6 & 0.0042 & 77.7 \\
\hline $\mathrm{WKM}_{D .10 \%}$ & 0.519 & 1.9 & 0.0046 & 90.5 & 0.371 & 2.1 & 0.0048 & 84.9 & 0.222 & 2.2 & 0.0043 & 77.5 \\
\hline $\mathrm{WKM}_{D .20 \%}$ & 0.527 & 2.7 & 0.0048 & 90.5 & 0.380 & 3.0 & 0.0052 & 84.2 & 0.231 & 3.1 & 0.0048 & 75.9 \\
\hline $\mathrm{WKM}_{D .30 \%}$ & 0.534 & 3.4 & 0.0051 & 89.3 & 0.388 & 3.8 & 0.0057 & 81.6 & 0.239 & 3.9 & 0.0055 & 73.3 \\
\hline $\mathrm{WKM}_{D .40 \%}$ & 0.540 & 4.0 & 0.0055 & 88.2 & 0.395 & 4.5 & 0.0063 & 79.8 & 0.244 & 4.4 & 0.0060 & 70.6 \\
\hline $\mathrm{WKM}_{D .50 \%}$ & 0.545 & 4.5 & 0.0059 & 86.8 & 0.401 & 5.1 & 0.0069 & 77.3 & 0.249 & 4.9 & 0.0065 & 68.9 \\
\hline $\mathrm{WKM}_{R .3 \%}$ & 0.512 & 1.2 & 0.0046 & 90.1 & 0.363 & 1.3 & 0.0049 & 84.6 & 0.213 & 1.3 & 0.0042 & 80.6 \\
\hline $\mathrm{WKM}_{R .5 \%}$ & 0.514 & 1.4 & 0.0045 & 90.3 & 0.365 & 1.5 & 0.0048 & 85.5 & 0.216 & 1.6 & 0.0042 & 81.8 \\
\hline $\mathrm{WKM}_{R .10 \%}$ & 0.519 & 1.9 & 0.0045 & 89.8 & 0.371 & 2.1 & 0.0048 & 86.4 & 0.222 & 2.2 & 0.0042 & 83.5 \\
\hline $\mathrm{WKM}_{R .20 \%}$ & 0.526 & 2.6 & 0.0047 & 90.0 & 0.380 & 3.0 & 0.0051 & 86.4 & 0.231 & 3.1 & 0.0047 & 83.3 \\
\hline $\mathrm{WKM}_{R .30 \%}$ & 0.533 & 3.3 & 0.0050 & 89.0 & 0.388 & 3.8 & 0.0056 & 85.2 & 0.239 & 3.9 & 0.0053 & 82.2 \\
\hline $\mathrm{WKM}_{R .40 \%}$ & 0.539 & 3.9 & 0.0053 & 86.2 & 0.395 & 4.5 & 0.0061 & 83.3 & 0.244 & 4.4 & 0.0059 & 81.1 \\
\hline $\mathrm{WKM}_{R .50 \%}$ & 0.544 & 4.4 & 0.0057 & 84.4 & 0.400 & 5.0 & 0.0067 & 81.9 & 0.249 & 4.9 & 0.0064 & 79.4 \\
\hline $\mathrm{WKM}_{U .3 \%}$ & 0.513 & 1.3 & 0.0046 & 91.6 & 0.364 & 1.4 & 0.0048 & 87.1 & 0.215 & 1.5 & 0.0041 & 85.2 \\
\hline $\mathrm{WKM}_{U .5 \%}$ & 0.517 & 1.7 & 0.0045 & 91.7 & 0.368 & 1.8 & 0.0047 & 88.9 & 0.220 & 2.0 & 0.0042 & 86.7 \\
\hline $\mathrm{WKM}_{U .10 \%}$ & 0.526 & 2.6 & 0.0048 & 91.4 & 0.379 & 2.9 & 0.0051 & 89.8 & 0.231 & 3.1 & 0.0046 & 87.9 \\
\hline $\mathrm{WKM}_{U .20 \%}$ & 0.541 & 4.1 & 0.0055 & 88.6 & 0.397 & 4.7 & 0.0063 & 86.8 & 0.250 & 5.0 & 0.0063 & 85.2 \\
\hline $\mathrm{WKM}_{U .30 \%}$ & 0.555 & 5.5 & 0.0067 & 83.0 & 0.414 & 6.4 & 0.0082 & 81.1 & 0.267 & 6.7 & 0.0084 & 80.0 \\
\hline $\mathrm{WKM}_{U .40 \%}$ & 0.568 & 6.8 & 0.0082 & 77.0 & 0.430 & 8.0 & 0.0105 & 73.8 & 0.281 & 8.1 & 0.0107 & 74.5 \\
\hline $\mathrm{WKM}_{U .50 \%}$ & 0.579 & 7.9 & 0.0099 & 71.4 & 0.443 & 9.3 & 0.0128 & 66.2 & 0.292 & 9.2 & 0.0128 & 69.9 \\
\hline $\mathrm{WKM}_{\mathcal{N}(0.1)}$ & 0.505 & 0.5 & 0.0050 & 89.4 & 0.355 & 0.5 & 0.0056 & 84.4 & 0.204 & 0.4 & 0.0052 & 78.8 \\
\hline $\mathrm{WKM}_{\mathcal{N}(0.5)}$ & 0.524 & 2.4 & 0.0045 & 90.7 & 0.375 & 2.5 & 0.0051 & 89.0 & 0.221 & 2.1 & 0.0045 & 86.9 \\
\hline $\mathrm{WKM}_{\mathcal{N}(1)}$ & 0.555 & 5.5 & 0.0067 & 82.0 & 0.410 & 6.0 & 0.0079 & 82.1 & 0.254 & 5.4 & 0.0071 & 83.6 \\
\hline $\mathrm{WKM}_{\mathcal{N}(2)}$ & 0.585 & 8.5 & 0.0109 & 66.7 & 0.447 & 9.7 & 0.0136 & 64.5 & 0.290 & 9.0 & 0.0126 & 70.8 \\
\hline $\mathrm{WKM}_{\mathcal{N}(5)}$ & 0.603 & 10.3 & 0.0140 & 54.0 & 0.468 & 11.8 & 0.0182 & 52.5 & 0.312 & 11.2 & 0.0173 & 59.8 \\
\hline
\end{tabular}




\section{Statistics}

\section{in Medicine}

Table 26. Monte Carlo results for estimating classical survival curve with independent censoring $(\mathbf{N}=\mathbf{1 0 0})$.

Censoring rate $=40 \%$ and the link functions correctly specified.

\begin{tabular}{|c|c|c|c|c|c|c|c|c|c|c|c|c|}
\hline \multirow[b]{2}{*}{ Method } & \multicolumn{4}{|c|}{$\begin{array}{c}\text { True value: } 0.5 \\
\text { Censoring rate }=35 \%\end{array}$} & \multicolumn{4}{|c|}{$\begin{array}{c}\text { True value: } 0.35 \\
\text { Censoring rate }=37 \%\end{array}$} & \multicolumn{4}{|c|}{$\begin{array}{c}\text { True value: } 0.2 \\
\text { Censoring rate }=39 \%\end{array}$} \\
\hline & Est * & $\mathrm{R}$ bias $^{\dagger}$ & $\mathrm{MSE}^{\ddagger}$ & $\mathrm{CR}^{\S}$ & Est & $\mathrm{R}$ bias & MSE & $\mathrm{CR}$ & Est & $\mathrm{R}$ bias & MSE & $\mathrm{CR}$ \\
\hline KM FO & 0.501 & 0.1 & 0.0024 & 94.8 & 0.349 & -0.1 & 0.0021 & 94.6 & 0.198 & -0.2 & 0.0015 & 93.5 \\
\hline KM PO & 0.502 & 0.2 & 0.0037 & 94.5 & 0.350 & 0.0 & 0.0036 & 94.4 & 0.198 & -0.2 & 0.0028 & 93.2 \\
\hline IPCW & 0.502 & 0.2 & 0.0034 & 94.7 & 0.350 & 0.0 & 0.0033 & 93.2 & 0.198 & -0.2 & 0.0027 & 92.3 \\
\hline KMIB & 0.504 & 0.4 & 0.0034 & 95.2 & 0.350 & 0.0 & 0.0034 & 94.7 & 0.197 & -0.3 & 0.0026 & 91.7 \\
\hline $\mathrm{WKM}_{4.1}$ & 0.501 & 0.1 & 0.0035 & 94.5 & 0.350 & 0.0 & 0.0034 & 94.4 & 0.200 & 0.0 & 0.0027 & 93.1 \\
\hline $\mathrm{WKM}_{4.2}$ & 0.502 & 0.2 & 0.0035 & 94.8 & 0.352 & 0.2 & 0.0034 & 93.8 & 0.203 & 0.3 & 0.0028 & 91.3 \\
\hline $\mathrm{WKM}_{8.1}$ & 0.502 & 0.2 & 0.0035 & 94.3 & 0.353 & 0.3 & 0.0035 & 93.8 & 0.204 & 0.4 & 0.0029 & 91.3 \\
\hline $\mathrm{WKM}_{D .3 \%}$ & 0.502 & 0.2 & 0.0038 & 90.6 & 0.351 & 0.1 & 0.0037 & 89.1 & 0.198 & -0.2 & 0.0030 & 80.2 \\
\hline $\mathrm{WKM}_{D .5 \%}$ & 0.502 & 0.2 & 0.0037 & 91.9 & 0.351 & 0.1 & 0.0036 & 88.8 & 0.198 & -0.2 & 0.0029 & 80.6 \\
\hline $\mathrm{WKM}_{D .10 \%}$ & 0.503 & 0.3 & 0.0037 & 92.0 & 0.351 & 0.1 & 0.0035 & 88.8 & 0.198 & -0.2 & 0.0029 & 81.9 \\
\hline $\mathrm{WKM}_{D .20 \%}$ & 0.503 & 0.3 & 0.0036 & 92.5 & 0.351 & 0.1 & 0.0035 & 88.7 & 0.197 & -0.3 & 0.0028 & 82.9 \\
\hline $\mathrm{WKM}_{D .30 \%}$ & 0.503 & 0.3 & 0.0036 & 92.5 & 0.350 & 0.0 & 0.0035 & 88.7 & 0.196 & -0.4 & 0.0028 & 82.8 \\
\hline $\mathrm{WKM}_{D .40 \%}$ & 0.504 & 0.4 & 0.0036 & 92.6 & 0.350 & 0.0 & 0.0035 & 88.9 & 0.196 & -0.4 & 0.0028 & 83.0 \\
\hline $\mathrm{WKM}_{D .50 \%}$ & 0.504 & 0.4 & 0.0036 & 92.5 & 0.350 & 0.0 & 0.0035 & 88.9 & 0.196 & -0.4 & 0.0028 & 83.0 \\
\hline $\mathrm{WKM}_{R .3 \%}$ & 0.502 & 0.2 & 0.0038 & 90.4 & 0.351 & 0.1 & 0.0037 & 89.4 & 0.198 & -0.2 & 0.0029 & 83.6 \\
\hline $\mathrm{WKM}_{R .5 \%}$ & 0.502 & 0.2 & 0.0037 & 91.2 & 0.351 & 0.1 & 0.0035 & 90.2 & 0.198 & -0.2 & 0.0028 & 85.3 \\
\hline $\mathrm{WKM}_{R .10 \%}$ & 0.502 & 0.2 & 0.0036 & 92.3 & 0.350 & 0.0 & 0.0035 & 91.1 & 0.198 & -0.2 & 0.0028 & 87.4 \\
\hline $\mathrm{WKM}_{R .20 \%}$ & 0.503 & 0.3 & 0.0035 & 93.1 & 0.350 & 0.0 & 0.0034 & 91.6 & 0.197 & -0.3 & 0.0027 & 88.7 \\
\hline $\mathrm{WKM}_{R .30 \%}$ & 0.503 & 0.3 & 0.0035 & 93.6 & 0.350 & 0.0 & 0.0034 & 91.8 & 0.196 & -0.4 & 0.0027 & 89.2 \\
\hline $\mathrm{WKM}_{R .40 \%}$ & 0.503 & 0.3 & 0.0035 & 93.6 & 0.350 & 0.0 & 0.0034 & 92.0 & 0.196 & -0.4 & 0.0027 & 89.4 \\
\hline $\mathrm{WKM}_{R .50 \%}$ & 0.503 & 0.3 & 0.0035 & 93.6 & 0.350 & 0.0 & 0.0034 & 92.3 & 0.196 & -0.4 & 0.0027 & 89.5 \\
\hline $\mathrm{WKM}_{U .3 \%}$ & 0.502 & 0.2 & 0.0037 & 91.9 & 0.351 & 0.1 & 0.0036 & 90.7 & 0.199 & -0.1 & 0.0029 & 86.3 \\
\hline $\mathrm{WKM}_{U .5 \%}$ & 0.503 & 0.3 & 0.0036 & 92.6 & 0.351 & 0.1 & 0.0035 & 92.4 & 0.198 & -0.2 & 0.0028 & 89.3 \\
\hline $\mathrm{WKM}_{U .10 \%}$ & 0.503 & 0.3 & 0.0035 & 94.1 & 0.350 & 0.0 & 0.0034 & 93.4 & 0.197 & -0.3 & 0.0027 & 91.5 \\
\hline $\mathrm{WKM}_{U .20 \%}$ & 0.504 & 0.4 & 0.0036 & 94.8 & 0.350 & 0.0 & 0.0035 & 94.1 & 0.195 & -0.5 & 0.0027 & 92.0 \\
\hline $\mathrm{WKM}_{U .30 \%}$ & 0.505 & 0.5 & 0.0036 & 94.9 & 0.349 & -0.1 & 0.0035 & 93.8 & 0.194 & -0.6 & 0.0027 & 91.6 \\
\hline $\mathrm{WKM}_{U .40 \%}$ & 0.505 & 0.5 & 0.0037 & 95.0 & 0.349 & -0.1 & 0.0036 & 93.9 & 0.194 & -0.6 & 0.0027 & 92.2 \\
\hline $\mathrm{WKM}_{U .50 \%}$ & 0.504 & 0.4 & 0.0037 & 94.9 & 0.349 & -0.1 & 0.0036 & 94.1 & 0.194 & -0.6 & 0.0027 & 92.0 \\
\hline $\mathrm{WKM}_{\mathcal{N}(0.1)}$ & 0.502 & 0.2 & 0.0036 & 92.8 & 0.351 & 0.1 & 0.0037 & 91.4 & 0.200 & 0.0 & 0.0030 & 87.0 \\
\hline $\mathrm{WKM}_{\mathcal{N}(0.5)}$ & 0.502 & 0.2 & 0.0035 & 94.7 & 0.350 & 0.0 & 0.0034 & 93.8 & 0.197 & -0.3 & 0.0027 & 91.7 \\
\hline $\mathrm{WKM}_{\mathcal{N}(1)}$ & 0.503 & 0.3 & 0.0035 & 95.2 & 0.349 & -0.1 & 0.0034 & 93.9 & 0.195 & -0.5 & 0.0026 & 92.1 \\
\hline $\mathrm{WKM}_{\mathcal{N}(2)}$ & 0.503 & 0.3 & 0.0036 & 95.0 & 0.350 & 0.0 & 0.0035 & 94.0 & 0.196 & -0.4 & 0.0027 & 91.9 \\
\hline $\mathrm{WKM}_{\mathcal{N}(5)}$ & 0.502 & 0.2 & 0.0037 & 94.4 & 0.350 & 0.0 & 0.0036 & 93.8 & 0.198 & -0.2 & 0.0028 & 92.0 \\
\hline
\end{tabular}


Table 27. Monte Carlo results for estimating classical survival curve with with dependent censoring $(\mathbf{N}=\mathbf{1 0 0})$.

Working failure model mis-specified (using only $Z_{1}, Z_{2}$ and $Z_{3}$ )

Overall censoring rate $=35 \%$ and the link functions correctly specified.

\begin{tabular}{|c|c|c|c|c|c|c|c|c|c|c|c|c|}
\hline \multirow[b]{2}{*}{ Method } & \multicolumn{4}{|c|}{$\begin{array}{c}\text { True value: } 0.5 \\
\text { Censoring rate }=26 \%\end{array}$} & \multicolumn{4}{|c|}{$\begin{array}{c}\text { True value: } 0.35 \\
\text { Censoring rate }=29 \%\end{array}$} & \multicolumn{4}{|c|}{$\begin{array}{c}\text { True value: } 0.2 \\
\text { Censoring rate }=32 \%\end{array}$} \\
\hline & Est * & $\mathrm{R}$ bias $^{\dagger}$ & $\mathrm{MSE}^{\ddagger}$ & $\mathrm{CR}^{\S}$ & Est & $\mathrm{R}$ bias & MSE & $\mathrm{CR}$ & Est & $\mathrm{R}$ bias & MSE & $\mathrm{CR}$ \\
\hline KM FO & 0.502 & 0.2 & 0.0024 & 94.0 & 0.352 & 0.2 & 0.0023 & 94.1 & 0.201 & 0.1 & 0.0016 & 93.5 \\
\hline KM PO & 0.569 & 6.9 & 0.0080 & 76.6 & 0.429 & 7.9 & 0.0098 & 73.6 & 0.272 & 7.2 & 0.0083 & 77.2 \\
\hline IPCW & 0.539 & 3.9 & 0.0053 & 86.0 & 0.389 & 3.9 & 0.0057 & 86.9 & 0.230 & 3.0 & 0.0042 & 90.8 \\
\hline $\mathrm{WKM}_{4.1}$ & 0.526 & 2.6 & 0.0043 & 91.0 & 0.378 & 2.8 & 0.0045 & 91.2 & 0.229 & 2.9 & 0.0038 & 90.3 \\
\hline $\mathrm{WKM}_{4.2}$ & 0.523 & 2.3 & 0.0042 & 90.1 & 0.383 & 3.3 & 0.0048 & 88.4 & 0.242 & 4.2 & 0.0049 & 85.3 \\
\hline $\mathrm{WKM}_{8.1}$ & 0.527 & 2.7 & 0.0045 & 89.3 & 0.385 & 3.5 & 0.0051 & 88.1 & 0.243 & 4.3 & 0.0052 & 84.2 \\
\hline $\mathrm{WKM}_{D .3 \%}$ & 0.518 & 1.8 & 0.0042 & 89.8 & 0.367 & 1.7 & 0.0041 & 87.5 & 0.212 & 1.2 & 0.0029 & 85.0 \\
\hline $\mathrm{WKM}_{D .5 \%}$ & 0.519 & 1.9 & 0.0042 & 89.4 & 0.368 & 1.8 & 0.0040 & 88.2 & 0.213 & 1.3 & 0.0029 & 85.5 \\
\hline $\mathrm{WKM}_{D .10 \%}$ & 0.521 & 2.1 & 0.0041 & 89.6 & 0.371 & 2.1 & 0.0039 & 88.1 & 0.216 & 1.6 & 0.0029 & 85.9 \\
\hline $\mathrm{WKM}_{D .20 \%}$ & 0.525 & 2.5 & 0.0043 & 89.2 & 0.375 & 2.5 & 0.0041 & 88.2 & 0.220 & 2.0 & 0.0030 & 85.3 \\
\hline $\mathrm{WKM}_{D .30 \%}$ & 0.529 & 2.9 & 0.0044 & 88.7 & 0.380 & 3.0 & 0.0043 & 87.5 & 0.224 & 2.4 & 0.0033 & 84.7 \\
\hline $\mathrm{WKM}_{D .40 \%}$ & 0.532 & 3.2 & 0.0046 & 88.4 & 0.383 & 3.3 & 0.0046 & 86.9 & 0.227 & 2.7 & 0.0035 & 83.4 \\
\hline $\mathrm{WKM}_{D .50 \%}$ & 0.535 & 3.5 & 0.0047 & 87.7 & 0.386 & 3.6 & 0.0048 & 86.2 & 0.230 & 3.0 & 0.0037 & 82.5 \\
\hline $\mathrm{WKM}_{R .3 \%}$ & 0.518 & 1.8 & 0.0042 & 89.5 & 0.368 & 1.8 & 0.0041 & 88.3 & 0.212 & 1.2 & 0.0029 & 86.8 \\
\hline $\mathrm{WKM}_{R .5 \%}$ & 0.519 & 1.9 & 0.0041 & 89.1 & 0.369 & 1.9 & 0.0040 & 88.8 & 0.213 & 1.3 & 0.0028 & 88.6 \\
\hline $\mathrm{WKM}_{R .10 \%}$ & 0.522 & 2.2 & 0.0041 & 89.5 & 0.371 & 2.1 & 0.0039 & 89.1 & 0.216 & 1.6 & 0.0028 & 90.3 \\
\hline $\mathrm{WKM}_{R .20 \%}$ & 0.526 & 2.6 & 0.0042 & 89.0 & 0.376 & 2.6 & 0.0041 & 89.4 & 0.221 & 2.1 & 0.0030 & 89.3 \\
\hline $\mathrm{WKM}_{R .30 \%}$ & 0.529 & 2.9 & 0.0043 & 88.1 & 0.380 & 3.0 & 0.0043 & 89.4 & 0.224 & 2.4 & 0.0032 & 89.0 \\
\hline $\mathrm{WKM}_{R .40 \%}$ & 0.532 & 3.2 & 0.0045 & 87.3 & 0.383 & 3.3 & 0.0045 & 88.7 & 0.228 & 2.8 & 0.0034 & 88.3 \\
\hline $\mathrm{WKM}_{R .50 \%}$ & 0.534 & 3.4 & 0.0046 & 86.6 & 0.386 & 3.6 & 0.0047 & 87.8 & 0.230 & 3.0 & 0.0036 & 87.7 \\
\hline $\mathrm{WKM}_{U .3 \%}$ & 0.518 & 1.8 & 0.0041 & 90.9 & 0.368 & 1.8 & 0.0040 & 89.5 & 0.213 & 1.3 & 0.0028 & 89.1 \\
\hline $\mathrm{WKM}_{U .5 \%}$ & 0.521 & 2.1 & 0.0041 & 90.7 & 0.371 & 2.1 & 0.0040 & 90.8 & 0.215 & 1.5 & 0.0028 & 91.9 \\
\hline $\mathrm{WKM}_{U .10 \%}$ & 0.525 & 2.5 & 0.0042 & 90.1 & 0.375 & 2.5 & 0.0040 & 91.5 & 0.220 & 2.0 & 0.0029 & 91.6 \\
\hline $\mathrm{WKM}_{U .20 \%}$ & 0.533 & 3.3 & 0.0046 & 88.7 & 0.385 & 3.5 & 0.0046 & 91.0 & 0.230 & 3.0 & 0.0035 & 90.1 \\
\hline $\mathrm{WKM}_{U .30 \%}$ & 0.540 & 4.0 & 0.0051 & 87.1 & 0.394 & 4.4 & 0.0053 & 88.7 & 0.239 & 3.9 & 0.0042 & 88.7 \\
\hline $\mathrm{WKM}_{U .40 \%}$ & 0.547 & 4.7 & 0.0056 & 84.9 & 0.402 & 5.2 & 0.0062 & 85.6 & 0.247 & 4.7 & 0.0050 & 85.8 \\
\hline $\mathrm{WKM}_{U .50 \%}$ & 0.553 & 5.3 & 0.0062 & 83.0 & 0.410 & 6.0 & 0.0070 & 82.6 & 0.254 & 5.4 & 0.0058 & 83.5 \\
\hline $\mathrm{WKM}_{\mathcal{N}(0.1)}$ & 0.518 & 1.8 & 0.0043 & 89.2 & 0.366 & 1.6 & 0.0042 & 89.4 & 0.209 & 0.9 & 0.0029 & 89.1 \\
\hline $\mathrm{WKM}_{\mathcal{N}(0.5)}$ & 0.526 & 2.6 & 0.0042 & 90.0 & 0.376 & 2.6 & 0.0041 & 90.9 & 0.219 & 1.9 & 0.0029 & 91.6 \\
\hline $\mathrm{WKM}_{\mathcal{N}(1)}$ & 0.541 & 4.1 & 0.0051 & 87.0 & 0.393 & 4.3 & 0.0053 & 88.5 & 0.235 & 3.5 & 0.0040 & 88.9 \\
\hline $\mathrm{WKM}_{\mathcal{N}(2)}$ & 0.557 & 5.7 & 0.0066 & 81.0 & 0.414 & 6.4 & 0.0075 & 80.4 & 0.255 & 5.5 & 0.0061 & 82.9 \\
\hline $\mathrm{WKM}_{\mathcal{N}(5)}$ & 0.567 & 6.7 & 0.0077 & 76.6 & 0.426 & 7.6 & 0.0093 & 74.1 & 0.268 & 6.8 & 0.0078 & 76.7 \\
\hline
\end{tabular}




\section{Statistics}

\section{in Medicine}

Table 28. Monte Carlo results for estimating classical survival curve with dependent censoring $(\mathbf{N}=\mathbf{1 0 0})$.

Working failure model mis-specified (using only $Z_{1}, Z_{2}$ and $Z_{3}$ )

Censoring rate $=51 \%$ and the link functions uncorrectly specified.

\begin{tabular}{|c|c|c|c|c|c|c|c|c|c|c|c|c|}
\hline \multirow[b]{2}{*}{ Method } & \multicolumn{4}{|c|}{$\begin{array}{c}\text { True value: } 0.5 \\
\text { Censoring rate }=34 \%\end{array}$} & \multicolumn{4}{|c|}{$\begin{array}{c}\text { True value: } 0.35 \\
\text { Censoring rate }=40 \%\end{array}$} & \multicolumn{4}{|c|}{$\begin{array}{c}\text { True value: } 0.2 \\
\text { Censoring rate }=46 \%\end{array}$} \\
\hline & Est * & $\mathrm{R}$ bias $^{\dagger}$ & $\mathrm{MSE}^{\ddagger}$ & $\mathrm{CR}^{\S}$ & Est & $\mathrm{R}$ bias & MSE & $\mathrm{CR}$ & Est & $\mathrm{R}$ bias & MSE & $\mathrm{CR}$ \\
\hline KM FO & 0.502 & 0.2 & 0.0026 & 93.8 & 0.353 & 0.3 & 0.0025 & 92.0 & 0.202 & 0.2 & 0.0017 & 93.0 \\
\hline KM PO & 0.607 & 10.7 & 0.0148 & 51.8 & 0.474 & 12.4 & 0.0195 & 49.5 & 0.317 & 11.7 & 0.0186 & 58.8 \\
\hline IPCW & 0.571 & 7.1 & 0.0096 & 71.3 & 0.425 & 7.5 & 0.0117 & 72.6 & 0.261 & 6.1 & 0.0106 & 78.3 \\
\hline $\mathrm{WKM}_{4.1}$ & 0.543 & 4.3 & 0.0063 & 86.4 & 0.405 & 5.5 & 0.0084 & 80.5 & 0.268 & 6.8 & 0.0097 & 77.5 \\
\hline $\mathrm{WKM}_{4.2}$ & 0.545 & 4.5 & 0.0065 & 83.9 & 0.419 & 6.9 & 0.0098 & 74.1 & 0.298 & 9.8 & 0.0148 & 56.6 \\
\hline $\mathrm{WKM}_{8.1}$ & 0.549 & 4.9 & 0.0069 & 81.7 & 0.419 & 6.9 & 0.0101 & 73.3 & 0.293 & 9.3 & 0.0135 & 61.3 \\
\hline $\mathrm{WKM}_{D .3 \%}$ & 0.531 & 3.1 & 0.0057 & 86.6 & 0.382 & 3.2 & 0.0067 & 79.2 & 0.227 & 2.7 & 0.0058 & 72.5 \\
\hline $\mathrm{WKM}_{D .5 \%}$ & 0.532 & 3.2 & 0.0056 & 86.5 & 0.385 & 3.5 & 0.0065 & 79.4 & 0.229 & 2.9 & 0.0056 & 72.8 \\
\hline $\mathrm{WKM}_{D .10 \%}$ & 0.536 & 3.6 & 0.0056 & 86.4 & 0.389 & 3.9 & 0.0065 & 79.2 & 0.235 & 3.5 & 0.0057 & 73.7 \\
\hline $\mathrm{WKM}_{D .20 \%}$ & 0.542 & 4.2 & 0.0059 & 85.3 & 0.396 & 4.6 & 0.0070 & 77.8 & 0.244 & 4.4 & 0.0063 & 69.6 \\
\hline $\mathrm{WKM}_{D .30 \%}$ & 0.547 & 4.7 & 0.0063 & 84.0 & 0.403 & 5.3 & 0.0076 & 76.3 & 0.250 & 5.0 & 0.0069 & 67.2 \\
\hline $\mathrm{WKM}_{D .40 \%}$ & 0.552 & 5.2 & 0.0067 & 82.5 & 0.409 & 5.9 & 0.0082 & 73.7 & 0.254 & 5.4 & 0.0075 & 66.1 \\
\hline $\mathrm{WKM}_{D .50 \%}$ & 0.556 & 5.6 & 0.0071 & 81.5 & 0.413 & 6.3 & 0.0087 & 71.8 & 0.258 & 5.8 & 0.0079 & 65.2 \\
\hline $\mathrm{WKM}_{R .3 \%}$ & 0.531 & 3.1 & 0.0057 & 86.2 & 0.383 & 3.3 & 0.0066 & 80.5 & 0.227 & 2.7 & 0.0058 & 77.1 \\
\hline $\mathrm{WKM}_{R .5 \%}$ & 0.532 & 3.2 & 0.0055 & 85.7 & 0.385 & 3.5 & 0.0064 & 80.5 & 0.230 & 3.0 & 0.0055 & 79.6 \\
\hline $\mathrm{WKM}_{R .10 \%}$ & 0.536 & 3.6 & 0.0055 & 85.6 & 0.389 & 3.9 & 0.0064 & 81.6 & 0.235 & 3.5 & 0.0055 & 80.8 \\
\hline $\mathrm{WKM}_{R .20 \%}$ & 0.541 & 4.1 & 0.0058 & 84.9 & 0.396 & 4.6 & 0.0068 & 80.0 & 0.244 & 4.4 & 0.0061 & 80.1 \\
\hline $\mathrm{WKM}_{R .30 \%}$ & 0.546 & 4.6 & 0.0061 & 82.8 & 0.402 & 5.2 & 0.0073 & 79.0 & 0.250 & 5.0 & 0.0067 & 78.9 \\
\hline $\mathrm{WKM}_{R .40 \%}$ & 0.551 & 5.1 & 0.0065 & 81.5 & 0.408 & 5.8 & 0.0079 & 76.8 & 0.254 & 5.4 & 0.0073 & 77.6 \\
\hline $\mathrm{WKM}_{R .50 \%}$ & 0.555 & 5.5 & 0.0069 & 79.6 & 0.412 & 6.2 & 0.0084 & 75.1 & 0.258 & 5.8 & 0.0077 & 76.3 \\
\hline $\mathrm{WKM}_{U .3 \%}$ & 0.532 & 3.2 & 0.0056 & 87.3 & 0.384 & 3.4 & 0.0065 & 83.0 & 0.229 & 2.9 & 0.0056 & 81.5 \\
\hline $\mathrm{WKM}_{U .5 \%}$ & 0.534 & 3.4 & 0.0055 & 87.9 & 0.387 & 3.7 & 0.0063 & 85.4 & 0.233 & 3.3 & 0.0053 & 86.1 \\
\hline $\mathrm{WKM}_{U .10 \%}$ & 0.540 & 4.0 & 0.0057 & 87.8 & 0.395 & 4.5 & 0.0066 & 85.5 & 0.243 & 4.3 & 0.0059 & 85.9 \\
\hline $\mathrm{WKM}_{U .20 \%}$ & 0.552 & 5.2 & 0.0066 & 83.1 & 0.410 & 6.0 & 0.0080 & 81.8 & 0.260 & 6.0 & 0.0077 & 82.2 \\
\hline $\mathrm{WKM}_{U .30 \%}$ & 0.563 & 6.3 & 0.0077 & 79.3 & 0.424 & 7.4 & 0.0098 & 76.0 & 0.275 & 7.5 & 0.0098 & 77.3 \\
\hline $\mathrm{WKM}_{U .40 \%}$ & 0.574 & 7.4 & 0.0091 & 74.2 & 0.437 & 8.7 & 0.0118 & 70.5 & 0.286 & 8.6 & 0.0117 & 72.0 \\
\hline $\mathrm{WKM}_{U .50 \%}$ & 0.583 & 8.3 & 0.0105 & 68.6 & 0.447 & 9.7 & 0.0137 & 63.0 & 0.295 & 9.5 & 0.0135 & 68.6 \\
\hline $\mathrm{WKM}_{\mathcal{N}(0.1)}$ & 0.530 & 3.0 & 0.0059 & 87.3 & 0.380 & 3.0 & 0.0069 & 82.4 & 0.225 & 2.5 & 0.0064 & 78.5 \\
\hline $\mathrm{WKM}_{\mathcal{N}(0.5)}$ & 0.544 & 4.4 & 0.0059 & 86.6 & 0.396 & 4.6 & 0.0069 & 83.7 & 0.239 & 3.9 & 0.0060 & 84.8 \\
\hline $\mathrm{WKM}_{\mathcal{N}(1)}$ & 0.567 & 6.7 & 0.0083 & 76.5 & 0.425 & 7.5 & 0.0100 & 74.6 & 0.267 & 6.7 & 0.0090 & 79.6 \\
\hline $\mathrm{WKM}_{\mathcal{N}(2)}$ & 0.591 & 9.1 & 0.0118 & 62.6 & 0.454 & 10.4 & 0.0151 & 59.8 & 0.297 & 9.7 & 0.0140 & 67.9 \\
\hline $\mathrm{WKM}_{\mathcal{N}(5)}$ & 0.604 & 10.4 & 0.0142 & 52.7 & 0.470 & 12.0 & 0.0186 & 51.2 & 0.313 & 11.3 & 0.0177 & 59.1 \\
\hline
\end{tabular}


Table 29. Monte Carlo results for estimating classical survival curve with independent censoring $(\mathbf{N}=\mathbf{1 0 0})$.

Working failure model mis-specified (using only $Z_{1}, Z_{2}$ and $Z_{3}$ )

Censoring rate $=40 \%$ and the link functions correctly specified.

\begin{tabular}{|c|c|c|c|c|c|c|c|c|c|c|c|c|}
\hline \multirow[b]{2}{*}{ Method } & \multicolumn{4}{|c|}{$\begin{array}{c}\text { True value: } 0.5 \\
\text { Censoring rate }=35 \%\end{array}$} & \multicolumn{4}{|c|}{$\begin{array}{c}\text { True value: } 0.35 \\
\text { Censoring rate }=37 \%\end{array}$} & \multicolumn{4}{|c|}{$\begin{array}{c}\text { True value: } 0.2 \\
\text { Censoring rate }=39 \%\end{array}$} \\
\hline & Est ${ }^{*}$ & $\mathrm{R} \operatorname{bias}^{\dagger}$ & $\mathrm{MSE}^{\ddagger}$ & $\mathrm{CR}^{\S}$ & Est & $\mathrm{R}$ bias & MSE & $\mathrm{CR}$ & Est & $\mathrm{R}$ bias & MSE & $\mathrm{CR}$ \\
\hline KM FO & 0.501 & 0.1 & 0.0024 & 94.8 & 0.349 & -0.1 & 0.0021 & 94.6 & 0.198 & -0.2 & 0.0015 & 93.5 \\
\hline KM PO & 0.502 & 0.2 & 0.0037 & 94.5 & 0.350 & 0.0 & 0.0036 & 94.4 & 0.198 & -0.2 & 0.0028 & 93.2 \\
\hline IPCW & 0.502 & 0.2 & 0.0036 & 94.1 & 0.350 & 0.0 & 0.0035 & 93.3 & 0.198 & -0.2 & 0.0028 & 92.4 \\
\hline $\mathrm{WKM}_{4.1}$ & 0.502 & 0.2 & 0.0035 & 95 & 0.35 & 0 & 0.0035 & 94.3 & 0.2 & 0 & 0.0028 & 92.2 \\
\hline $\mathrm{WKM}_{4.2}$ & 0.502 & 0.2 & 0.0036 & 94 & 0.352 & 0.2 & 0.0035 & 93.8 & 0.204 & 0.4 & 0.0028 & 92.3 \\
\hline $\mathrm{WKM}_{8.1}$ & 0.503 & 0.3 & 0.0036 & 94.4 & 0.352 & 0.2 & 0.0036 & 93.5 & 0.203 & 0.3 & 0.003 & 91.3 \\
\hline $\mathrm{WKM}_{D .3 \%}$ & 0.503 & 0.3 & 0.0038 & 92.5 & 0.351 & 0.1 & 0.0040 & 87.4 & 0.199 & -0.1 & 0.0033 & 79.2 \\
\hline $\mathrm{WKM}_{D .5 \%}$ & 0.503 & 0.3 & 0.0038 & 92.8 & 0.351 & 0.1 & 0.0038 & 88.4 & 0.199 & -0.1 & 0.0031 & 80.5 \\
\hline $\mathrm{WKM}_{D .10 \%}$ & 0.503 & 0.3 & 0.0037 & 92.9 & 0.351 & 0.1 & 0.0037 & 88.6 & 0.199 & -0.1 & 0.0030 & 81.4 \\
\hline $\mathrm{WKM}_{D .20 \%}$ & 0.504 & 0.4 & 0.0037 & 93.1 & 0.351 & 0.1 & 0.0037 & 88.6 & 0.198 & -0.2 & 0.0030 & 82.1 \\
\hline $\mathrm{WKM}_{D .30 \%}$ & 0.504 & 0.4 & 0.0037 & 93.1 & 0.351 & 0.1 & 0.0036 & 88.6 & 0.198 & -0.2 & 0.0029 & 82.3 \\
\hline $\mathrm{WKM}_{D .40 \%}$ & 0.504 & 0.4 & 0.0037 & 92.9 & 0.351 & 0.1 & 0.0036 & 88.4 & 0.198 & -0.2 & 0.0029 & 82.6 \\
\hline $\mathrm{WKM}_{D .50 \%}$ & 0.504 & 0.4 & 0.0037 & 92.8 & 0.351 & 0.1 & 0.0036 & 88.4 & 0.198 & -0.2 & 0.0029 & 82.5 \\
\hline $\mathrm{WKM}_{R .3 \%}$ & 0.503 & 0.3 & 0.0038 & 92.2 & 0.351 & 0.1 & 0.0039 & 88.2 & 0.199 & -0.1 & 0.0032 & 82.2 \\
\hline $\mathrm{WKM}_{R .5 \%}$ & 0.503 & 0.3 & 0.0037 & 92.9 & 0.351 & 0.1 & 0.0037 & 89.2 & 0.199 & -0.1 & 0.0030 & 84.5 \\
\hline $\mathrm{WKM}_{R .10 \%}$ & 0.503 & 0.3 & 0.0036 & 92.9 & 0.351 & 0.1 & 0.0036 & 90.2 & 0.198 & -0.2 & 0.0029 & 87.2 \\
\hline $\mathrm{WKM}_{R .20 \%}$ & 0.503 & 0.3 & 0.0036 & 92.9 & 0.351 & 0.1 & 0.0035 & 90.7 & 0.198 & -0.2 & 0.0029 & 88.5 \\
\hline $\mathrm{WKM}_{R .30 \%}$ & 0.503 & 0.3 & 0.0036 & 93.1 & 0.351 & 0.1 & 0.0035 & 91.2 & 0.198 & -0.2 & 0.0028 & 88.9 \\
\hline $\mathrm{WKM}_{R .40 \%}$ & 0.503 & 0.3 & 0.0036 & 93.2 & 0.350 & 0.0 & 0.0035 & 91.7 & 0.197 & -0.3 & 0.0028 & 89.0 \\
\hline $\mathrm{WKM}_{R .50 \%}$ & 0.503 & 0.3 & 0.0036 & 93.2 & 0.350 & 0.0 & 0.0035 & 91.8 & 0.197 & -0.3 & 0.0028 & 89.0 \\
\hline $\mathrm{WKM}_{U .3 \%}$ & 0.503 & 0.3 & 0.0037 & 92.8 & 0.351 & 0.1 & 0.0038 & 90.1 & 0.199 & -0.1 & 0.0031 & 86.9 \\
\hline $\mathrm{WKM}_{U .5 \%}$ & 0.503 & 0.3 & 0.0037 & 93.7 & 0.350 & 0.0 & 0.0036 & 91.7 & 0.198 & -0.2 & 0.0029 & 89.5 \\
\hline $\mathrm{WKM}_{U .10 \%}$ & 0.503 & 0.3 & 0.0036 & 94.1 & 0.350 & 0.0 & 0.0035 & 93.8 & 0.198 & -0.2 & 0.0028 & 91.3 \\
\hline $\mathrm{WKM}_{U .20 \%}$ & 0.503 & 0.3 & 0.0037 & 94.4 & 0.350 & 0.0 & 0.0035 & 93.7 & 0.197 & -0.3 & 0.0028 & 92.4 \\
\hline $\mathrm{WKM}_{U .30 \%}$ & 0.504 & 0.4 & 0.0037 & 94.7 & 0.350 & 0.0 & 0.0035 & 93.7 & 0.196 & -0.4 & 0.0027 & 92.5 \\
\hline $\mathrm{WKM}_{U .40 \%}$ & 0.504 & 0.4 & 0.0037 & 94.5 & 0.350 & 0.0 & 0.0036 & 93.8 & 0.196 & -0.4 & 0.0028 & 91.9 \\
\hline $\mathrm{WKM}_{U .50 \%}$ & 0.503 & 0.3 & 0.0038 & 94.4 & 0.35 & 0.0 & 0.0036 & 93.8 & 0.196 & -0.4 & 0.0028 & 92.2 \\
\hline $\mathrm{WKM}_{\mathcal{N}(0.1)}$ & 0.503 & 0.3 & 0.0036 & 94.0 & 0.351 & 0.1 & 0.0037 & 91.5 & 0.199 & -0.1 & 0.0032 & 87.0 \\
\hline $\mathrm{WKM}_{\mathcal{N}(0.5)}$ & 0.503 & 0.3 & 0.0035 & 94.9 & 0.350 & 0.0 & 0.0034 & 93.7 & 0.198 & -0.2 & 0.0028 & 91.3 \\
\hline $\mathrm{WKM}_{\mathcal{N}(1)}$ & 0.503 & 0.3 & 0.0036 & 94.5 & 0.350 & 0.0 & 0.0034 & 93.9 & 0.197 & -0.3 & 0.0027 & 92.2 \\
\hline $\mathrm{WKM}_{\mathcal{N}(2)}$ & 0.503 & 0.3 & 0.0037 & 94.9 & 0.350 & 0.0 & 0.0035 & 93.9 & 0.198 & -0.2 & 0.0028 & 92.3 \\
\hline $\mathrm{WKM}_{\mathcal{N}(5)}$ & 0.502 & 0.2 & 0.0037 & 94.2 & 0.350 & 0.0 & 0.0036 & 93.8 & 0.198 & -0.2 & 0.0028 & 92.0 \\
\hline
\end{tabular}




\section{Statistics in Medicine}

Table 30. Monte Carlo results for estimating an hypothetical HIV-1 RNA reduction ( $\mathbf{N}=\mathbf{2 0 0})$. 70\% $\mathrm{LOD}=\mathbf{1 0 0} \mathrm{copies} / \mathrm{ml}$ and $\mathbf{3 0} \% \mathrm{LOD}=\mathbf{2 0 0}$ copies/ml leading to an overall censoring rate of $\mathbf{4 5 \%}$

Using Risk Score instead of principal component analysis (PCA).

Estimators are derived using the 5 covariates.

\begin{tabular}{|c|c|c|c|c|c|c|c|c|c|c|c|c|}
\hline \multirow[b]{2}{*}{ Method } & \multicolumn{4}{|c|}{$\begin{array}{c}\text { True value: } 0.5 \\
\text { Censoring rate }=24 \%\end{array}$} & \multicolumn{4}{|c|}{$\begin{array}{c}\text { True value: } 0.35 \\
\text { Censoring rate }=34 \%\end{array}$} & \multicolumn{4}{|c|}{$\begin{array}{c}\text { True value: } 0.2 \\
\text { Censoring rate }=42 \%\end{array}$} \\
\hline & Est ${ }^{*}$ & $\mathrm{R}$ bias $^{\dagger}$ & $\mathrm{MSE}^{\ddagger}$ & $\mathrm{CR}^{\S}$ & Est & $\mathrm{R}$ bias & MSE & $\mathrm{CR}$ & Est & $\mathrm{R}$ bias & MSE & $\mathrm{CR}$ \\
\hline KM FO & 0.500 & 0.0 & 0.0014 & 93.6 & 0.351 & 0.1 & 0.0012 & 95.5 & 0.202 & 0.2 & 0.0009 & 93.7 \\
\hline KM PO & 0.523 & 2.3 & 0.0022 & 90.0 & 0.381 & 3.1 & 0.0028 & 88.9 & 0.237 & 3.7 & 0.0038 & 87.8 \\
\hline $\mathrm{WKM}_{U .2 .5 \%}$ & 0.502 & 0.2 & 0.0019 & 91.2 & 0.352 & 0.2 & 0.0021 & 89.6 & 0.208 & 0.8 & 0.0026 & 85.4 \\
\hline $\mathrm{WKM}_{U .5 \%}$ & 0.502 & 0.2 & 0.0019 & 92.4 & 0.354 & 0.4 & 0.0021 & 91.3 & 0.210 & 1.0 & 0.0025 & 89.7 \\
\hline $\mathrm{WKM}_{U .10 \%}$ & 0.504 & 0.4 & 0.0018 & 92.9 & 0.356 & 0.6 & 0.0020 & 92.4 & 0.215 & 1.5 & 0.0025 & 90.7 \\
\hline $\mathrm{WKM}_{U .15 \%}$ & 0.506 & 0.6 & 0.0018 & 93.0 & 0.359 & 0.9 & 0.0020 & 92.8 & 0.218 & 1.8 & 0.0026 & 91.0 \\
\hline $\mathrm{WKM}_{U .20 \%}$ & 0.507 & 0.7 & 0.0018 & 93.2 & 0.362 & 1.2 & 0.0020 & 92.3 & 0.221 & 2.1 & 0.0028 & 90.7 \\
\hline $\mathrm{WKM}_{U .30 \%}$ & 0.511 & 1.1 & 0.0019 & 92.9 & 0.367 & 1.7 & 0.0021 & 92.2 & 0.225 & 2.5 & 0.0030 & 89.9 \\
\hline $\mathrm{WKM}_{U .40 \%}$ & 0.514 & 1.4 & 0.0019 & 92.6 & 0.371 & 2.1 & 0.0023 & 91.4 & 0.229 & 2.9 & 0.0032 & 89.4 \\
\hline $\mathrm{WKM}_{U .50 \%}$ & 0.516 & 1.6 & 0.0020 & 92.2 & 0.374 & 2.4 & 0.0024 & 90.8 & 0.231 & 3.1 & 0.0034 & 88.6 \\
\hline $\mathrm{WKM}_{\mathcal{N}(0.1}$ & 0.500 & 0.0 & 0.0019 & 91.8 & 0.350 & 0.0 & 0.0023 & 90.5 & 0.204 & 0.4 & 0.0033 & 81.7 \\
\hline $\mathrm{WKM}_{\mathcal{N}(0.5)}$ & 0.505 & 0.5 & 0.0018 & 93.0 & 0.357 & 0.7 & 0.0020 & 92.7 & 0.211 & 1.1 & 0.0026 & 90.3 \\
\hline $\mathrm{WKM}_{\mathcal{N}(1)}$ & 0.513 & 1.3 & 0.0019 & 92.4 & 0.367 & 1.7 & 0.0022 & 91.9 & 0.222 & 2.2 & 0.0029 & 90.1 \\
\hline $\mathrm{WKM}_{\mathcal{N}(2)}$ & 0.519 & 1.9 & 0.0021 & 90.9 & 0.376 & 2.6 & 0.0026 & 90.1 & 0.231 & 3.1 & 0.0034 & 88.8 \\
\hline $\mathrm{WKM}_{\mathcal{N}(5)}$ & 0.522 & 2.2 & 0.0022 & 90.1 & 0.380 & 3.0 & 0.0028 & 88.4 & 0.236 & 3.6 & 0.0037 & 87.8 \\
\hline
\end{tabular}

I Censoring rate at the time of the true value of $S(t)$

* Average of 1000 point estimates

$\dagger$ Relative bias $(100 \times($ Bias $/ S(t))$

$\ddagger$ Mean square error

$\S$ Coverage rate of 100095 per cent confidence intervals 


\section{Statistics} in Medicine

Table 31. Monte Carlo results for estimating an hypothetical HIV-1 RNA reduction ( $\mathbf{N = 2 0 0})$. 30\% LOD=100 copies/ml and $\mathbf{7 0} \% \mathrm{LOD}=\mathbf{2 0 0}$ copies $/ \mathbf{m l}$ leading to an overall censoring rate of $\mathbf{5 0 \%}$

Using Risk Score instead of principal component analysis (PCA).

Estimators are derived using the 5 covariates.

True value: 0.5

Censoring rate $=30 \%$ व

\begin{tabular}{|c|c|c|c|}
\hline \multirow[b]{2}{*}{ Method } & \multicolumn{3}{|c|}{ Censoring rate $=30^{\circ}$} \\
\hline & Est $*$ & $\mathrm{R}_{\text {bias }^{\dagger}}^{\dagger}$ & MS \\
\hline KM FO & 0.500 & 0.0 & 0.00 \\
\hline KM PO & 0.528 & 2.8 & .00 \\
\hline $\mathrm{WKM}_{U .2 .5 \%}$ & 0.503 & 0.3 & 0.00 \\
\hline $\mathrm{WKM}_{U .5 \%}$ & 0.504 & 0.4 & 0.00 \\
\hline $\mathrm{WKM}_{U .10 \%}$ & 0.506 & 0.6 & 0.00 \\
\hline $\mathrm{WKM}_{U .15 \%}$ & 0.508 & 0.8 & 0.00 \\
\hline $\mathrm{WKM}_{U .20 \%}$ & 0.510 & 1.0 & 0.00 \\
\hline $\mathrm{WKM}_{U .30 \%}$ & 0.514 & 1.4 & 0.00 \\
\hline $\mathrm{WKM}_{U .40 \%}$ & 0.517 & 1.7 & 0.00 \\
\hline $\mathrm{WKM}_{U .50 \%}$ & 0.520 & 2.0 & 000 \\
\hline $\mathrm{WKM}_{\mathcal{N}(0.1)}$ & 0.501 & 0.1 & 0.00 \\
\hline $\mathrm{WKM}_{\mathcal{N}(0.5)}$ & 0.507 & 0.7 & v \\
\hline $\mathrm{WKM}_{\mathcal{N}(1)}$ & 0.516 & 1.6 & 0.00 \\
\hline $\mathrm{WKM}_{\mathcal{N}(2)}$ & 0.524 & 2.4 & 0.00 \\
\hline $\mathrm{WKM}_{\mathcal{N}(5)}$ & 0.527 & 2.7 & 0.00 \\
\hline $\begin{array}{l}\text { Average of } 100 \\
\text { Relative bias (1 } \\
\text { Mean square er }\end{array}$ & $\begin{array}{l}\text { time o } \\
\text { t estin } \\
\text { (Bias }\end{array}$ & e $v^{2}$ & \\
\hline
\end{tabular}

True value: 0.35

Censoring rate $=40 \%$

Est $\mathrm{R}$ bias MSE CR

True value: 0.2

Censoring rate $=47 \%$

\begin{tabular}{cccc}
\multicolumn{4}{c}{ Censoring rate=47\% } \\
\hline Est & R bias & MSE & CR \\
0.202 & 0.2 & 0.0009 & 93.7 \\
0.242 & 4.2 & 0.0051 & 85.8 \\
0.211 & 1.1 & 0.0036 & 84.5 \\
0.213 & 1.3 & 0.0034 & 88.0 \\
0.218 & 1.8 & 0.0034 & 90.0 \\
0.222 & 2.2 & 0.0036 & 89.6 \\
0.225 & 2.5 & 0.0038 & 89.6 \\
0.230 & 3.0 & 0.0040 & 88.3 \\
0.233 & 3.3 & 0.0043 & 87.6 \\
0.236 & 3.6 & 0.0045 & 87.3 \\
0.204 & 0.4 & 0.0047 & 78.6 \\
0.213 & 1.3 & 0.0036 & 88.5 \\
0.226 & 2.6 & 0.0040 & 88.9 \\
0.236 & 3.6 & 0.0046 & 86.7 \\
0.241 & 4.1 & 0.0050 & 85.3
\end{tabular}




\section{Statistics \\ in Medicine}

Table 32. Monte Carlo results for estimating an hypothetical HIV-1 RNA reduction ( $\mathbf{N = 2 0 0})$. 70\% LOD=200 copies/ml and $\mathbf{3 0} \% \mathrm{LOD}=\mathbf{5 0 0}$ copies $/ \mathrm{ml}$ leading to an overall censoring rate of $\mathbf{5 7 \%}$

Using Risk Score instead of principal component analysis (PCA).

Estimators are derived using the 5 covariates.

\begin{tabular}{|c|c|c|c|c|c|c|c|c|c|c|c|c|}
\hline \multirow[b]{2}{*}{ Method } & \multicolumn{4}{|c|}{$\begin{array}{c}\text { True value: } 0.5 \\
\text { Censoring rate }=39 \%\end{array}$} & \multicolumn{4}{|c|}{$\begin{array}{c}\text { True value: } 0.35 \\
\text { Censoring rate }=49 \%\end{array}$} & \multicolumn{4}{|c|}{$\begin{array}{c}\text { True value: } 0.2 \\
\text { Censoring rate }=56 \%\end{array}$} \\
\hline & Est * & $\mathrm{R}$ bias $^{\dagger}$ & $\mathrm{MSE}^{\ddagger}$ & $\mathrm{CR}^{\S}$ & Est & $\mathrm{R}$ bias & MSE & $\mathrm{CR}$ & Est & $\mathrm{R}$ bias & MSE & $\mathrm{CR}$ \\
\hline KM FO & 0.500 & 0.0 & 0.0014 & & 0.351 & 0.1 & 0.0012 & 95.5 & 0.202 & 0.2 & 0.0009 & 93.7 \\
\hline KM PO & 0.536 & 3.6 & 0.0033 & 84.6 & 0.396 & 4.6 & 0.0048 & 84.7 & 0.252 & 5.2 & 0.0087 & 81.3 \\
\hline $\mathrm{WKM}_{U .2 .5 \%}$ & 0.502 & 0.2 & 0.0026 & 89.1 & 0.356 & 0.6 & 0.0034 & 87.3 & 0.217 & 1.7 & 0.0059 & 80.6 \\
\hline $\mathrm{WKM}_{U .5 \%}$ & 0.504 & 0.4 & 0.0024 & 91.0 & 0.359 & 0.9 & 0.0032 & 89.8 & 0.221 & 2.1 & 0.0059 & 86.0 \\
\hline $\mathrm{WKM}_{U .10 \%}$ & 0.507 & 0.7 & 0.0024 & 92.0 & 0.364 & 1.4 & 0.0030 & 91.9 & 0.226 & 2.6 & 0.0060 & 87.5 \\
\hline $\mathrm{WKM}_{U .15 \%}$ & 0.510 & 1.0 & 0.0023 & 91.7 & 0.368 & 1.8 & 0.0031 & 92.4 & 0.230 & 3.0 & 0.0063 & 87.7 \\
\hline $\mathrm{WKM}_{U .20 \%}$ & 0.513 & 1.3 & 0.0024 & 91.9 & 0.372 & 2.2 & 0.0032 & 92.1 & 0.234 & 3.4 & 0.0066 & 87.0 \\
\hline $\mathrm{WKM}_{U .30 \%}$ & 0.518 & 1.8 & 0.0024 & 91.4 & 0.378 & 2.8 & 0.0035 & 91.1 & 0.239 & 3.9 & 0.0071 & 85.5 \\
\hline $\mathrm{WKM}_{U .40 \%}$ & 0.522 & 2.2 & 0.0026 & 90.2 & 0.383 & 3.3 & 0.0037 & 89.9 & 0.242 & 4.2 & 0.0075 & 84.6 \\
\hline $\mathrm{WKM}_{U .50 \%}$ & 0.526 & 2.6 & 0.0027 & 89.1 & 0.387 & 3.7 & 0.0040 & 88.5 & 0.245 & 4.5 & 0.0078 & 84.3 \\
\hline $\mathrm{WKM}_{\mathcal{N}(0.1)}$ & 0.500 & 0.0 & 0.0026 & 90.5 & 0.351 & 0.1 & 0.0040 & 86.0 & 0.206 & 0.6 & 0.0079 & 74.4 \\
\hline $\mathrm{WKM}_{\mathcal{N}(0.5)}$ & 0.509 & 0.9 & 0.0023 & 92.3 & 0.363 & 1.3 & 0.0031 & 91.9 & 0.220 & 2.0 & 0.0065 & 85.8 \\
\hline $\mathrm{WKM}_{\mathcal{N}(1)}$ & 0.521 & 2.1 & 0.0025 & 90.7 & 0.378 & 2.8 & 0.0036 & 90.3 & 0.235 & 3.5 & 0.0071 & 85.3 \\
\hline $\mathrm{WKM}_{\mathcal{N}(2)}$ & 0.530 & 3.0 & 0.0030 & 86.7 & 0.390 & 4.0 & 0.0043 & 87.5 & 0.246 & 4.6 & 0.0080 & 84.3 \\
\hline $\mathrm{WKM}_{\mathcal{N}(5)}$ & 0.535 & 3.5 & 0.0032 & 85.1 & 0.395 & 4.5 & 0.0047 & 84.7 & 0.251 & 5.1 & 0.0086 & 83.1 \\
\hline
\end{tabular}

ฯ Censoring rate at the time of the true value of $S(t)$

* Average of 1000 point estimates

$\dagger$ Relative bias $(100 \times($ Bias $/ S(t))$

$\ddagger$ Mean square error

$\S$ Coverage rate of 100095 per cent confidence intervals 
Table 33. Monte Carlo results for estimating an hypothetical HIV-1 RNA reduction ( $\mathbf{N = 2 0 0})$. 30\% LOD=200 copies/ml and $70 \% \mathrm{LOD}=\mathbf{5 0 0}$ copies $/ \mathrm{ml}$ leading to an overall censoring rate of $64 \%$

Using Risk Score instead of principal component analysis (PCA).

Estimators are derived using the 5 covariates.

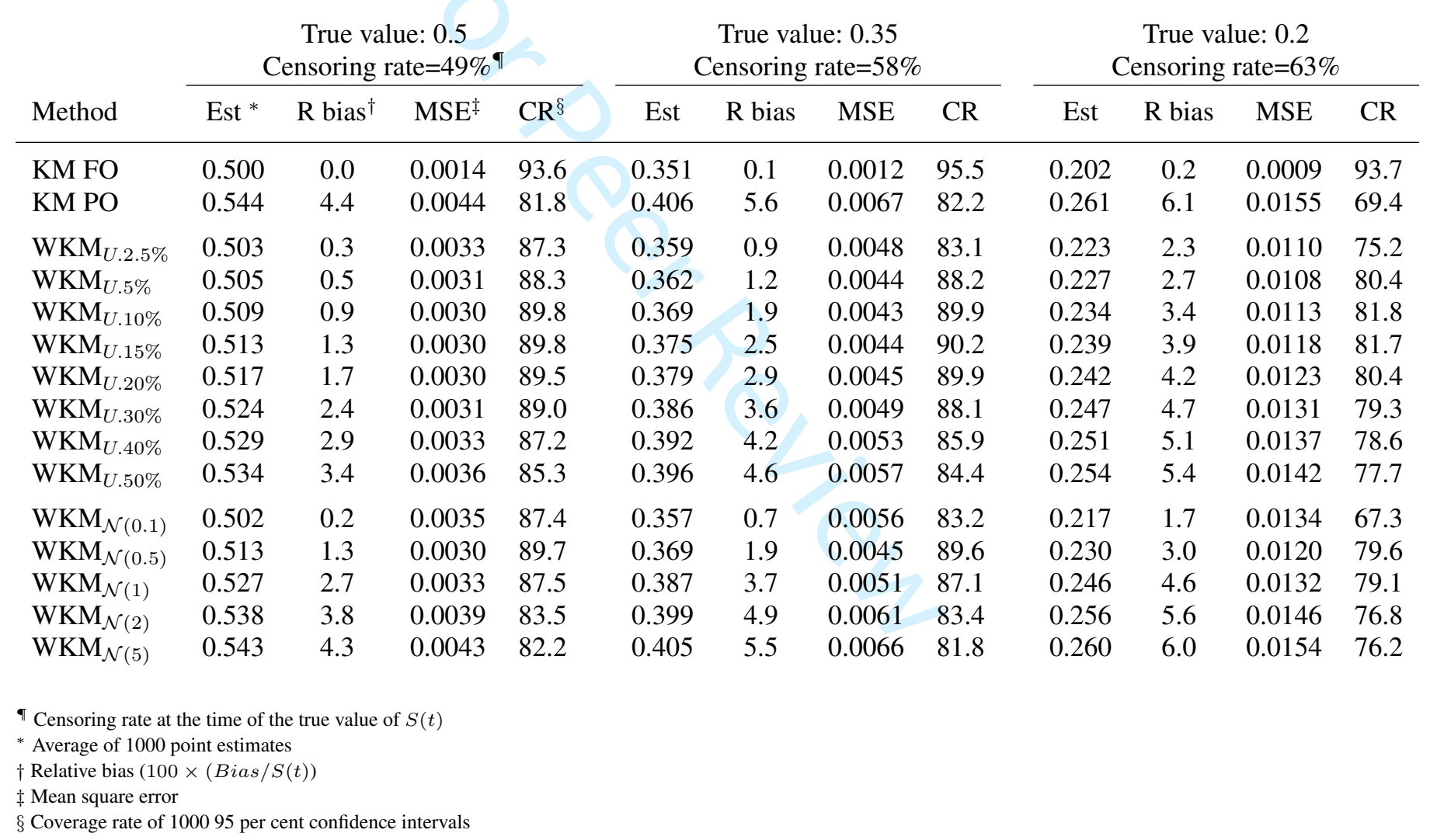




\section{Statistics \\ in Medicine}

Table 34. Monte Carlo results for estimating classical survival curve with with dependent censoring ( $\mathbf{N}=\mathbf{2 0 0})$.

Using Risk Score instead of principal component analysis (PCA).

Overall censoring rate $=35 \%$ and the link functions correctly specified.

\begin{tabular}{|c|c|c|c|c|c|c|c|c|c|c|c|c|}
\hline \multirow[b]{2}{*}{ Method } & \multicolumn{4}{|c|}{$\begin{array}{c}\text { True value: } 0.5 \\
\text { Censoring rate }=26 \%\end{array}$} & \multicolumn{4}{|c|}{$\begin{array}{c}\text { True value: } 0.35 \\
\text { Censoring rate }=29 \%\end{array}$} & \multicolumn{4}{|c|}{$\begin{array}{c}\text { True value: } 0.2 \\
\text { Censoring rate }=32 \% \\
\end{array}$} \\
\hline & Est * & $\mathrm{R}$ bias $^{\dagger}$ & $\mathrm{MSE}^{\ddagger}$ & $\mathrm{CR}^{\S}$ & Est & $\mathrm{R}$ bias & MSE & $\mathrm{CR}$ & Est & $\mathrm{R}$ bias & MSE & $\mathrm{CR}$ \\
\hline KM FO & 0.501 & 0.1 & 0.0013 & & 0.351 & 0.1 & 0.0012 & 94.4 & 0.199 & -0.1 & 0.0008 & 94.4 \\
\hline KM PO & 0.569 & 6.9 & 0.0063 & 59.6 & 0.428 & 7.8 & 0.0079 & 53.1 & 0.269 & 6.9 & 0.0063 & 58.7 \\
\hline $\mathrm{WKM}_{U .2 .5 \%}$ & 0.507 & 0.7 & 0.0018 & 92.6 & 0.356 & 0.6 & 0.0018 & 91.8 & 0.201 & 0.1 & 0.0011 & 91.3 \\
\hline $\mathrm{WKM}_{U .5 \%}$ & 0.510 & 1.0 & 0.0018 & 92.5 & 0.358 & 0.8 & 0.0018 & 92.6 & 0.204 & 0.4 & 0.0011 & 93.0 \\
\hline $\mathrm{WKM}_{U .10 \%}$ & 0.515 & 1.5 & 0.0019 & 92.4 & 0.364 & 1.4 & 0.0019 & 92.5 & 0.209 & 0.9 & 0.0012 & 93.6 \\
\hline $\mathrm{WKM}_{U .15 \%}$ & 0.521 & 2.1 & 0.0021 & 91.4 & 0.370 & 2.0 & 0.0021 & 91.2 & 0.214 & 1.4 & 0.0014 & 92.8 \\
\hline $\mathrm{WKM}_{U .20 \%}$ & 0.526 & 2.6 & 0.0023 & 89.7 & 0.375 & 2.5 & 0.0024 & 88.9 & 0.219 & 1.9 & 0.0016 & 91.0 \\
\hline $\mathrm{WKM}_{U .30 \%}$ & 0.535 & 3.5 & 0.0029 & 84.8 & 0.386 & 3.6 & 0.0031 & 84.9 & 0.230 & 3.0 & 0.0022 & 88.2 \\
\hline $\mathrm{WKM}_{U .40 \%}$ & 0.543 & 4.3 & 0.0035 & 79.9 & 0.396 & 4.6 & 0.0040 & 78.5 & 0.239 & 3.9 & 0.0029 & 82.3 \\
\hline $\mathrm{WKM}_{U .50 \%}$ & 0.550 & 5.0 & 0.0042 & 75.9 & 0.405 & 5.5 & 0.0049 & 71.9 & 0.247 & 4.7 & 0.0037 & 76.8 \\
\hline $\mathrm{WKM}_{\mathcal{N}(0 .}$ & 0.506 & 0.6 & 0.0018 & 92.5 & 0.354 & 0.4 & 0.0018 & 92.1 & 0.200 & 0.0 & 0.0011 & 91.6 \\
\hline $\mathrm{WKM}_{\mathcal{N}(0.5)}$ & 0.523 & 2.3 & 0.0022 & 89.8 & 0.373 & 2.3 & 0.0023 & 89.6 & 0.215 & 1.5 & 0.0014 & 92.0 \\
\hline $\mathrm{WKM}_{\mathcal{N}(1)}$ & 0.545 & 4.5 & 0.0036 & 78.6 & 0.397 & 4.7 & 0.0040 & 76.6 & 0.237 & 3.7 & 0.0028 & 84.1 \\
\hline $\mathrm{WKM}_{\mathcal{N}(2)}$ & 0.560 & 6.0 & 0.0053 & 67.9 & 0.417 & 6.7 & 0.0063 & 61.5 & 0.257 & 5.7 & 0.0048 & 68.5 \\
\hline $\mathrm{WKM}_{\mathcal{N}(5)}$ & 0.567 & 6.7 & 0.0061 & 61.2 & 0.426 & 7.6 & 0.0076 & 53.4 & 0.267 & 6.7 & 0.0060 & 60.2 \\
\hline
\end{tabular}

ब Censoring rate at the time of the true value of $S(t)$

* Average of 1000 point estimates

$\dagger$ Relative bias $(100 \times($ Bias $/ S(t))$

$\ddagger$ Mean square error

$\S$ Coverage rate of 100095 per cent confidence intervals 
Table 35. Monte Carlo results for estimating classical survival curve with with dependent censoring $(\mathbf{N}=\mathbf{2 0 0})$.

Using Risk Score instead of principal component analysis (PCA).

Overall censoring rate $=51 \%$ and the link functions uncorrectly specified.

\begin{tabular}{|c|c|c|c|c|c|c|c|c|c|c|c|c|}
\hline \multirow[b]{2}{*}{ Method } & \multicolumn{4}{|c|}{$\begin{array}{c}\text { True value: } 0.5 \\
\text { Censoring rate }=34 \%\end{array}$} & \multicolumn{4}{|c|}{$\begin{array}{c}\text { True value: } 0.35 \\
\text { Censoring rate }=40 \%\end{array}$} & \multicolumn{4}{|c|}{$\begin{array}{c}\text { True value: } 0.2 \\
\text { Censoring rate }=46 \% \\
\end{array}$} \\
\hline & Est ${ }^{*}$ & $\mathrm{R}$ bias $^{\dagger}$ & $\mathrm{MSE}^{\ddagger}$ & $\mathrm{CR}^{\S}$ & Est & $\mathrm{R}$ bias & MSE & $\mathrm{CR}$ & Est & $\mathrm{R}$ bias & MSE & $\mathrm{CR}$ \\
\hline KM FO & 0.502 & 0.2 & 0.0013 & 94.2 & 0.352 & 0.2 & 0.0011 & 94.6 & 0.201 & 0.1 & 0.0008 & 95.1 \\
\hline KM PO & 0.605 & 10.5 & 0.0128 & 27.3 & 0.472 & 12.2 & 0.0171 & 22.6 & 0.321 & 12.1 & 0.0169 & 28.1 \\
\hline $\mathrm{WKM}_{U .2 .5 \%}$ & 0.508 & 0.8 & 0.0023 & 89.8 & 0.358 & 0.8 & 0.0023 & 87.6 & 0.210 & 1.0 & 0.0021 & 86.7 \\
\hline $\mathrm{WKM}_{U .5 \%}$ & 0.512 & 1.2 & 0.0023 & 90.4 & 0.363 & 1.3 & 0.0023 & 91.3 & 0.216 & 1.6 & 0.0021 & 89.7 \\
\hline $\mathrm{WKM}_{U .10 \%}$ & 0.521 & 2.1 & 0.0025 & 89.6 & 0.373 & 2.3 & 0.0026 & 91.0 & 0.228 & 2.8 & 0.0025 & 87.6 \\
\hline $\mathrm{WKM}_{U 15 \%}$ & 0.529 & 2.9 & 0.0028 & 87.6 & 0.383 & 3.3 & 0.0031 & 88.0 & 0.239 & 3.9 & 0.0033 & 83.6 \\
\hline $\mathrm{WKM}_{U .20 \%}$ & 0.536 & 3.6 & 0.0033 & 85.0 & 0.393 & 4.3 & 0.0038 & 84.0 & 0.250 & 5.0 & 0.0042 & 77.8 \\
\hline $\mathrm{WKM}_{U .30 \%}$ & 0.550 & 5.0 & 0.0044 & 77.6 & 0.411 & 6.1 & 0.0056 & 70.6 & 0.268 & 6.8 & 0.0065 & 64.3 \\
\hline $\mathrm{WKM}_{U .40 \%}$ & 0.564 & 6.4 & 0.0059 & 66.8 & 0.427 & 7.7 & 0.0079 & 57.3 & 0.282 & 8.2 & 0.0088 & 53.6 \\
\hline $\mathrm{WKM}_{U .50 \%}$ & 0.576 & 7.6 & 0.0076 & 54.0 & 0.441 & 9.1 & 0.0102 & 45.1 & 0.294 & 9.4 & 0.0109 & 45.0 \\
\hline $\mathrm{WKM}_{\mathcal{N}(0 .}$ & 0.505 & 0.5 & 0.0025 & 89.7 & 0.3 & 0.6 & 0.0025 & 8 & 0.206 & 0.6 & 0.0025 & 82.8 \\
\hline $\mathrm{WKM}_{\mathcal{N}(}$ & 0.537 & 3.7 & 0.0033 & 83.7 & 0.390 & 4.0 & 0.0037 & 84.6 & 0.238 & 3.8 & 0.0034 & 82.9 \\
\hline $\mathrm{WKM}_{\mathcal{N}}$ & 0.570 & 7.0 & 0.0068 & 61.2 & 0.429 & 7.9 & 0.0083 & 55.1 & 0.275 & 7.5 & 0.0078 & 59.1 \\
\hline $\mathrm{WKM}_{\mathcal{N}(2}$ & 0.593 & 9.3 & 0.0105 & 37.1 & 0.457 & 10.7 & 0.0135 & 32.9 & 0.305 & 10.5 & 0.0132 & 38.3 \\
\hline $\mathrm{WKM}_{\mathcal{N}(5)}$ & 0.603 & 10.3 & 0.0124 & 29.2 & 0.470 & 12.0 & 0.0164 & 24.0 & 0.318 & 11.8 & 0.0162 & 28.8 \\
\hline
\end{tabular}

I Censoring rate at the time of the true value of $S(t)$

* Average of 1000 point estimates

$\dagger$ Relative bias $(100 \times($ Bias $/ S(t))$

$\ddagger$ Mean square error

$\S$ Coverage rate of 100095 per cent confidence intervals 


\section{Statistics \\ in Medicine}

Table 36. Monte Carlo results for estimating classical survival curve with independent censoring ( $\mathbf{N = 2 0 0 )}$.

Using Risk Score instead of principal component analysis (PCA).

Censoring rate $=40 \%$ and the link functions correctly specified.

\begin{tabular}{|c|c|c|c|c|c|c|c|c|c|c|c|c|}
\hline \multirow[b]{2}{*}{ Method } & \multicolumn{4}{|c|}{$\begin{array}{c}\text { True value: } 0.5 \\
\text { Censoring rate }=35 \%\end{array}$} & \multicolumn{4}{|c|}{$\begin{array}{c}\text { True value: } 0.35 \\
\text { Censoring rate }=37 \%\end{array}$} & \multicolumn{4}{|c|}{$\begin{array}{c}\text { True value: } 0.2 \\
\text { Censoring rate }=39 \%\end{array}$} \\
\hline & Est * & $\mathrm{R}$ bias $^{\dagger}$ & $\mathrm{MSE}^{\ddagger}$ & $\mathrm{CR}^{\S}$ & Est & $\mathrm{R}$ bias & MSE & $\mathrm{CR}$ & Est & $\mathrm{R}$ bias & MSE & CR \\
\hline KM FO & 0.498 & -0.2 & 0.0012 & 94.9 & 0.348 & -0.2 & 0.0011 & 95.0 & 0.198 & -0.2 & 0.0008 & 94.4 \\
\hline KM PO & 0.500 & 0.0 & 0.0018 & 95.0 & 0.348 & -0.2 & 0.0017 & 95.4 & 0.198 & -0.2 & 0.0014 & 93.7 \\
\hline $\mathrm{WKM}_{U .2 .5 \%}$ & 0.500 & 0.0 & 0.0017 & 93.4 & 0.348 & -0.2 & 0.0015 & 92.1 & 0.198 & -0.2 & 0.0013 & 90.4 \\
\hline $\mathrm{WKM}_{U .5 \%}$ & 0.500 & 0.0 & 0.0017 & 93.4 & 0.348 & -0.2 & 0.0015 & 94.1 & 0.197 & -0.3 & 0.0013 & 91.8 \\
\hline $\mathrm{WKM}_{U .10 \%}$ & 0.501 & 0.1 & 0.0017 & 93.9 & 0.348 & -0.2 & 0.0015 & 94.3 & 0.195 & -0.5 & 0.0013 & 92.3 \\
\hline $\mathrm{WKM}_{U .15 \%}$ & 0.502 & 0.2 & 0.0017 & 94.4 & 0.347 & -0.3 & 0.0016 & 94.4 & 0.193 & -0.7 & 0.0014 & 92.5 \\
\hline $\mathrm{WKM}_{U}$ & 0.503 & 0.3 & 0.0018 & 94.4 & 0.347 & -0.3 & 0.0016 & 94.9 & 0.191 & -0.9 & 0.0014 & 92.2 \\
\hline $\mathrm{WKM}_{U .30 \%}$ & 0.504 & 0.4 & 0.0018 & 94.4 & 0.346 & -0.4 & 0.0017 & 94.7 & 0.189 & -1.1 & 0.0014 & 91.0 \\
\hline $\mathrm{WKM}_{U .40 \%}$ & 0.504 & 0.4 & 0.0019 & 94.7 & 0.345 & -0.5 & 0.0017 & 95.2 & 0.189 & -1.1 & 0.0015 & 91.2 \\
\hline $\mathrm{WKM}_{U .50 \%}$ & 0.504 & 0.4 & 0.0019 & 94.5 & 0.345 & -0.5 & 0.0017 & 94.9 & 0.19 & -1.0 & 0.0014 & 91.6 \\
\hline $\mathrm{WKM}_{\mathcal{N}(0.1)}$ & 0.500 & 0.0 & 0.0017 & 93.6 & 0.348 & -0.2 & 0.0015 & 93.8 & 0.197 & -0.3 & 0.0013 & 91.2 \\
\hline $\mathrm{WKM}_{\mathcal{N}(0.5)}$ & 0.502 & 0.2 & 0.0017 & 94.5 & 0.347 & -0.3 & 0.0015 & 94.7 & 0.194 & -0.6 & 0.0013 & 92.5 \\
\hline $\mathrm{WKM}_{\mathcal{N}(1)}$ & 0.502 & 0.2 & 0.0018 & 94.3 & 0.347 & -0.3 & 0.0016 & 95.1 & 0.193 & -0.7 & 0.0014 & 92.0 \\
\hline $\mathrm{WKM}_{\mathcal{N}(2)}$ & 0.501 & 0.1 & 0.0018 & 95.1 & 0.347 & -0.3 & 0.0017 & 95.0 & 0.195 & -0.5 & 0.0014 & 93.0 \\
\hline $\mathrm{WKM}_{\mathcal{N}(5)}$ & 0.500 & 0.0 & 0.0018 & 95.1 & 0.348 & -0.2 & 0.0017 & 94.3 & 0.197 & -0.3 & 0.0014 & 93.2 \\
\hline
\end{tabular}

T Censoring rate at the time of the true value of $S(t)$

* Average of 1000 point estimates

$\dagger$ Relative bias $(100 \times($ Bias $/ S(t))$

$\ddagger$ Mean square error

$\S$ Coverage rate of 100095 per cent confidence intervals 